Estimativa e aproximação em sala de aula:

o caso do conceito de área no ensino fundamental

Renato Martins

DISSERTAÇÃO APRESENTADA

$\mathrm{AO}$

INSTITUTO DE MATEMÁTICA E ESTATÍSTICA

DA

UNIVERSIDADE DE SÃO PAULO

PARA

OBTENÇÃO DO TÍTULO

$\mathrm{DE}$

MESTRE EM ENSINO DE MATEMÁTICA

Programa: Mestrado Profissional em Ensino de Matemática

Orientadora: Profa. Dra. Cristina Cerri

São Paulo, abril de 2019 


\title{
Estimativa e aproximação em sala de aula: \\ o caso do conceito de área \\ no ensino fundamental
}

\author{
Renato Martins
}

Esta versão da dissertação/tese contém as correções e alterações sugeridas pela Comissão Julgadora durante a defesa da versão original do trabalho, realizada em 21/03/2019. Uma cópia da versão original está disponível no Instituto de Matemática e Estatística da Universidade de São Paulo.

Comissão Julgadora:

- Profa . Dra . Cristina Cerri (orientadora) - IME-USP

- Profa. Dra. Gleiciane da Silva Aragão - UNIFESP

- Prof. Dr. Ruy César Pietropaolo - UNIAN/SP 


\section{RESUMO}

\section{MARTINS, R.. Estimativa e aproximação em sala de aula: o caso do conceito de} área no ensino fundamental. 2019. 145 f. Dissertação (Mestrado) - Instituto de Matemática e Estatística, Universidade de São Paulo, São Paulo, 2019.

Nesta pesquisa o objetivo principal é avaliar a influência da estimativa para a compreensão do conceito de área de uma superfície plana. A estimativa de medida aproxima o aluno das aplicações práticas da Matemática e, além disso, contribui para que nos familiarizemos com as unidades padronizadas. A metodologia de pesquisa utilizada foi o Design Experiments. Nessa metodologia o professor assume também o papel de pesquisador e pode investigar, por exemplo, novas formas de aprendizagem com abordagens diferenciadas. Nossa proposta de ensino enfatizou os processos de percepção, comparação e medição e foi aplicada em dois momentos. Realizamos uma oficina com professores da rede estadual e alunos graduação no Centro de Aperfeiçoamento do Ensino de Matemática (CAEM) no Instituto de Matemática e Estatística da Universidade de São Paulo. Esse estudo prévio teve como objetivo aprimorar e refinar nossa primeira versão do experimento de ensino. Após as análises dos registros das atividades realizadas pelo grupo participante da oficina foi elaborada uma sequência de ensino, que foi aplicada a duas turmas de estudantes do $9^{\mathrm{O}}$ do Ensino Fundamental de uma escola da rede pública estadual de ensino. Foram feitas análises do experimento de ensino, com base na observação e nos registros dos alunos.

Palavras-chave: área; medida; estimativa; educação básica. 


\begin{abstract}
MARTINS, R. Estimation and approximation in the classroom: the case of the area concept in elementary school. 2019. 145 f. Dissertação (Mestrado) - Instituto de Matemática e Estatística, Universidade de São Paulo, São Paulo, 2019.

In this research the main objective is to evaluate the influence of the estimation for the understanding of the concept of the area of a flat surface. The measurement estimate brings the student closer to the practical applications of Mathematics and, in addition, helps us to familiarize ourselves with the standardized units. The research methodology used was Design Experiments. In this methodology the teacher also assumes the role of researcher and can investigate, for example, new forms of learning with differentiated approaches. Our teaching proposal emphasized the processes of perception, comparison and measurement and was applied in two moments. We held a workshop with teachers from the state network and undergraduate students at the Center for Improvement of Mathematics Education (CAEM) at the Mathematics and Statistics Institute of the University of São Paulo. This previous study aimed to refine and refine our first version of the teaching experiment. After the analysis of the records of the activities carried out by the group participating in the workshop, a teaching sequence was elaborated, which was applied to two classes of students from the 9th Elementary School of a public school system. Analyzes of the teaching experiment were made, based on observation and student records.
\end{abstract}

Keywords: area; measure; estimative; basic education. 


\section{Sumário}

Introdução ……….....................................................................................................................................9

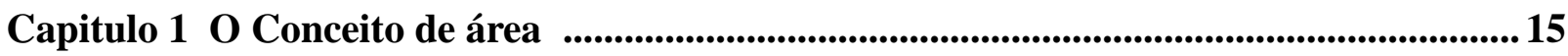

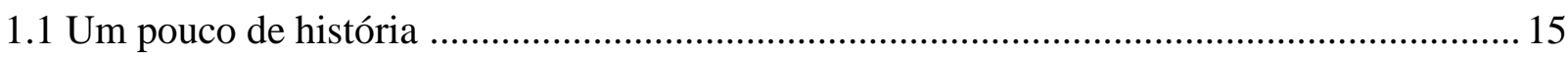

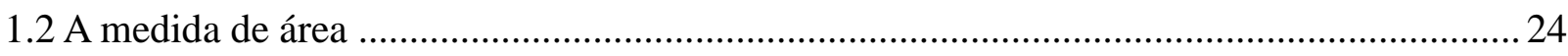

1.3 Ensino e aprendizagem da noção de área na perspectiva de Douady e Perrin- Glorian ...... 28

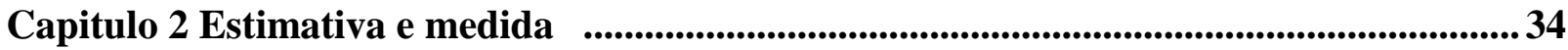

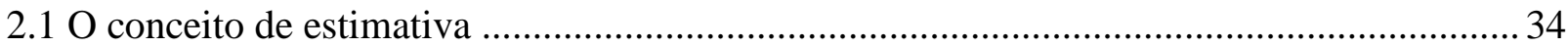

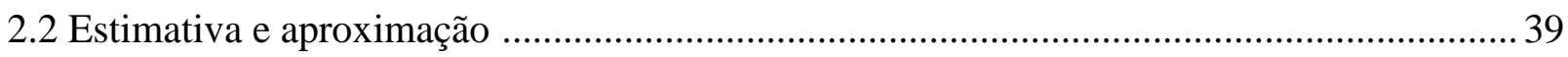

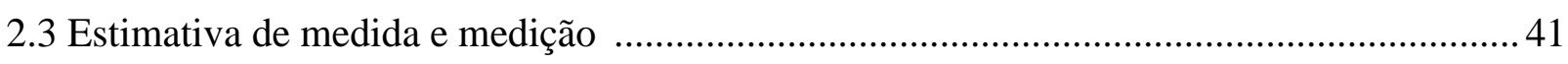

2.4 Sobre o ensino e aprendizagem de grandezas e medidas ................................................ 46

Capitulo 3 Procedimentos Metodológicos $\quad$............................................................................................ 49

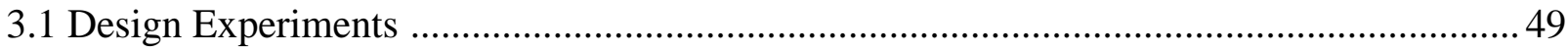

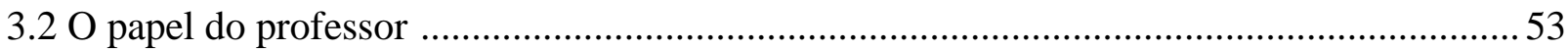

3.3 Relação do nosso estudo com a metodologia ................................................................... 54

Capitulo 4 Experimento com professores ...............................................................................5

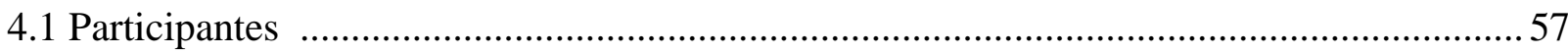

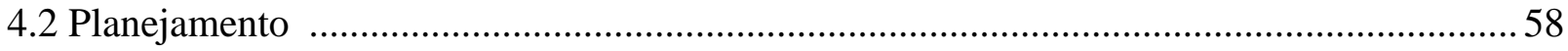

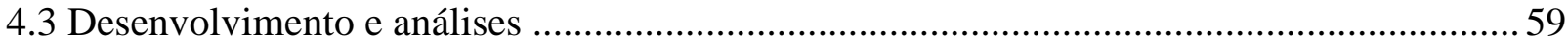

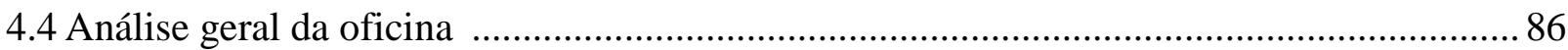

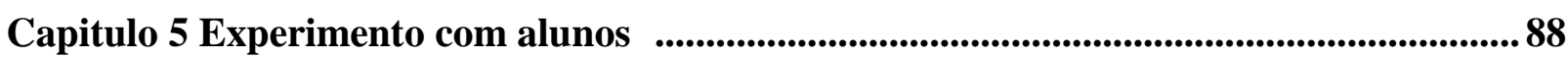

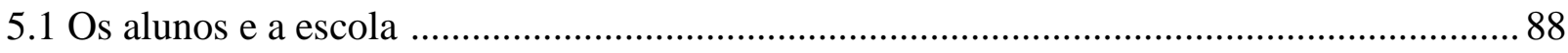

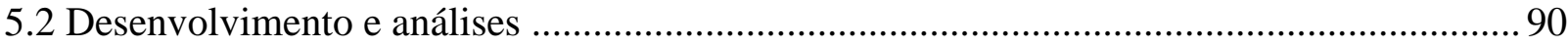

Capitulo 6 Considerações finais .........................................................................................122 


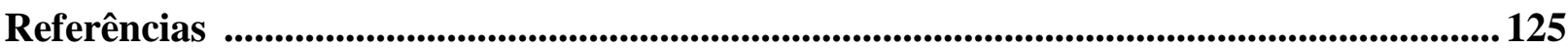

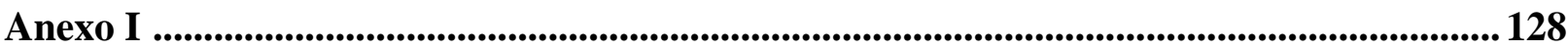

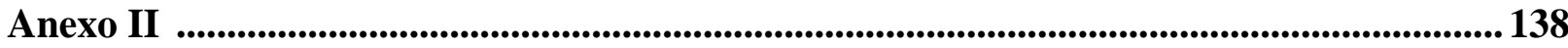




\section{LISTA DE FIGURAS}

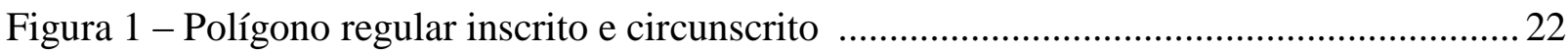

Figura 2 - Definição da integral de Riemann ....................................................................... 23

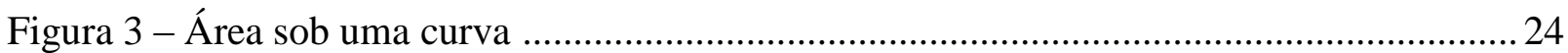

Figura 4 - Uma figura plana F contida num polígono P' e contendo um polígono P .............. 27

Figura 5 - Relação entre o objeto geométrico, grandeza e medida ........................................ 29

Figura 6 - Relação da estimativa com o problema proposto ................................................. 37

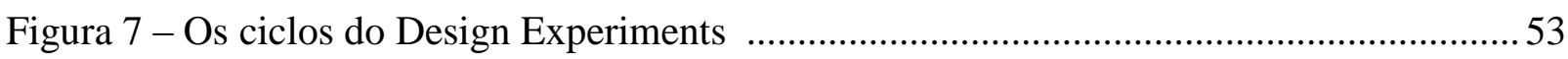

Figura 8 - Pessoas em manifestação ................................................................................... 72

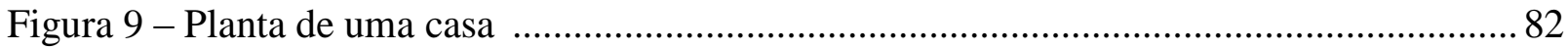

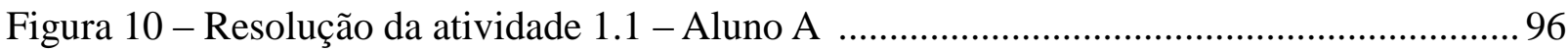

Figura 11 - Resolução da atividade 1.2 - Aluno B .............................................................. 99

Figura 12 - Resolução da atividade 1.3 - Aluno C .............................................................. 101

Figura 13 - Material utilizado na atividade .................................................................. 102

Figura 14 - Resolução da atividade 2.1 - Aluno D ............................................................. 104

Figura 15 - Resolução da atividade 2.2 - Aluno E ............................................................... 105

Figura 16 - Produção dos alunos na atividade 2.3 ............................................................ 107

Figura 17 - Resolução da atividade 3.1 - Aluno F ................................................................. 109

Figura 18 - Resolução da atividade 3.2 - Aluno G ............................................................ 111

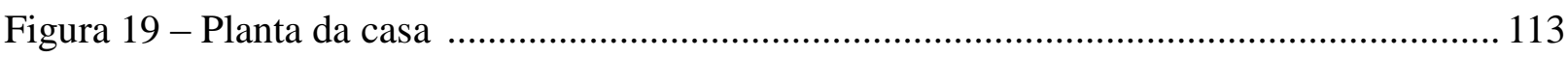

Figura 20 - Resolução da atividade 4.2 - Aluno H ......................................................... 118

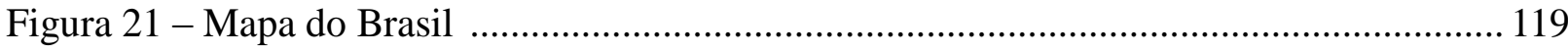

Figura 22 - Resolução da atividade 4.3 - Aluno I .............................................................. 120 


\section{LISTA DE TABELAS}

Tabela 1 - Comparativo dos quatro últimos anos IDEBs $\left(9^{\circ}\right.$ do ensino fundamental) 89

Tabela 2 - Comparativo dos quatro últimos IDESPs $\left(9^{\circ}\right.$ do ensino fundamental) 89

Tabela 3 - Desempenho dos alunos na atividade 4.1 115 


\title{
Introdução
}

O conceito de área é considerado um dos mais importantes para o ensino e aprendizagem da Matemática.

\begin{abstract}
Sua relevância é indiscutível para a formação do cidadão pleno, que necessita medir, ou estimar a medida de regiões planas nas suas atividades cotidianas. No âmbito cientifico e tecnológico, são muitíssimos frequentes as situações nas quais a área de superfícies intervém como grandeza básica do processo ou fenômeno abordado. Área é, também, um conceito muito rico do ponto de vista da matemática escolar por ser um polo de confluência dos grandes eixos temáticos dos números, da geometria, das grandezas e da álgebra (...). Por fim, o conceito de área está presente na produção contemporânea do conhecimento matemático em diversos campos: teoria da medida, teoria ergódica, teoria dos fractais, entre outras.
\end{abstract}

(BELLEIMAIN; LIMA, 2002, apud LIMA, SILVA, 2004, p. 3)

Observamos dessa forma a relevância do conceito de área como um tema articulador de vários tópicos da matemática da educação básica e notamos, ainda, a presença marcante das grandezas e medida em nosso cotidiano.

$\mathrm{Na}$ aprendizagem das grandezas geométricas, é indispensável que o estudante compreenda que a um mesmo objeto geométrico podem ser associadas diferentes grandezas, como sua área e seu perímetro. Em relação a essas duas grandezas observam-se várias limitações nos livros didáticos, em particular nas obras aprovadas no Programa Nacional do Livro Didático (PNLD, 2017). Entre as deficiências apontadas no relatório são destacadas as seguintes:

- há uma tendência a definir perímetro somente para superfícies planas poligonais. É o que ocorre quando se define perímetro como "a soma dos lados de uma figura plana";

- em geral, não se identifica o comprimento de uma circunferência como o perímetro do círculo correspondente;

- são raras as atividades que visam à distinção entre área e perímetro de uma superfície plana; porém existem atividades interessantes que poderiam ser incluídas nos livros, como solicitar ao estudante que modifique uma superfície plana para obter outra com menor perímetro e maior área que a original.

- somente em algumas das coleções aprovadas são propostas atividades que possibilitem ao estudante desenvolver a prática de estimativas, a capacidade de escolher 
instrumentos de medidas adequados e discutir o caráter aproximado e incerto dos resultados das medições empíricas.

Além disso, alguns livros apresentam exclusivamente as unidades padronizadas de medição de grandezas e outros dedicam excessiva importância à conversão de unidades de medida. Em alguns casos, nos primeiros anos do Ensino Fundamental é dada atenção precoce às fórmulas de cálculo de perímetro e de área de figuras planas.

De acordo com Bellemain e Lima (2010, pg. 167) o ensino e a pesquisa das Grandezas e Medidas têm avançado, "podemos observar alguma evolução no ensino deste campo e, sem dúvida, é dada maior atenção a ele nos estudos acadêmicos sobre questões de ensino e de aprendizagem de conceitos matemáticos". Apesar disso, os estudantes apresentam algumas dificuldades no trabalho com grandezas e medidas, como afirma Perrot et al. (1998, apud Lima,Silva, 2004, p. 4), por exemplo, fazem confusão entre grandezas e medidas de grandezas; sabem calcular medidas, usando fórmulas, sem saber o que eles calculam; acham que somente os polígonos "particulares", “os que têm um nome e fórmulas", têm também um perímetro e uma área.

Em nosso dia a dia, muitas vezes, não há necessidade de maior exatidão na medida de uma grandeza, apenas uma estimativa dessa medida é suficiente. Assim, a introdução de atividades com estimativa de medida tem o mérito de aproximar os alunos das aplicações práticas da Matemática e de acordo com Bellemain e Lima (2010, p.181) “contribui ainda para que os alunos se familiarizem com modelos concretos de unidades padronizadas, o que pode ajudá-los na escolha da unidade mais adequada a uma determinada medição".

A capacidade de realizar estimativas tem sido defendida como uma das aprendizagens mais úteis para a inserção das pessoas nas atividades da vida social. O trabalho com estimativas é recomendado nos Parâmetros Curriculares Nacionais - PCN (BRASIL, 1997).

(...) desde as primeiras experiências com quantidades e medidas, as estimativas devem estar presentes em diversas estratégias que levem os alunos a perceber o significado de um valor aproximado, decidir quando é conveniente usá-lo e que aproximação é pertinente a uma determinada situação, como, por exemplo, identificar unidades de medida adequadas ás grandezas. (BRASIL, 1997, p. 77)

O documento aponta que devemos fazer com que os alunos desenvolvam e sistematizem procedimentos de cálculo por estimativa. De fato, em muitas situações 
cotidianas não necessitamos de um valor exato, pois para tomar uma decisão basta uma estimativa ou o valor aproximado da medida de uma grandeza.

Existem muitas situações cotidianas em que se faz necessário o uso da estimativa como forma de resolução de problemas. Na disciplina Matemática, além de evidenciar procedimentos que conduzem a respostas exatas e únicas, é importante desenvolver estratégias para estimar valores, ou seja, formar uma opinião com base num julgamento de valor aproximado. Ao adotar esse processo, o aluno terá uma ideia do resultado aproximado que poderá encontrar diante do contexto em que a situação ocorre.

Conforme a Proposta Curricular do Estado de São Paulo (SÃO PAULO, 2008, p.51) "longe de ser o lugar por excelência da exatidão, da precisão absoluta, a Matemática não sobrevive nos contextos práticos, nos cálculos do dia a dia sem uma compreensão nítida da importância das aproximações". O mesmo documento afirma que:

\footnotetext{
(...) é importante destacar, no entanto, que, ao realizar aproximações, não estamos nos resignando a resultados inexatos, por limitações em nossos conhecimentos: um cálculo aproximado pode ser - e em geral o é - tão bom, tão digno de crédito quanto um cálculo exato, desde que satisfaça a certas condições muito bem explicitadas nos procedimentos matemáticos e o critério decisivo é o seguinte: uma aproximação é ótima, se e somente se, temos permanentemente condições de melhorá-la, caso desejemos. (ibid, p. 51)
}

O professor ao trabalhar com medição e aproximação está lidando com duas das “doze ideias fundamentais da Matemática": a ideia de medição (grandezas contínuas, comprimentos, áreas, volumes, ordem de grandeza, estimativas,...) e de aproximação (operações, resultados exatos e aproximados, erros, propagação de erros, linearidade, aproximação de funções por polinômios,...) segundo Machado (2013) a disciplina de Matemática pode ser organizada de acordo com algumas ideias centrais. Uma ideia fundamental articula diversas partes de um tema; elas transbordam os limites do tema, explicitando conexões com outros temas.

Segundo Bellemain e Lima (2010) o ensino e a pesquisa das grandezas e medidas têm avançado, mas alguns problemas persistem, por exemplo, alguns professores apoiados no livro didático introduzem o conceito de área apresentando exclusivamente as unidades padronizadas de medida e dando importância demasiada a conversão de unidades e, em alguns casos é dada a atenção precoce as fórmulas de cálculo de áreas de figuras planas.

Os pesquisadores enfatizam que o trabalho com área no Ensino Fundamental foi marcado durante muito tempo por uma abordagem aritmética, na qual se prioriza o cálculo, o 
uso de fórmulas e as conversões de unidades; as aplicações estão relacionadas, quase que exclusivamente, ao cálculo de áreas de polígonos. Ao se trabalhar com atividades sobre áreas, podemos utilizar procedimentos que favorecem o cálculo por meio da composição e decomposição de figuras, cujas áreas sejam mais fáceis de calcular com o auxílio de papel quadriculado, ladrilhamento, valendo-se, assim, também de aproximações.

Diante desses resultados decidimos realizar nossa investigação tendo como enfoque o conceito de área de superfícies planas, pretendemos compreender melhor os aspectos associados ao estudo dessa grandeza no ensino fundamental.

Acreditamos que o uso da estimativa em aulas de Matemática pode ser uma alternativa para desenvolver a motivação, a capacidade de obter cálculos aproximados, bem como de sistematização de estratégias. A nossa expectativa é que o trabalho possa fornecer um material útil e adequado para o ensino e aprendizagem do conceito de áreas de superfícies planas. Apesar da importância da estimativa para o desenvolvimento de estratégias e do "cálculo oral", observa-se seu pouco uso nas aulas de matemática. Corbellini et al (2012) relatam em sua pesquisa que um grupo de professores declarou pouco utilizar esse procedimento devido a falta de subsídios para o trabalho em sala de aula.

Nosso objetivo com este trabalho é apresentar uma abordagem para o tratamento do conceito de área de superfícies planas que enfatize suas principais características e não apenas o cálculo por meio de fórmulas. Pretendemos analisar se uma abordagem utilizando estimativas e aproximações contribuem para o aprendizado desse importante tópico do currículo de Matemática.

As seguintes hipóteses guiaram nossos estudos:

- Uma sequência de atividades utilizando estimativas e aproximações pode ampliar a compreensão sobre o processo de medida de área.

- A exploração de procedimentos de cálculo de área de figuras não poligonais contribui para o aprendizado do conceito de área.

- O uso de estimativas e aproximações é uma estratégia pertinente que pode ser usada para ensinar o conceito de área.

Para nossa pesquisa, adotamos a metodologia de pesquisa Design Experiments, cuja descrição está presente no terceiro capítulo. O objetivo deste tipo de metodologia consiste em analisar processos de aprendizagem e oferecer meios para que os alunos criem modelos de 
aprendizagem em domínios específicos. Deste modo em coerência com esta perspectiva metodológica, foram elaboradas atividades sobre o conceito de áreas de superfícies planas, desenvolvidas com ênfase nos processos de percepção, comparação, medida e estimativa. Pretendemos, assim, observar as produções escritas e a compreensão do estudante, quando este se depara com uma abordagem diferenciada do conteúdo áreas de figuras planas.

O nosso design inicial foi proposto a partir das necessidades apontadas pelos resultados das pesquisas presentes nas referências bibliográficas analisadas, as quais apontaram os seguintes fatores em relação ao objeto matemático "áreas de figuras planas": memorização sem compreensão de fórmulas; a carência do tema "estimativa" nos livros didáticos; o trabalho exclusivamente com unidades padronizadas onde o único objetivo proposto é a conversão de unidades; a fórmula geométrica e as operações aritméticas são o único meio para achar a medida de área das figuras planas; a importância da estimativa nas situações cotidianas; o desconhecimento dos alunos de um método que permita estimar a medida de área de uma figura qualquer.

Design Experiments apresenta algumas características relevantes como: trazer para os estudantes uma nova abordagem de estudo diferente da convencional, praticada na maioria das escolas. Essa nova abordagem com caráter intervencionista poderá possibilitar o surgimento de modelos inéditos por parte dos alunos; o pesquisador após cada aplicação da atividade pode fazer a análise da mesma e identificar quais modificações são necessárias para atingir o objetivo especifico daquela atividade, devido a esse caráter cíclico possibilita aos pesquisadores fazer análises sobre suas conjecturas durante todo o processo.

No nosso experimento de ensino o conceito de área é abordado por meio de situações de medição onde estão incluídos os processos fundamentais (percepção, comparação, medição e estimativa) que são base para o ensino da grandeza área, processos com os quais o estudante pode entender o significado das fórmulas e a conversão de unidades de medida.

Inicialmente, optamos por realizar um estudo preliminar com alguns professores que participaram de uma oficina oferecida no Centro de Aperfeiçoamento do Ensino de Matemática (CAEM) no Instituto de Matemática e Estatística (IME) da Universidade de São Paulo (USP). Os encontros com os professores foram realizados no período de um mês com três seções semanais de três horas.

Essa atividade prévia serviu para compreendermos melhor nosso tema de pesquisa e também contribuiu para o refinamento do experimento de ensino. Do ponto de vista dos 
professores, foram avaliadas suas produções escritas a partir de um conjunto de atividades sobre estimativas e o conceito de áreas de figuras planas. Os resultados desses estudos motivaram e ajudaram na elaboração final de um experimento de ensino que foi aplicado aos alunos do $9^{\circ}$ de uma escola pública da rede estadual de ensino.

Esse trabalho é composto de seis capítulos, que discutem conceitos sobre área e estimativa em uma proposta de atividades para o ensino e aprendizagem do conteúdo áreas de figuras planas que enfatiza os processos de medição e estimativas que estão relacionados diretamente com este conteúdo do ensino básico.

No primeiro capítulo apresentamos um rápido contexto histórico, medida de área e estudos anteriores sobre o conteúdo área.

Dedicamos o segundo capítulo para abordar os conceitos de estimativa e aproximação, estimativa de medida e apresentar algumas reflexões sobre o ensino de grandezas e medidas.

No terceiro capítulo explicitamos a problemática, o planejamento e os procedimentos metodológicos.

Apresentamos no quarto capítulo os resultados de uma sequência de atividades realizadas com professores em uma oficina no Centro de Aprendizagem em Ensino de Matemática (CAEM) do Instituto de Matemática e Estatística (IME-USP).

No quinto capítulo é feita uma análise da aplicação do experimento aos alunos do $9^{\circ}$ de uma escola pública localizada na zona oeste de São Paulo.

E no sexto e último capítulo apresentamos as considerações finais dos estudos deste trabalho.

Constam, nos anexos, as atividades realizadas na oficina do CAEM com professores e as atividades do experimento de ensino que foram aplicadas aos estudantes. 


\section{Capítulo 1}

\section{$O$ conceito de área}

Neste capitulo procuramos abordar alguns aspectos históricos relacionados com o processo de medição e o conceito de área, a contribuição de alguns estudos para o ensino e aprendizagem desse conteúdo e a sua formalização do ponto de vista matemático.

\section{1 - Um pouco de história}

A medição está presente em todos os aspectos sociais da vida humana desde a origem das civilizações até a atualidade e seu uso é indispensável para realizar todo tipo de atividades comerciais e cotidianas.

O processo de medição na Babilônia parece estar relacionado intimamente com problemas práticos. De acordo com Eves (2011), infere-se que os babilônios do período 2000 a.C. a 1600 a.C. deviam estar familiarizados com as regras gerais da área do retângulo, do triângulo retângulo, do triângulo isósceles (e talvez da área de um triângulo genérico) e da área de um trapézio retângulo.

Devemos também aos babilônios antigos a divisão da circunferência de um círculo em 360 partes iguais. Existem diversas explicações para o motivo dessa escolha e segundo Eves (2011), a mais plausível é a seguinte:

\footnotetext{
(...) nos remotos tempos dos sumérios, existia uma unidade de medida grande, uma espécie de milha (aproximadamente 1609m) babilônica, igual a sete das milhas atuais. Como a milha babilônica era usada para medir distâncias mais longas, era natural que viesse a se transformar numa unidade de tempo, a saber, o tempo necessário para se percorrer uma milha babilônica. Mais tarde, talvez no primeiro milênio a.C., quando a astronomia babilônica atingiu o estágio de manter registros sistemáticos de fenômenos celestes, a milha-tempo babilônica foi adotada para mensuração de espaços de tempo. Como se determinou que um dia era formado de 12 milhas-tempo, e um dia completo equivale a uma revolução no céu, dividiu-se um ciclo completo em 12 partes iguais.Mas, por conveniência, a milha-tempo babilônica fora dividida em 30 partes iguais. Dessa forma chegamos a $12.30=360$ partes iguais num ciclo completo. (EVES, 2022, p. 61)
}

A Babilônia localizava-se numa região que era rota de grandes caravanas e, portanto alcançou um grande desenvolvimento econômico. Esse fato é utilizado por alguns 
historiadores para justificar o porquê a matemática babilônica alcançou um nível jamais obtido pela matemática no antigo Egito.

Os egípcios antigos utilizaram seu conhecimento principalmente para a construção de sistemas de irrigação, grandes templos e pirâmides. Apoiado em uma matemática experimental, construíram um conjunto arquitetônico cujo destaque é as enormes pirâmides. Por exemplo, a base da pirâmide de Quéops, construída há mais de 4500 anos, é composta de pedras esquadrejadas e tem por base um quadrilátero muito próximo de um quadrado, tal fato sugere que esse povo sabia construir ângulos retos.

$\mathrm{Na}$ civilização egípcia o processo de medição surge, segundo alguns estudos, com a necessidade de delimitar as terras depois das frequentes inundações do rio Nilo, devido a esse fato formaram-se especialistas nos cálculos de agrimensura (medição de terras, campos, etc.;) do mesmo modo teria surgido à necessidade de comparar áreas e volumes de figuras simples.

Segundo Eves (2011) a maior parte do que se conhece da matemática produzida pelos antigos egípcios está registrada no papiro Rhind (ou Ahmes), um texto matemático na forma de manual prático que contém 85 problemas copiados em escrita hierática pelo escriba Ahmes, de um trabalho mais antigo, é uma fonte rica sobre a matemática egípcia antiga, descreve os métodos de multiplicação e divisão dos egípcios, o uso que faziam das frações unitárias, sua solução para o problema da determinação da área de um círculo e muitas aplicações da matemática a problemas práticos. Alguns problemas são geométricos e, muitos deles decorrem de fórmulas de mensuração necessárias para o cálculo de áreas de terras e volume de grãos. 
O aparecimento de uma nova civilização nas cidades comerciais espalhadas ao longo das costas da Ásia Menor e, mais tarde, na parte continental da Grécia, na Sicília e no litoral da Itália, trouxe uma nova visão racionalista do mundo e o homem começou a indagar como e por quê. Essa mudança na forma de enxergar o mundo teve reflexos marcantes nas ciências

\begin{abstract}
(...) na matemática, como em outros campos, o homem começou a formular questões fundamentais como "Por que os ângulos da base de um triângulo isósceles são iguais?" e "Por que o diâmetro de um círculo divide esse círculo ao meio?". Os processos empíricos do Oriente Antigo, suficiente o bastante para responder questões na forma de como, não mais bastavam para as indagações mais científicas na forma de por quê. Algumas experiências com o método demonstrativo foram se consubstanciando e se impondo, e a feição dedutiva da matemática, considerada pelos doutos como sua característica fundamental, passou ao primeiro plano. (EVES, 2011, p. 94)
\end{abstract}

Por volta do ano 300 a.C., aproximadamente, o geômetra grego Euclides teria escrito os " Elementos", um trabalho que trouxe um modelo de exposição da matemática que marcou significativamente o mundo ocidental. Segundo diversos historiadores, essa obra memorável está entre as que mais influenciaram o pensamento científico; nenhum livro, com exceção da Bíblia, foi tão largamente usado e estudado tendo sido impressas, até hoje, mais de mil edições deste texto, a primeira delas em 1482 na cidade de Veneza. Por mais de dois milênios esse trabalho dominou o ensino de geometria.

Apesar da grande relevância do conteúdo dos Elementos, mais importante ainda é a maneira formal como se apresenta seu conteúdo. Certamente um dos grandes feitos dos matemáticos gregos antigos foi o desenvolvimento da noção de discurso lógico como uma sequência de afirmações estabelecidas por raciocínio dedutivo a partir de um conjunto inicial de afirmações assumidas fora do escopo do discurso. Essas afirmações são chamadas postulados, ou axiomas, do discurso e delas devem decorrer logicamente todas as demais afirmações, estas chamadas proposições, ou teoremas, do discurso. 
No seu trabalho Euclides não definiu área. Para ele duas figuras planas são chamadas iguais quando tem a mesma área. Conforme Lima (1991)

\begin{abstract}
Para Euclides, a coincidência de duas figuras planas por superposição era um passo intermediário para concluir a igualdade de suas áreas (Com efeito, o AXIOMA 4 dos elementos diz: "Duas figuras que coincidem por superposição são iguais".). Assim, era importante para ele dispor de critérios que assegurassem a superponibilidade, por exemplo, de dois triângulos. (Os 3 casos familiares de "igualdade de triângulos").Cumpridas essas condições, o AXIOMA 4 garantiria a mesma área para os triângulos dados. (LIMA, 1991, p. 24)
\end{abstract}

Percebemos uma concepção um pouco limitada do conceito de área, pois podemos encontrar figuras de mesma área que não sobrepostas devido a sua forma. Os matemáticos gregos interessavam-se pelo problema de transformar a área de uma figura plana em outra figura de mesma área. Conforme Eves (2011), a solução dada por eles ao problema básico da construção de um quadrado de área igual à de um polígono dado pode ser encontrada nas Proposições 42, 44 e 45 do livro I e Proposição 14 do livro II dos Elementos de Euclides.

Outro problema enfrentado pelos matemáticos gregos era o de comparar grandezas (tudo aquilo que pode ser contado ou medido) da mesma espécie, como dois segmentos de reta, duas áreas ou dois volumes. Segundo Ávila (2006), no tempo de Pitágoras (580-500 a.C. aproximadamente) - e mesmo durante boa parte do $5^{\circ}$ século a.C. - pensava se, que:

\footnotetext{
os números racionais fossem suficientes para comparar segmentos de reta; isto é, dados dois segmentos $\mathrm{AB}$ e $\mathrm{CD}$, seria sempre possível encontrar um terceiro segmento $\mathrm{EF}$ contido um número inteiro de vezes em $\mathrm{AB}$ e outro número inteiro de vezes em $\mathrm{CD}$, situação esta que descrevemos dizendo que EF é um submúltiplo comum de $\mathrm{AB}$ e $\mathrm{CD}$. Uma simples reflexão revela que essa ideia é muito razoável. Afinal, se EF não serve, podemos imaginar um segmento menor, outro menor ainda, e assim por diante. Nossa intuição geométrica parece dizer-nos que há de existir um certo segmento EF, talvez muito pequeno, mas satisfazendo aos propósitos desejados. (AVILA, 1984, RPM 05)
}

Dois segmentos nessas condições são ditos comensuráveis, justamente por ser possível medi-los ao mesmo tempo, com a mesma unidade EF. Entretanto, não é verdade que dois segmentos quaisquer sejam sempre comensuráveis. Em outras palavras, existem segmentos $\mathrm{AB}$ e $\mathrm{CD}$ sem unidade comum $\mathrm{EF}$, os chamados segmentos incomensuráveis. Esse é um fato que contraria nossa intuição geométrica, e por isso mesmo a descoberta de grandezas incomensuráveis na Antiguidade representou, segundo alguns estudiosos, um momento de crise no desenvolvimento da Matemática. 
O aparecimento de grandezas incomensuráveis é associado, segundo alguns pesquisadores, com a aplicação do teorema de Pitágoras no triângulo retângulo em que a hipotenusa é a diagonal de um quadrado que tem lado de medida 1 . No caso das medidas desses dois segmentos 1 e $\sqrt{2}$ é impossível encontrar uma subdivisão da unidade de medida de comprimento que caiba um número inteiro de vezes em ambos os segmentos dizemos, então que esses dois segmentos são incomensuráveis, isto é equivalente a dizer que $\sqrt{2}$ é um número irracional, ou seja, um número cuja representação decimal é infinita e não periódica.

A descoberta dos incomensuráveis representou, no $5^{\circ}$ século a.C. uma derrota para os pitagóricos. Afirma Ávila (1984)

De fato, para eles o número era a essência de tudo. Eles acreditavam na
possibilidade de explicar todos os fenômenos do mundo sensível em termos dos
números e suas relações, tanto na Geometria como na Música, na Astronomia ou na
Física, enfim, o número seria a essência última do ser e de todos os fenômenos. Mas
por número eles entendiam apenas o que chamamos hoje de números naturais, ou
inteiros positivos: $1,2,3,4, \ldots$ Nem as frações eram números, já que elas apareciam
como relações entre grandezas de mesma espécie. Agora que haviam sido
descobertas grandezas incomensuráveis, estava claro que os números (naturais) eram
insuficientes até mesmo para definir a razão entre duas grandezas, o que se
constituía num sério entrave á Filosofia Pitagórica. (AVILA, 1984, p.)

Alguns historiadores da Matemática apontam que a descoberta de segmentos incomensuráveis, na Grécia antiga, foi o responsável por uma crise na escola pitagórica e, ao que se sabe, o matemático grego Eudoxo (século IV a.C.) foi o primeiro a lidar de forma precisa com as grandezas incomensuráveis.

Pouco se sabe da vida de Eudoxo. Foi discípulo de Platão e parece ter sido o primeiro a resolver completamente o problema das grandezas incomensuráveis construindo uma teoria das proporções que se aplicava tanto a grandezas comensuráveis quanto a grandezas incomensuráveis. Essa teoria encontra-se exposta no livro V de Euclides.

Eudoxo evitou a discussão sobre a natureza dos irracionais e sobre a validade dos processos infinitos e definiu a igualdade entre duas razões de uma maneira engenhosa. 
Esta definição, como afirma Bongiovanni (2005), fixa o critério de razões idênticas:

\begin{abstract}
"Diz-se que quatro grandezas estão na mesma razão, a primeira para a segunda e a terceira para a quarta se, quando equimúltiplos quaisquer são tomados da primeira e da terceira e equimúltiplos quaisquer da segunda e da quarta, os primeiros equimúltiplos são ambos maiores que, ou ambos iguais a, ou ambos menores que, os últimos equimúltiplos considerados em ordem correspondentes". (BONGIOVANNI, 2005, p. 96)
\end{abstract}

Utilizando a linguagem moderna e considerando como grandezas os segmentos AD, DB, AE e EC (comensuráveis ou não), para Eudoxo, dizer que

$$
\frac{A D}{D B}=\frac{A E}{E C},
$$

significava dizer que para todo $\mathrm{m}$ e $\mathrm{n}$ inteiros e positivos, as condições a seguir são verificadas:

Se $m$ DB $<$ n AD então $m$ EC $<$ n AE.

Se $m$ DB $>$ n AD então $m$ EC > n AE.

Se $m \mathrm{DB}=\mathrm{n}$ AD então $\mathrm{m} \mathrm{EC}=\mathrm{n} \mathrm{AE}$.

Com a teoria das proporções de Eudoxo foi possível, por exemplo, dar uma demonstração completa (para grandezas comensuráveis e incomensuráveis) do teorema de Tales:

"Se duas retas são transversais de um feixe de retas paralelas, então a razão entre dois segmentos quaisquer de uma delas é igual à razão entre os segmentos correspondentes da outra".

Outra contribuição importante de Eudoxo permitiu comparar figuras curvas com figuras poligonais. Os matemáticos gregos sabiam comparar figuras poligonais. Todo polígono podia ser transformado num quadrado equivalente (igual em área).

A proposição, conhecida mais tarde como princípio de exaustão de Eudoxo, consta no livro "Elementos" de Euclides.

\footnotetext{
"Dadas duas grandezas de mesma espécie, se retirarmos da maior uma parte maior que sua metade e do resto retirarmos uma parte maior que sua metade e assim por diante, obteremos após um numero finito de etapas uma grandeza menor do que a menor das duas grandezas consideradas".

(BONGIOVANNI, 2005, p. 102)
}

Arquimedes de Siracusa (287-212 a.C) usou essa ideia para obter áreas de figuras planas e volumes de sólidos diversos, através de provas por contradição.Ele encontrou 
respostas aproximadas para vários problemas, além disso, criou tanta matemática, que alguns historiadores atribuem a ele o título de precursor do cálculo integral; ele obtém a área de um círculo considerando dois polígonos regulares de n lados: um inscrito e um outro circunscrito ao círculo.

No tratado "A medida do círculo" de Arquimedes podemos acompanhar o seu raciocínio. Este texto, na forma que chegou até os dias atuais, contém somente três proposições; a segunda, sendo uma dedução das Proposições 1 e 3, está fora de lugar na medida em que utiliza o resultado da Proposição 3.

$\mathrm{Na}$ Proposição 1 Arquimedes inscreve e circunscreve a um círculo uma série de polígonos regulares, começando com um quadrado, e dobrando o número de lados continuamente; ele então prova de maneira rigorosa, pelo método da exaustão, que a área de um círculo é equivalente (igual em área) a de um triângulo retângulo no qual um dos catetos tem medida igual ao raio do círculo e o outro cateto tem medida igual ao comprimento da sua circunferência.

A Proposição 3 é a famosa proposição em que Arquimedes encontra uma aproximação do perímetro da circunferência do círculo pelo uso de polígonos regulares inscritos e circunscritos, levando essa aproximação a polígonos de 96 lados, e encontra a seguinte estimativa para $\pi: 223 / 71<\pi<22 / 7$.

Para facilitar podemos tomar um círculo de diâmetro unitário, então o comprimento (perímetro) da circunferência do círculo está compreendido entre o perímetro de qualquer polígono regular inscrito e de qualquer polígono regular circunscrito. Arquimedes teria iniciado calculando os perímetros dos hexágonos regulares inscritos e circunscritos, obtendo limites para $\pi$. Aplicando esse processo de forma sucessiva, podemos calcular os perímetros dos polígonos regulares de 12, 24, 48 e 96 lados e, dessa forma, obter melhores aproximações para o valor de $\pi$. Foi isso o que teria feito Arquimedes, chegando à conclusão de que $\pi$ está entre 223/71 e 22/7. Considerando-se as dificuldades do sistema de numeração da época, podemos concluir que Arquimedes tinha uma habilidade notável para fazer cálculo. 
Figura 1 - Polígono regular inscrito e circunscrito

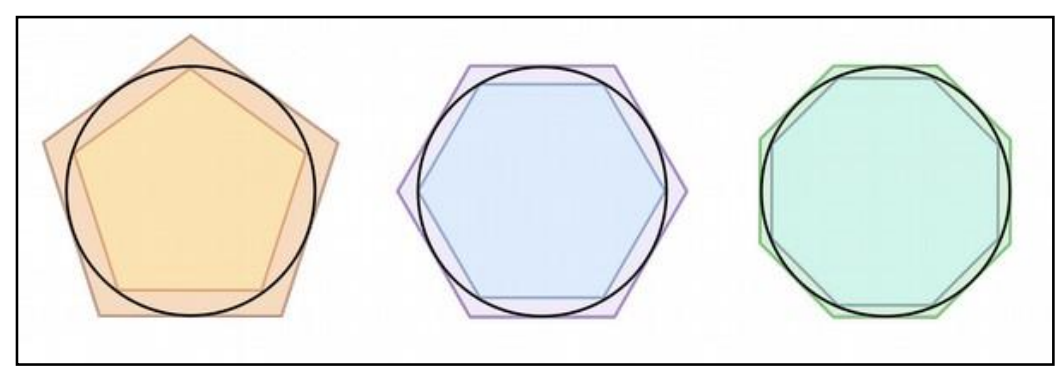

Fonte: PERUCHIN, Débora, 2012

A Proposição 2 que depende do resultado da proposição anterior é a seguinte: "A área de um círculo está para o quadrado de seu diâmetro aproximadamente como 11 está para 14".

Arquimedes escreveu ainda, outro tratado intitulado "Sobre a esfera e o cilindro" considerado o mais profundo dos seus trabalhos, pois contém, entre outras coisas, uma prova rigorosa de suas grandes descobertas do volume e da área da superfície de uma esfera.

Em resumo, a questão do cálculo de áreas de vários tipos de figuras planas foi abordada no século III a. C. por Arquimedes, que calculou estas áreas por um processo de exaustão. O procedimento é inscrever um polígono de área conhecida, em seguida inscrevemos outro polígono que inclui o anterior, obtendo assim uma melhor aproximação para a medida de área. Arquimedes elaborou este esquema geral para o círculo e para o segmento parabólico.

A questão de medir áreas ou volumes de regiões vem a ser abordado de forma mais geral com o desenvolvimento de outros conceitos: o Cálculo Diferencial e Integral.

A invenção do Cálculo é frequentemente atribuída a Isaac Newton (1643-1727) e Gottfried W. Leibniz (1646-1716). Na realidade, este é o produto de uma longa evolução, mas, sem dúvida, ambos desempenharam papel decisivo. Na Europa do século XVII dois problemas centrais chamavam a atenção dos cientistas. Em primeiro lugar, o problema das tangentes: determinar as tangentes a uma curva dada, o problema fundamental do Cálculo Diferencial. Em segundo lugar, o problema da quadratura: determinar a área dentro de uma curva dada, o problema fundamental do Cálculo Integral. O grande mérito de Newton e Leibniz foi o de terem identificado de forma clara a estreita associação entre estes dois problemas. Conforme COURANT E ROBBINS (p. 453) "nas mãos deles, os novos métodos unificados tornaram-se poderosos instrumentos da Ciência”. 
A seguir apresentamos a definição da integral de Riemann (Ver Figura 2) de uma função definida em um intervalo da reta real [a,b], conforme GUIDORIZZI (p. 306):

Figura 2- Definição da integral de Riemann

\subsection{INTEGRAL DE RIEMANN: DEFINIÇÃo}

Sejam $f$ uma função definida em $[a, b]$ e $L$ um número real. Dizemos que $\sum_{i=1}^{n} f\left(c_{i}\right) \Delta x_{i}$ tende a $L$, quando máx $\Delta x_{i} \rightarrow 0$, e escrevemos

$$
\lim _{\text {máx } \Delta x_{i} \rightarrow 0} \sum_{i=1}^{n} f\left(c_{i}\right) \Delta x_{i}=L
$$

se, para todo $\epsilon>0$ dado, existir um $\delta>0$ que só dependa de $\epsilon$ mas não da particular escolha $\operatorname{dos} c_{i}$, tal que

$$
\left|\sum_{i=1}^{n} f\left(c_{i}\right) \Delta x_{i}-L\right|<\epsilon
$$

para toda partição $P$ de $[a, b]$, com máx $\Delta x_{i}<\delta$.

Tal número $L$, que quando existe é único (verifique), denomina-se integral (de Riemann) de $f$ em $[a, b]$ e indica-se por $\int_{a}^{b} f(x) d x$. Então, por definição,

$$
\int_{a}^{b} f(x) d x=\lim _{\max x x_{i} \rightarrow 0} \sum_{i=1}^{n} f\left(c_{i}\right) \Delta x_{i}
$$

Se $\int_{a}^{b} f(x) d x$ existe, então diremos que $f$ é integrável (segundo Riemann) em $[a, b]$.É comum referirmo-nos a $\int_{a}^{b} f(x) d x$ como integral definida de $f$ em $[a, b]$.

Fonte: Guidorizzi (1997)

E o Teorema Fundamental do Cálculo estabelece uma conexão entre os dois principais conceitos: de integração e de diferenciação de uma função.

Teorema 1. Se f for integrável em [ a,b ] e se F for uma primitiva de f em [ a, b ], então

$$
\int_{a}^{b} f(x) d x=F(b)-F(a)
$$


Assim foi possível colocar e resolver o seguinte problema:

Se $f$ é uma função contínua em $[a, b]$ e tal que $f(x) \geq 0$, para todo $x$ pertencente ao intervalo $[a, b]$, então a área $S$ da região compreendida entre o eixo x e o gráfico de f, para x variando em $[a, b]$, é dada por:

$$
\text { Área }(\mathrm{S})=\int_{a}^{b} f(x) d x \text {. }
$$

Figura 3- Área sob uma curva

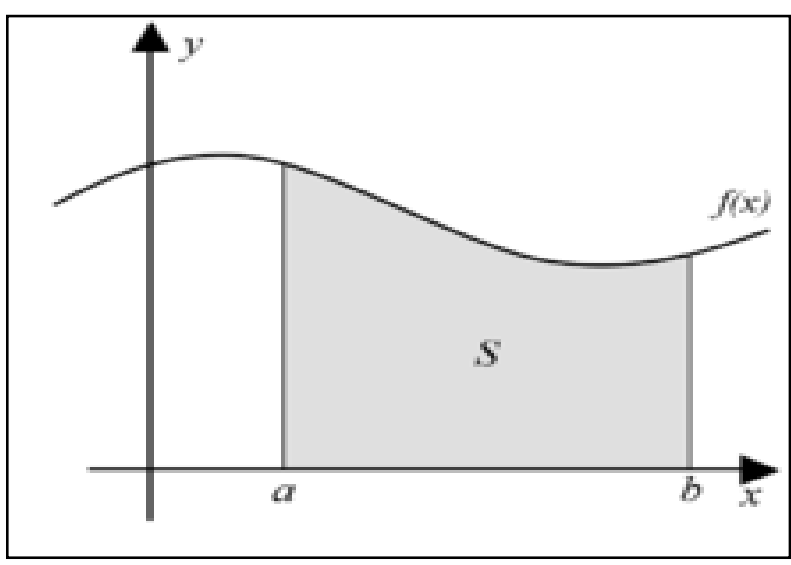

Fonte: brasilescola.uol.com.br

O conceito de integral é aplicado em diversas situações, tais como calcular o volume de sólidos, áreas de superfícies, o comprimento de arco de uma curva, etc., além de aplicações em outras áreas do conhecimento.

\section{2 - A medida de área}

Os números naturais são abstrações do processo de contar coleções finitas de objetos. $\mathrm{Na}$ vida diária precisamos não apenas contar objetos individuais, mas também medir grandezas tais como comprimentos, áreas, pesos e tempos. A importância de se abordar temas relacionados a grandezas e medidas é clara, pois estão muito presentes em nosso cotidiano.

A medição começa com a percepção do que deve ser medido. Explicar as marcas de um termômetro a uma criança sem desenvolver alguma sensação e percepção do que ela mede não é senão outra maneira de ler escalas. A altura de uma criança, por exemplo, dá significado ao comprimento. 
A maioria dos estudantes tem alguma experiência que lhes permite desenvolver a percepção do mundo que os rodeia. Cabe ao professor estimular seus alunos a realizarem medições e mostrar-lhes as muitas propriedades dos objetos que eventualmente devem medir.

A comparação é o começo da medição e a comparação vem logo após a percepção do atributo a ser medido. Tendo percebido alguma propriedade de algum objeto, nós, de um modo natural, comparamos com outros objetos que tem a mesma propriedade. Ao medir sua altura, alguns alunos podem desejar compará-la com a de outros alunos da classe. A comparação de atributos de objetos conduz de um modo bastante lógico a necessidade de um padrão que possamos aplicar sucessivamente.

Um padrão de medida é uma referência que podemos dispor a qualquer momento. A referência inicial que usamos não precisa ser uma referência padrão ou que seja usada em todo o mundo. Por exemplo, as partes do corpo são referências facilmente disponíveis para medir comprimentos.

As referências não padronizadas são úteis para fazermos comparações, mas desejamos levar aos nossos alunos mais além do óbvio e ensinar-lhes as referências que podem ser usadas por mais de uma pessoa: nossos padrões de medida.

Os padrões de medidas têm no mínimo duas funções importantes. Primeiro, permitem a uma pessoa comunicar uma medida à outra de um modo breve e direto. Segundo, permitem medidas precisas e consistentes em diferentes áreas geográficas. Quando viajamos de um país a outro, podemos estar seguros de que, quase sempre, as medidas que são padrões em nosso país são padrão em outro também.

Com o Sistema Internacional de Unidades, temos um sistema de unidades padronizadas e que tem substituído amplamente aos padrões locais arbitrários. Foram necessários centenas de anos para que o sistema fosse aceito no mundo todo.

A importância da medição em nossa vida pessoal é muitas vezes dada como certa. O cientista conhece sua importância, e o engenheiro não pode prescindir dela, mas o cidadão comum às vezes não percebe o papel da medida. Os alunos devem aprender a função importante que a medição tem para o progresso científico - tecnológico.

O estudo da medida na educação básica requer, segundo Van de Walle (2009), o uso de modelos físicos das unidades de medidas para que os estudantes compreendam os atributos dos objetos medidos, dominem os instrumentos correspondentes e adquiram a noção do tamanho das principais unidades padronizadas. 
Para realizarmos uma medida, em primeiro lugar, escolhemos de maneira arbitrária, a unidade de medida - grama, segundo ou metro, dependendo do caso - a qual atribuímos à medida 1. Em seguida, contamos o número destas unidades que, juntas, constituirão a quantidade a ser medida. De maneira geral, entretanto, o processo de contar unidades não é suficiente sempre que a quantidade dada não for exatamente mensurável em termos de múltiplos inteiros da unidade escolhida. Quando isto ocorre, damos outro passo e introduzimos novas subunidades, obtidas mediante a divisão da unidade original em um número n de partes iguais. Na Matemática, segundo Courant e Robbins (2000)

(...) uma subunidade obtida pela divisão da unidade original em n partes iguais é representada pelo símbolo $1 / \mathrm{n}$; e se uma determinada quantidade contém exatamente $\mathrm{m}$ destas subunidades, sua medida é representada pelo símbolo $\mathrm{m} / \mathrm{n}$. Este símbolo é denominado de fração ou razão. (COURANT; ROBBINS, 2000, p. 62)

Conforme os autores depois de séculos de tentativas o numero $\mathrm{m} / \mathrm{n}$ foi dissociado de sua referência concreta ao processo de medir e considerado como um número puro no mesmo nível dos números naturais. Quando m e n são números inteiros e n é não nulo, o símbolo $\mathrm{m} / \mathrm{n}$ é denominado de número racional.

Vejamos agora o procedimento para a realização da medida da grandeza "área" de uma figura F. Em primeiro lugar escolhemos uma unidade de medida de área e depois comparamos F com a unidade de área escolhida. O resultado dessa comparação será um número que deverá exprimir quantas vezes a superfície $\mathrm{F}$ contém a unidade de área. Comecemos com uma definição.

Um segmento de reta u chamado de segmento unitário (ou unidade de comprimento) possui, por definição, comprimento igual a 1. Todos os segmentos de reta congruentes a u terão (ainda por definição) o comprimento 1. 
Dessa forma segundo Lima (1991) podemos associar a cada polígono $P$ um número real não negativo, chamado área de $P$, com as seguintes propriedades:

1. Polígonos congruentes têm áreas iguais.

2. Se P é um quadrado com segmento unitário, então a área de $P$ é 1.

3. Se $\mathrm{P}$ pode ser decomposto como reunião de $\mathrm{n}$ polígono $P_{1}, \ldots, P_{n}$ tais que dois quaisquer deles têm em comum no máximo alguns lados, então a área de $P$ é a soma das áreas do $P_{i}, i=1, \ldots$, n.

Segue de 3) que se o polígono $\mathrm{P}$ está contido no polígono Q, então a área de $\mathrm{P}$ é menor do que a área de $\mathrm{Q}$.

A área de uma superfície plana F arbitrária, ainda segundo Lima (1991), deve ser um número real não negativo, que podemos indicar por $\mathrm{a}(\mathrm{F})$. Ele ficará bem determinado se conhecermos seus valores aproximados, por falta ou por excesso.

Os valores de $\mathrm{a}(\mathrm{F})$ aproximados por falta são, por definição, as áreas dos polígonos $P$ contidos em F. Os valores de a(F) aproximados por excesso são as áreas dos polígonos P' que contém F. Portanto, quaisquer que sejam os polígonos P (contido em F) e P' (contendo F), o número a(F) satisfaz as desigualdades.

$$
\mathrm{a}(\mathrm{P}) \leq \mathrm{a}(\mathrm{F}) \leq \mathrm{a}\left(\mathrm{P}^{\prime}\right)
$$

Na Figura 4 abaixo a área de $\mathrm{P}$ é uma aproximação por falta e área de P' é uma aproximação por excesso, para a área de F.

Figura 4- Uma figura plana $\mathrm{F}$ (negra) contida num polígono P' e contendo um polígono $\mathrm{P}$

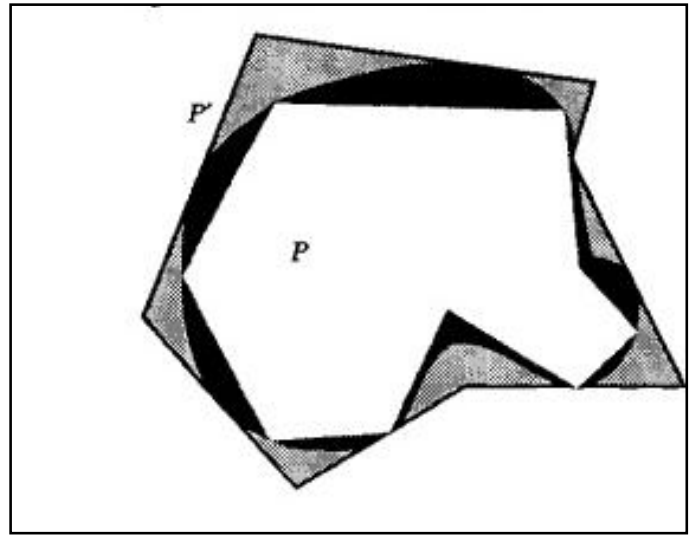

Fonte: Lima (1991) 
Temos, portanto do ponto de vista matemático a identificação entre área e número. Por outro lado se refletirmos a respeito do ensino e aprendizagem dessa grandeza e levando em consideração os estudos das pesquisadoras francesas Douady e Perrin-Glorian notaremos uma divergência. A identificação precoce entre área e número é apontada como uma fonte de erros. Quando a área esta sempre representada por um número os estudantes tendem a considerar apenas os aspectos relacionados aos cálculos, por exemplo, ao expressar a medida de área, consideram apenas o número ou associam a uma unidade de medida não adequada.

As autoras propõem o desenvolvimento de área como grandeza, isto é, a separação do quadro geométrico (superfícies planas), do quadro numérico (medida de área) e do quadro da grandeza (área). Dessa forma para que aluno compreenda com clareza o objeto matemático “área de superfícies planas" é necessário que ele saiba articular os três quadros. Em suma, a medida da grandeza área é identificada pelo par (número, unidade), se a unidade de medida é modificada a medida de área também muda embora a área permaneça a mesma. Temos ainda que superfícies planas de formas diferentes podem ser equivalentes, ou seja, possuírem a mesma medida de área.

A definição matemática do conceito de área associa esta a um número, mas para o ensino e aprendizagem desse conteúdo precisamos estar atento a muitos outros aspectos relacionados a este tema. Queremos que o estudante tenha um aprendizado com compreensão do objeto de estudo e não tenha a impressão equivocada de que basta saber uma fórmula e sair fazendo contas sem saber o que está calculando.

\section{3 - Ensino e aprendizagem da noção de área na perspectiva de Douady e Perrin- Glorian}

As dificuldades e a importância na aprendizagem do conceito de área levaram muitos pesquisadores a investigar e propor maneiras de se abordar o assunto. Vários educadores contribuíram com um estudo sistemático do conceito de medida de grandezas. Uma importante contribuição foi feita pelas pesquisadoras francesas Régine Douady e MarieJeanne Perrin-Glorian. O conceito de "quadro, mudança de quadro e jogo de quadros" foi utilizado na didática da matemática francesa pela primeira vez por Régine Douady, em 1986, na sua tese de doutorado.

Segundo Douady e Perrin-Glorian (1989) "um quadro é constituído de objetos de um ramo da matemática, das relações entre esses objetos, de suas formulações eventualmente 
diversas e das imagens mentais que o sujeito associa num dado momento, a esses objetos e relações" (p. 389 - tradução nossa). ${ }^{1}$

As pesquisadoras francesas classificam as concepções relacionadas as grandezas geométricas, em particular área, com base na seguinte organização conceitual:

Um quadro geométrico: constituído pelas superfícies planas; um quadro da medida (numérico), constituídos das medidas das superfícies planas, ou seja, o conjunto dos números reais positivos; um quadro da grandeza, constituído por classes de equivalência de superfícies de mesma área.

(DOUADY; PERRIN-GLORIAN, 1989, apud LIMA; SILVA 2000, p. 3),

Podemos observar a relação entre os três componentes: o objeto geométrico, a grandeza a ele associada e a medida dessa grandeza na seguinte representação gráfica.

Figura 5- Relação entre o objeto geométrico, grandeza e medida.

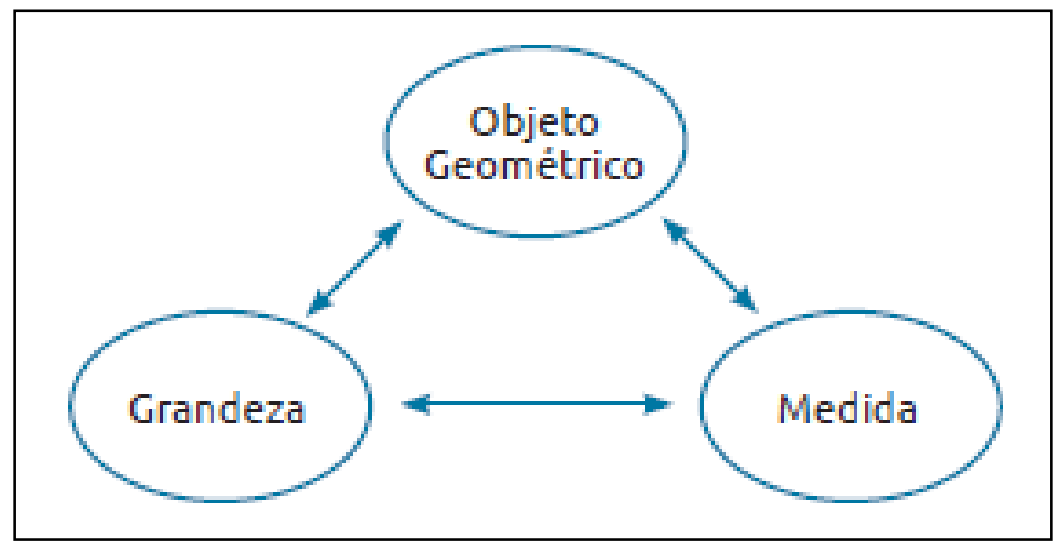

Fonte: PNLD (2017)

As pesquisadoras francesas Douady e Perrin-Glorian destacam que o ponto de vista geralmente adotado no ensino é selecionar uma unidade de medida e, em seguida, identificar áreas e medidas. Neste caso, existem apenas dois "quadros" escolhidos: o geométrico (superfícies planas) e o numérico (medida). No seu estudo com alunos franceses os resultados das avaliações mostraram que a identificação entre área e número (proposta por alguns autores em livros didáticos) é uma fonte de erros: na ausência de conhecimento sobre áreas,

\footnotetext{
${ }^{1}$ Nous disons qu'un cadre est constitué des objets d'une branche des mathématiques, des relations entre les objets, de leurs formulations éventuellement diverses et des images mentales que le sujet asscocie á un moment donné á ces objets et ces relations.
} 
os alunos podem, por exemplo, fabricar fórmulas para chegar a um número que meça a superfície. Baseadas em suas investigações, as autoras afirmam que:

\begin{abstract}
Em relação ao objeto área, os alunos desenvolvem uma "concepção forma” ligada ao quadro geométrico ou uma "concepção número" ligada ao quadro numérico, ou as duas, mas de forma independente, eles tratam os problemas sem estabelecer uma relação entre os dois pontos de vista. Ora os problemas sobre áreas abordam essencialmente as relações entre os quadros numérico e geométrico. (DOUADY; PERRIN-GLORIAN, 1989, p. 395- tradução nossa)2
\end{abstract}

Quando a medida de área está sempre representada por um número, o aluno mobiliza uma concepção numérica e considera apenas os aspectos relacionados aos cálculos. Os alunos "criam" fórmulas para determinar a medida de área e/ou fazem uso inadequado das unidades (por exemplo, expressar a área de uma figura em metros, que são unidades de comprimento).

Ao associar a medida de área a uma superfície plana, o aluno mobiliza uma concepção geométrica. Se a superfície é decomposta em outra sem perda nem sobreposição de uma de suas partes, o aluno entende que esta outra figura não tem a mesma medida de área que a figura original.

No intuito de construir um processo de aprendizagem para o conceito de área de superfície plana, para alunos de 9-12 anos, as autoras partem das seguintes hipóteses: desenvolver o conceito de área como grandeza ajuda os alunos a estabelecerem as relações necessárias entre o quadro geométrico e o numérico; uma identificação precoce entre as grandezas e os números reforça as confusões feitas pelos alunos entre medida de comprimento e de área.

As pesquisadoras construíram e testaram um experimento de ensino adaptado às hipóteses e na qual distinguem três pontos: construir a noção de área como grandeza autônoma; estender a aplicação medida a superfícies não totalmente cobertas pela unidade A; destacar as diferenças e estabelecer a relação entre área e perímetro focando-se nas variações respectivas usando-se várias transformações.

A construção da noção de área como grandeza autônoma consiste em: diferenciar a área de uma superfície da sua forma, considerando que duas superfícies de formas diferentes

\footnotetext{
${ }^{2}$ Ainsi, au sujet de l'aire, les eleves développeraient une "conception forme" liée au cadre géométrique ou une "conception nombre" liée au cadre numérique, ou les deux, mais de façon indépendante, et ils traiteraient les problémes sans établir de relation entre les deux points de vue. Or les problémes d'aire mettent de façon essentielle en relation les cadres numérique et géometrique.
} 
podem ter a mesma área; distinguir área do número, onde a uma mesma superfície podem corresponder números diferentes associados às unidades de medidas escolhidas, sem modificar a sua área. Isso é feito usando os procedimentos de comparação direta de superfícies por inclusão ou indiretamente por "recorte-colagem", superposição e recobrimento das superfícies com várias unidades.

Em relação à extensão da aplicação medida a superfícies não preenchidas totalmente (recoberta) com uma dada unidade A, dois pontos de vista são abordados: utilizar recortecolagem para construir uma superfície $\mathrm{S}^{\prime}$ de mesma área que $\mathrm{S}$ e coberta pela unidade $\mathrm{A}$; utilizar os enquadramentos de $\mathrm{S}$ para recobrir as superfícies com A, ou com subdivisões de A que se aproxime de $\mathrm{S}$ por falta ou por excesso.

O trabalho foi proposto depois das pesquisadoras Douady e Perrin-Glorian terem identificado algumas dificuldades de compreensão do conceito de área:

-Para alguns alunos a possibilidade de determinar a medida da área de uma superfície plana $\mathrm{S}$ depende da forma da unidade de medida, e da superfície $\mathrm{S}$ ser ou não totalmente preenchida com um número inteiro de unidades. Por exemplo, se o aluno não consegue cobrir um triângulo com uma quantidade finita de quadrados de lado $1 \mathrm{~cm}$, entende que também não é possível determinar a medida da área $\mathrm{S} \mathrm{em} \mathrm{cm}^{2}$;

- A área está ligada a superfície e não se dissocia desta. Por exemplo, se duas superfícies distintas possuem a mesma área, os alunos afirmam que as superfícies têm o mesmo perímetro. Se uma superfície tem sua medida de área determinada por um número associado a uma unidade de medida, os alunos compreendem que ao mudar a unidade de medida, a medida e área da superfície também variam.

- O uso de certas fórmulas é estendido para situações em que elas não são válidas: por exemplo, o produto das medidas dos lados de um triângulo para determinar a sua área.

A partir da perspectiva de Douady, Baltar (1996, apud Ferreira, 2010) propõe um conjunto de situações que dão sentido à área como grandeza separada em três grupos: comparação de área, medida de área e produção de superfície.

As situações de comparação estão situadas essencialmente no quadro das grandezas, ao comparar superfícies planas e decidir se pertencem ou não a uma mesma classe de equivalência (igual em área). As situações de medição estão situadas essencialmente no quadro numérico, e na passagem da grandeza ao número, através de uma unidade de medida. O resultado esperado nesta situação é um par (número, unidade de medida). E as situações de 
produção, que se diferenciam das anteriores, já que podemos determinar várias respostas corretas para uma mesma situação. Aqui, o quadro geométrico tem destaque, considerando a produção de uma superfície, embora a intervenção do quadro numérico e das grandezas também seja importante. A seguir detalharemos os diferentes conjuntos de situações.

\section{Situação de comparação}

De acordo com Ferreira (2010) dependendo das variáveis escolhidas e os valores assumidos, os procedimentos de resolução são diferenciados. Nesse tipo de situação, a primeira distinção a ser feita é em relação ao número de superfícies a comparar: duas ou mais superfícies. O autor também afirma que quando passamos da comparação de área de duas superfícies aquelas de várias superfícies (seriação) a distinção é importante, uma vez que, nos problemas de seriação é necessário colocar em prática a transitividade da relação de ordem, o que não ocorre na comparação de duas superfícies. Baltar (1996 apud Ferreira, 210) ainda subdivide as situações de comparação em estáticas e dinâmicas. Nas situações estáticas as superfícies não são alteradas diante dos procedimentos utilizados e no caso das situações dinâmicas são tratadas as variações das áreas e dos perímetros.

\section{Situação de medida}

De acordo com Ferreira (2010, p. 31) "essa situação tem como objetivo a passagem da grandeza ao número por meio da escolha de uma unidade". Para essa autora a medida de área de uma superfície pode ser expressa por um número seguido de uma unidade (medida exata) ou por um intervalo (medidas aproximadas por enquadramento) com uma escolha sucessiva de unidades que permitam uma medida mais aproximada da área da superfície. Dois tipos de medidas são evidenciados nos estudos de Baltar: as situações de enquadramento e as de medida exata. Além disso, (FERREIRA, 2010, p.32) aponta que "nas situações de enquadramento, a área de uma superfície de borda irregular ou arredondada será aproximada. As situações de medida exata de área são aquelas em que, para a escolha de uma unidade, é atribuído um número a área da superfície".

\section{Situação de produção}

São diferentes das anteriores do ponto de vista da tarefa cognitiva do aluno. Enquanto nas situações de comparação e de medida em geral há apenas uma resposta correta para cada 
situação, as situações de produção, frequentemente admitem várias respostas corretas. Além disso, apesar de a resposta esperada para cada situação de produção ser uma superfície (objeto geométrico), a intervenção dos outros quadros pode ser tão importante quanto à do quadro geométrico. De acordo com Ferreira (2010) as situações de produção são divididas em três subclasses: produção de uma superfície de mesma área que uma superfície dada, produção de uma superfície de área maior ou menor que uma superfície dada e produção de superfícies de área dada. 


\section{Capítulo 2}

\section{Estimativa e medida}

Neste capítulo explicitamos os conceitos de estimativa e medição, pois estão relacionados intimamente e são fundamentais para a compreensão do processo de medida de uma grandeza contínua.

\section{1 - O conceito de estimativa}

A estimativa é um "juízo sobre o valor do resultado de uma operação numérica ou da medida de uma grandeza, dependendo das circunstâncias individuais de quem o emite" Segovia et al., (1989, tradução nossa) ${ }^{3}$. Os autores por questões metodológicas dividem as estimativas em dois grupos:

a) Estimativa em cálculo: refere-se as operações matemáticas e aos juízos que podem ser estabelecidos sobre seus resultados. Exemplo: uma estimativa do resultado de 2345 multiplicado por 52 é 120.000 (2400 multiplicado por 50).

b) Estimativa em medida: refere-se aos juízos que podem ser estabelecidos sobre o valor de uma grandeza bem como a valoração que pode ser feita do resultado de uma medida. Por exemplo, uma estimativa para o caso de grandezas contínuas é a valoração que fazemos sobre a estatura de uma pessoa quando comparamos com a nossa própria; para o caso de grandezas discretas é a estimativa do número de pessoas que participam de uma manifestação.

\footnotetext{
${ }^{3}$ Juicio sobre el valor del resultado de una operación numérica o de la medida de una cantidad, en función de circunstancias individuales del que ló emite
} 
Os pesquisadores também afirmam que o conceito geral de estimativa possui as seguintes características:

1. Consiste em valorar uma grandeza ou o resultado de uma operação aritmética;

2. O sujeito que faz a valoração tem alguma informação, referência ou experiência sobre a situação que deve avaliar;

3. A valoração é feita geralmente de forma mental;

4. Faz-se com rapidez e utiliza números mais simples possíveis;

5. O valor atribuído não é exato, mas adequado para tomar decisões;

6. O valor atribuído admite distintas aproximações dependendo de quem fez a valoração. (SEGOVIA et al ,1989, p.21 , tradução nossa)4

A estimativa, tanto em cálculo como em medida, é uma competência matemática que vem sendo incorporada gradativamente no currículo de matemática da Espanha desde os anos oitenta de acordo com Segovia et al., (1989). Desde essa década, e também nos Estados Unidos, tem-se realizado muitas investigações buscando esclarecer os elementos que caracterizam a estimativa assim como formas de incluir o tema em currículos.

No Brasil também temos os documentos com orientações curriculares recomendando o trabalho com estimativa no Ensino Básico. Nos Parâmetros Curriculares Nacionais - PCN é salientado que devemos trabalhar com o cálculo mental e as estimativas.

A estimativa constrói-se juntamente com o sentido numérico e com o significado das operações e muito auxilia no desenvolvimento da capacidade de tomar decisões. $\mathrm{O}$ trabalho com estimativas supõe a sistematização de estratégias. Seu desenvolvimento e aperfeiçoamento depende de um trabalho continuo de aplicações, construções, interpretações, análises, justificativas e verificações a partir de resultados exatos. (...) (BRASIL, 1997, p.77)

E a Base Nacional Comum Curricular - BNCC do Ensino Fundamental, aprovada em 2017, ressalta a importância no trabalho com estimativa em cálculo:

No tocante aos cálculos, espera-se que os alunos desenvolvam diferentes estratégias para a obtenção dos resultados, sobretudo por estimativa e cálculo mental, além de algoritmos e uso de calculadoras. (BRASIL, 2018, p. 266)

\footnotetext{
${ }^{4}$ Consiste en valorar una cantidad o el resultado de una operación aritmética.

El sujeto que hace la valoración tiene alguna información, referencia o experiência sobre la situación que debe enjuiciar.

La valoración se realiza por lo general de forma mental.

Se hace con rapidez y empleando números lo más sencillos posibles.

El valor asignado no es exacto, pero si adecuado para tomar decisiones.

El valor asignado admite distintas aproximaciones dependiendo de quien realice la valoración.
} 
E ainda a BNCC recomenda que ao se trabalhar medidas de várias grandezas sejam utilizadas unidades não convencionais e convencionais, registros, estimativas e comparações.

A Base Nacional Comum Curricular - BNCC do Ensino Fundamental é um documento que regulamenta quais são as aprendizagens essenciais a serem trabalhadas nas escolas brasileiras, públicas e particulares da Educação Infantil, Ensino Fundamental e Ensino Médio para garantir o direito á aprendizagem e o desenvolvimento integral dos estudantes.

Apesar das alterações, o documento não propõe uma ruptura com a visão sobre a Matemática adotada desde os Parâmetros Curriculares Nacionais- PCN: documento que durante anos serviu de referência para as escolas.

Na BNCC, em relação ao conteúdo do bloco Grandezas e Medidas, o foco é a resolução de problemas envolvendo medidas e medições, compreendendo que medir é comparar uma grandeza contínua com diferentes unidades, padronizadas ou não.

Segundo Usiskin (1986, apud Segovia et al., 1989, ) as pessoas, em geral, tem uma visão distorcida da Matemática. A opinião que muitos têm a respeito desta área do conhecimento, e especialmente da aritmética, é de uma ciência que nos conduz a respostas exatas, mas isso é apenas um aspecto; a estimativa e a aproximação tem uma grande importância na estatística, no cálculo numérico e na matemática aplicada. Ainda de acordo com o autor, uma instrução dedicada apenas a produzir respostas únicas perde outras faces da Matemática, e fazem um mau serviço, pois passa uma visão distorcida desta ciência e dos seus usos. A obsessão por respostas exatas a qualquer preço leva a cálculos desnecessários e impede as pessoas de adquirirem experiências e confiança para a realização de estimativas.

É importante deixar claro que a estimativa não é um "chute" Smoothey $(1998$, p. 7) enfatiza que:

\footnotetext{
Uma estimativa é um palpite inteligente não é um número qualquer, escolhido a esmo, mas um número baseado na observação e no raciocínio. Também não se trata de um erro, ou de uma mentira. Algumas vezes você só precisa de uma boa estimativa, não de uma resposta exata. Uma boa palavra para estimativa é aproximação. Quando você topa expressões como "cerca de", "aproximadamente", "mais do que", "quase", ou o clássico "mais ou menos", está sendo feita uma estimativa. ( SMOOTHEY, 1998, p. 7)
}

Parece-nos que o ensino escolar deve abarcar este duplo caráter da Matemática, exato e aproximado, e deve proporcionar aos estudantes atividades que lhes permitam apreciar em que circunstâncias convêm utilizar uma ou outra. 
O esquema proposto por Parra et.al (1996, p. 188) ,mostrado na Figura 6, ilustra a estimativa e suas relações com o problema que se quer resolver, o tipo de resposta que se deseja e os procedimentos de cálculo que podem ser usados em cada situação.

Figura 6 - Relação da estimativa com o problema proposto

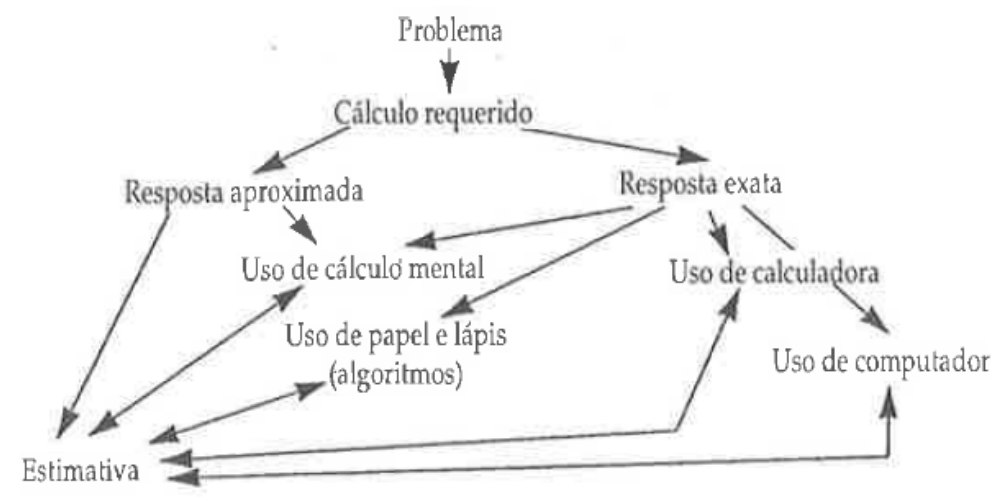

Fonte: Parra et.al (1996)

Este esquema sugere que a estimativa pode e deve ser usada junto com os procedimentos com os quais se produz a resposta, de modo a antecipar, controlar e julgar a confiabilidade dos resultados.

A estimativa é também uma estratégia para trabalhar com números em situações reais, que nos permite fazer uma atribuição rápida de valores numéricos mantendo ao mesmo tempo certo controle sobre a validade dessa valoração. 
Segovia et al (1989) apontam algumas razões para o ensino da estimativa.

Em primeiro lugar, a estimativa ajuda a promover o uso da matemática na vida cotidiana, permitindo trabalhar em alguns tópicos que possuem utilidade social e usam argumentos e técnicas matemáticas para controlar e melhorar a razoabilidade dos resultados de nossos raciocínios.

Em segundo lugar, a inclusão da estimativa nos programas escolares permite melhorar o ensino de tópicos recentes. Dessa forma incorporamos o processo de atualização do currículo, que vem sendo produzido em outros países, através da implementação de inovações didáticas trazidas pelos campos de pesquisa em Educação Matemática. Além disso, a estimativa é um recurso muito útil na aprendizagem da matemática.

(SEGOVIA et al ,1989, p. 58)5

Portanto, duas são as razões fundamentais para incluir a estimativa na escola. A primeira é sua utilidade prática, e a segunda, é que ela completa a formação escolar que atualmente os estudantes recebem.

Em nosso dia a dia, muitas vezes, não há necessidade de maior exatidão na medida de uma grandeza, apenas uma estimativa dessa medida é suficiente. Assim, a introdução de atividades com estimativa de medida tem o mérito de aproximar os alunos das aplicações práticas da Matemática e de acordo com Bellemain e Lima (2010, p.181) "contribui ainda para que os alunos se familiarizem com modelos concretos de unidades padronizadas, o que pode ajudá-los na escolha da unidade mais adequada a uma determinada medição".

${ }^{5}$ En primer lugar, la Estimación contribuye a potenciar el uso de las matemáticas en la vida diária, permitiendo trabajar en algunos tópicos que tienen utilidad social y emplear argumentos y técnicas matemáticas para controlar y mejorar la razonabilidad de los resultados de nuestros razonamientos.

En segundo lugar, la incorporación de la Estimación a los Programas Escolares permite mejorar la instrucción de los nuevos tópicos que en ellos aparecen. Nos incorporamos, de esta manera, al proceso de actualización del currículo, que se viene produciendo en otros países, medidante la integración de innovaciones didácticas aportadas por los campos de investigación surgidos en Educación Matemática. Además, la Estimación es um recurso muy útil en el aprendizaje de la matemática. 
As razões pelas quais a estimativa é necessária podem ser classificadas em quatro grupos de acordo com Segovia et al., (2009)

1) Impossibilidade do conhecimento de um valor exato; como é o caso do emprego em algum cálculo de um valor que não conhecemos de maneira exata; por exemplo, o número de automóveis que saem de viagem num fim de semana.

2) Impossibilidade de tratamento numérico exato; por exemplo, quando empregamos em um cálculo um número decimal periódico.

3) Clareza numérica; os meios de comunicação, por exemplo, para maior clareza e compreensão das informações empregam estimativas no lugar de quantidades exatas.

4) Facilidade no cálculo; são numerosas as situações em que a exatidão não é necessária, basta um resultado aproximado; um arredondamento e algoritmos mentais adequados proporcionam de maneira fácil um resultado bastante aproximado do exato, e útil para tomar decisões. ${ }^{6}$

( SEGOVIA et al., 2009, p.506 )

As estimativas não são um conteúdo do currículo de Matemática, mas é uma habilidade importante que pode ser ensinada durante o estudo de outros assuntos. Segovia et al., (2009) apontam que é essencial que estratégias para estimar sejam trabalhadas com os alunos, pois, a menos que estratégias específicas sejam ensinadas, poucos estudantes terão condições de desenvolvê-las por si próprios.

\section{2 - Estimativa e aproximação}

A expressão "fazer uma estimativa" possui vários significados, quando utilizado no contexto das grandezas e medidas refere-se ao valor aproximado de uma grandeza sem a realização efetiva da medição. Também significa obter o número aproximado de elementos de um conjunto discreto, sem a contagem um a um. Outro significado também encontrado em

\footnotetext{
${ }^{6}$ Imposibilidad de conocimiento de un valor exacto; como es el caso del empleo em algún cálculo de um valor desconocido de manera exacta; por ejemplo, el número de automóviles que salen de viaje un fin de semana. Imposibilidad de tratamiento numérico exacto; por ejemplo, cuando empleamos en un cálculo un número decimal periódico.

Claridad numérica; los medios de comunicación, por ejemplo, para mayor claridad y comprensión de la información emplean estimaciones em lugar de cantidades exactas como "150 millones para una población escolar de 63 mil alumnos em lugar de "148739426 pesetas para una población escolar de 62879 alumnos".

Facilidad en el cálculo; son numerosas las aituaciones en que la exactitud no es necesaria y es suficiente y útil un resultado aproximado; un redondeo apropriado y unos algoritmos mentales apropriados, proporcionam de manera sencilla um resultado bastante aproximado al exacto y útil para tomar decisiones.
} 
alguns textos é o de estimar o resultado de uma operação numérica (cálculo estimado), por meio de outro mais simples, realizado com valores aproximados.

A aproximação é um termo frequente em cálculo numérico, um conjunto de ferramentas ou métodos usados para se obter a solução de problemas matemáticos de forma aproximada. Esses métodos se aplicam principalmente a problemas que não apresentam uma solução exata, portanto precisam ser resolvidos numericamente, na maioria das vezes, com o auxílio de um computador ou calculadora.

A aproximação e a estimativa estão relacionadas, mas não são sinônimos. Mais detalhadamente, em Segovia et. al (1989) se define a aproximação e sua relação com a estimativa.Aproximar-se é encontrar um resultado suficientemente preciso para um determinado propósito.Na aproximação existem métodos para o controle do erro; aproxima-se tanto quanto a situação exige. Para controlar o erro temos como ferramenta os teoremas do cálculo diferencial e integral, um importante ramo da Matemática, que se dedica ao estudo de taxas de variação de grandezas e acumulação de quantidades. O conceito de taxa de variação (derivada) permite, por exemplo, a abordagem do crescimento de uma população ou da variação dos preços; o cálculo integral permite, entre outras aplicações, o cálculo de volumes e áreas de uma grande variedade de figuras.

A estimativa leva o erro em conta, mas com menos precisão. Às vezes, este não tem o controle garantido. Na estimativa a valoração é realizada, em geral, de forma mental e o valor atribuído a uma medida ou operação aritmética admite distintas aproximações dependendo de quem realiza a valoração, tais características não são parte da aproximação. Os termos aproximado e aproximação serão usados com muita frequência para referirmos aos resultados da estimativa, que podem ser qualificados de aproximações do valor exato e, portanto aproximados, como também são os resultados de uma aproximação nos termos descrito. 


\section{3 - Estimativa de medida e medição}

Para Albarracín et al. (2016) "uma estimativa de medida é atribuir perceptivamente um valor ou um intervalo de valores em uma unidade correspondente a uma grandeza discreta ou contínua por meio dos conhecimentos prévios ou por comparação indireta de algum objeto auxiliar" (p. 94 - tradução nossa). ${ }^{7}$ Portanto, é baseada em três componentes fundamentais: atribuir um valor numérico com a unidade correspondente, realizar a tarefa perceptivamente e a relação da percepção com os conhecimentos prévios, isto é, com base em uma referência.

- Atribuir um valor numérico: Para que a tarefa possa ser considerada estimativa, devese requerer a atribuição de um valor numérico. Caso contrário, a tarefa seria apenas um trabalho perceptivo.

- Realizar a tarefa perceptivamente: para estimar é necessário utilizar os sentidos, evitando o uso direto de qualquer instrumento de medida, seja padronizado ou não. Quando se usa um instrumento de medida, fazendo uma comparação direta, está medindo e não estimando.

- Relacionar a percepção com os conhecimentos prévios ou com a imagem mental de um objeto auxiliar: para estimar deve ter referências ou idealmente possuir uma noção mental de alguma unidade de medida; caso contrário trataria de adivinhar ou dar um resultado inventado aleatoriamente.

Podemos observar que os autores consideram a percepção como um processo primordial para a estimativa de medida, isto é, para estimar fazemos uso dos sentidos sem dispor de nenhum instrumento de medida. Conforme Albarracín et al. (2016) "o desenvolvimento de imagens mentais das referências apoiam a tarefa para que o trabalho esteja relacionado ao raciocínio lógico, não dando lugar a resposta aleatória. Por último, a valoração é parte do desenvolvimento do sentido numérico na estimativa de medida"(p. 95 tradução nossa). ${ }^{8}$

\footnotetext{
${ }^{7}$ Estimar una medida: Asignar perceptivamente um valor o un intervalo de valores y la unidad correspondiente a una magnitud discreta o continua, por meio de los conocimientos previos o por comparación no directa a algún objeto auxiliar.

${ }^{8}$ El desarrollo de imágenes mentales a modo de referencia que fundamentan la tarea para que el trabajo se relacione con el razonamiento lógico, no dando lugar a la respuesta aleatória. Por último, la valoración es parte del desarrollo del sentido numérico en la estimación de medida.
} 
Portanto, nota-se que em ambos os processos, estimativa de medida e medição, existe um objetivo comum, que corresponde a dar um valor para uma medida. Na medição, utilizamos um padrão definido a priori, chamado unidade de medida, que comparamos com a grandeza correspondente por meio da interação direta. Na estimativa de medida, utiliza-se uma referência auxiliar mental, como unidade de medida, para avaliar por meio de uma interação indireta ou comparação mental, a medida da grandeza a estimar. Dessa forma estimativa significa, no campo das grandezas e medidas, a determinação do resultado da medição de uma grandeza sem a realização efetiva dessa medição.

As tarefas de estimativa de medida diferenciam-se pelo tipo de referência utilizado. A referência auxiliar, que Segovia et al.(1989) consideram como unidade presente, é uma referência que está em cena na estimativa da medida, por exemplo um lápis, uma carta,etc. Em contrapartida, temos a unidade ausente que corresponde a uma representação mental da referência, por exemplo, a ideia de centímetro quadrado.Todas as tarefas de estimativa de medida envolvem cálculo mental ou estimativa de cálculo.

As estratégias para estimar medida de grandezas tem, em princípio, uma componente mais subjetiva do que as estratégias de estimativa de cálculo, uma vez que, é necessário fazer a escolha da unidade de referência e o estabelecimento de uma comparação entre a grandeza a ser estimada e a unidade. Há, neste caso, umas habilidades necessárias para realizar estimativas de medida tais como: interiorização de unidades, conhecimento de referências e estimativa indireta, que passaremos a detalhar.

Por interiorização de unidades de medida entendem-se, neste caso, as referências perceptivas que tem cada sujeito em relação às unidades principais de medida das grandezas básicas. Por exemplo, no caso do comprimento é importante a apreciação visual de comprimentos próximos a $1 \mathrm{~m}, 1 \mathrm{dm}, 1 \mathrm{~cm}$; igualmente situar objetos ou assinalar marcas que estão entre si a uma distância próxima a cada uma destas unidades, ou também conhecer partes do corpo cujo comprimento seja de cada uma dessas unidades.Em todo o caso uma unidade de comprimento está interiorizada quando um estudante é capaz de reconhecê-la, construí-la ou assinalar dimensões e distâncias cujo comprimento seja aproximadamente cada uma dessas unidades.

Uma segunda habilidade relacionada com a interiorização é a do conhecimento de referências. Trata-se, neste caso, de conhecer a medida de grandezas que estão muito próximas, como ocorre com o comprimento de algumas partes do nosso corpo (palmo, pé, 
dedo) ou de objetos frequentes em nosso cotidiano (altura usual de uma porta ou altura do teto de uma casa). A busca de referências é praticamente ilimitada, ainda mais em nossa sociedade que tem a maior parte dos objetos normalizados. Associar as dimensões de alguns objetos usuais com as unidades de comprimento ou as capacidades dos recipientes comerciais e caseiros mais comuns com as unidades de volume facilita a possibilidade de estimar. Albarracín et al. (2016, p. 96), classificam as estimativas de medidas com o uso de referências em dois tipos:

a) Estimativa com referências próprias: Quando a valoração realiza-se por meio da percepção de referências próprias, isto é, por meio de unidades de medidas ou medidas de objetos que estão internalizados pelo estimador, realiza-se este tipo de estimativa. Neste tipo de estimativa, as imagens mentais ou as ideias perceptíveis de unidades de medidas distintas entram em jogo para valorar uma medida. A seguinte situação corresponde a este tipo de tarefa: João tem a imagem mental de um metro quadrado, a partir dela, olha o jardim e estima que sua superfície tem cinco metros quadrados. Nesta tarefa, podemos observar que João tem uma ideia mental do que é um metro quadrado, isto é, uma referência própria. No exemplo, explicitamos a ação que João realiza para valorar a área da superfície: olha, portanto não há uma interação direta da referência mental. Por outro lado, o estimador atribui um valor para a medição: $5 \mathrm{~m}^{2}$

b) Estimativa com referências auxiliares: Este tipo de estimativa corresponde à tarefa de avaliar numericamente uma medida, e é realizada por meio de uma interação mental de um objeto auxiliar presente. Estes objetos auxiliares atuam como uma unidade de medida não tendo uma interação direta. Por exemplo, se queremos estimar a largura de uma parede e para isso temos uma corda pequena, podemos olhar a corda e considerar que cabe umas cinco vezes na largura da parede. Neste caso, a referência é a corda e a interação é visual. Observemos o exemplo: Ana tem um tapete que mede $1 \mathrm{~m}^{2}$, considerando sua superfície, observa um quarto e considera que o quarto mede $10 \mathrm{~m}^{2}$. Nesta situação, a referência da estimativa de Ana é um tapete que mede $1 \mathrm{~m}^{2}$; portanto, realiza uma comparação ou interação indireta da mesma sobre a superfície do quarto. Deste modo, estima que o quarto tenha $10 \mathrm{~m}^{2}$. Neste caso, a interação do objeto, que atua como referência, sobre a grandeza deve ser indireta, caso contrário, é uma medição. Do mesmo modo, para que a tarefa seja uma estimativa, é indispensável que o processo acabe com um valor numérico. Por exemplo, se uma pessoa diz "este móvel se encaixa na largura da porta" não é uma estimativa, compara-se 
o móvel coma a largura da porta, mas a atividade é reduzida a um trabalho perceptivo, porque não existe um valor numérico associado.

Uma última habilidade útil na estimativa é o conhecimento de técnicas indiretas de medida como são as fórmulas mais importantes para o cálculo de áreas e de volumes ou algumas relações fundamentais como as que são expressas pelo teorema de Tales, teorema de Pitágoras ou a medida dos ângulos internos de um polígono. Há algumas situações em que uma estimativa é feita através da atribuição de um valor a uma medida por um processo de modelagem de uma realidade ou fenômeno complexo. Neste caso, há dificuldades para medições precisas e simplificamos a situação de modo que o resultado seja obtido a partir de uma ou várias estimativas de quantidades relevantes e são feitos cálculos apropriados para encaixar o modelo utilizado. Albarracín e Gorgorió (2014, apud Pizarro, Albarracín et al., 2016) têm estudado processos de estimativas relacionados a grandes quantidades e tarefas relacionadas com resolução de problemas. Estes autores observaram o desenvolvimento de diversos tipos de modelagem para resolvê-los. Vejamos um exemplo de estimativa indireta: Se um pátio tem $250 \mathrm{~m}^{2}$ e cada estudante ocupa 0,3 metros quadrados, a capacidade máxima do pátio é de 833 pessoas. Neste exemplo, os alunos consideram o espaço necessário para que uma pessoa possa estar localizada no pátio dentro dos parâmetros de conforto regulada pelo contexto. Neste caso, esse espaço ocupado é entendido como uma unidade de medida para ser aplicado diretamente sobre toda a superfície. Uma vez que no caso em que o resultado é produzido a partir de uma estimativa, o estudante divide a área total pela estimativa do espaço pessoal.

A associação entre grandeza e número, segundo Clements e Sarama (2014, apud Albarracín et.al., 2016), baseiam-se em dois aspectos: identificar uma unidade de medida e subdividir a grandeza por meio de uma interação. Considera três tipos de tarefas associadas à medição que podem ser utilizadas em diferentes fases do trabalho curricular de medição: medições com unidades não padronizadas, medições com unidades padronizadas e medições indiretas. Detalharemos tais fases a seguir.

a) A medição com unidades não padronizadas consiste em atribuir um valor ou um intervalo de valores a uma grandeza contínua usando uma unidade de medida, por meio de uma comparação direta com algum objeto auxiliar ou contar. A diferença entre a estimativa de medidas e a medição é o uso da percepção. Se a interação da unidade não tradicional é direta é medição, se for indireta, é estimativa, porque faz uso da percepção. Vejamos o seguinte 
exemplo: Se para medir a largura de uma mesa usamos lápis como unidade e fizermos uma interação direta, estamos realizando uma medição. Se não for possível encontrar uma quantidade representada por um número natural de lápis, temos que recorrer a um número misto, porque é necessário atribuir uma fração ao último lápis; esta última tarefa é uma estimativa da medida. A tarefa corresponde a uma medição porque majoritariamente há uma interação direta da unidade de medida com a superfície. Por outro lado, foi realizada uma estimativa da medida para avaliar a fração da última unidade.

b) A medição com unidades padronizadas é a fase em que professores podem disponibilizar para os alunos instrumentos de medida do tamanho da unidade de medida, por exemplo, varas de um metro, cartolinas que medem um metro quadrado, etc. Essas unidades podem ser utilizadas para os estudantes se familiarizarem com modelos concretos que representam unidades padronizadas que são abordadas nas aulas. Com esse material os estudantes podem medir diferentes grandezas tais como: comprimento, área.

c) A medição indireta é análoga à estimativa indireta, isto é, consiste em atribuir um valor e uma unidade de medida a uma grandeza por meio de uma modelagem ou um modelo matemático, dado que na maioria dos casos é impossível realizar a medição de modo direto, por exemplo, na seguinte questão. Uma árvore projeta uma sombra de $6 \mathrm{~m}$ de comprimento quando o ângulo de elevação dos raios do sol mede $60^{\circ}$, com essa informação podemos saber a altura da árvore. 


\section{4 - Sobre o ensino e aprendizagem de grandezas e medidas}

Compreender os objetivos do currículo é indispensável para a prática docente, tanto fora quanto dentro da sala de aula. Medir e estimar são, de acordo com Albarracín et al. (2016), dois procedimentos diferentes, mas mantêm uma estreita relação e se complementam. É por isso que os professores devem considerar tarefas distintas com as quais se pode atribuir uma medida a uma grandeza. A medida como parte da matemática, é um conhecimento social, no entanto, geram alguns paradoxos no seu ensino.

\footnotetext{
(...) a escola delega boa parte do ensino de medir a sociedade, com a convicção de que os estudantes acabem aprendendo certos assuntos em seu ambiente familiar e social, o que lamentavelmente não ocorre. Apesar disso, os alunos mais tarde terão que usar certos conteúdos em suas vidas pessoais e no trabalho.

(CHAMORRO, 2003 apud ALBARRACÍN et al, 2016, p. 102)9
}

Singular é o caso da estimativa de medida, uma vez que é um conceito que aparece habitualmente em contextos não educativos e todas as pessoas tem algum conhecimento ou compreensão do significado de estimativa de medida embora possa ser incompleta ou incorreta. Porém, os professores devem compreender a estimativa de medida como uma tarefa matemática que desenvolve o trabalho perceptivo, de referência e o sentido numérico.

Um caminho metodológico para o ensino de Matemática que vem sendo discutido ao longo dos últimos anos é o da resolução de problemas. A resolução de problemas enfatiza o processo de raciocínio sobre o produto ou resultado. $\mathrm{O}$ objetivo ao resolver um problema é alcançar um resultado: porém, não qualquer resultado e nem de qualquer modo.

Não se trata de proporcionar uma resposta imediata a qualquer questão que possa surgir. A ideia fundamental é outra: quando nos sentimos interessados - por qualquer motivo em ajustar uma informação ou uma série de dados entre si para satisfazer uma necessidade, quando nos deparamos com uma situação para a qual não temos prevista e ensaiada uma resposta, e os elementos dos quais dispomos não proporcionam de modo imediato uma solução, estamos diante de um problema. Com a resolução de problemas é enfatizado que a matemática é uma ferramenta de trabalho cujo uso e utilidade deve ser aprendida para dar

\footnotetext{
${ }^{9}$ La escuela delega Buena parte de la enseñanza de la medición a la sociedad, con la convicción de que los estudiantes terminarán aprendiendo ciertos temas en su entorno familiar o social, lo que lamentablemente no ocurre a pesar de que los estudiantes posteriormente tendrán que utilizar ciertos contenidos en sus vidas personales y laborales.
} 
resposta a múltiplas questões, umas de interesse propriamente matemático e outras de interesse geral.

A estimativa ajuda os estudantes na tarefa de resolver problemas

(...) diante de um problema é conveniente estimular os estudantes a realizarem uma estimativa da solução, bem antes de resolvê-lo, ou depois. Se feito antes o processo de estimativa libera os estudantes de pensar no problema de maneira mecânica e facilita a compreensão do mesmo. Se os alunos são ensinados a avaliar a resposta depois de resolver um problema, se eles são colocados em condições de verificar se isso faz sentido, e, portanto eles têm uma abordagem que ira permitir-lhes verificar a solução obtida.

( REYS ,apud SEGOVIA et al.,1989, p. 60)10

Dessa forma o autor considera que a estimativa é parte do processo geral da resolução de problemas e que o ensino de estratégias de estimativas reforça e estimula processos corretos de resolução de problemas. Assume ainda que a formação prática na estimativa fornece um contexto natural, não só para o desenvolvimento, mas também para praticar algumas técnicas importantes do pensamento matemático como: ler um problema e decidir que tipo de resposta é adequado; adquirir flexibilidade mental com os números (sentido numérico); selecionar a estratégia apropriada; reconhecer que existe mais de um caminho a seguir; comprovar a razoabilidade dos resultados; que é uma parte significativa do processo de resolução de problemas.

${ }^{10}(\ldots)$ ante un problema es conveniente estimular a los estudiantes a que realicen una estimación de la solución, bien antes de resolverlo, o bien, después. Si se realiza antes, el proceso de estimación libera a los estudiantes de pensar en el problema de una manera mecánica y facilita la comprensión del mismo. Si se enseña a los estudiantes a valorar la respuesta después de resolver un problema, se les pone en condiciones de verificar si ésta tiene sentido, y así dispondrán de un método que les permitirá verificar la solución obtenida. 
Os Parâmetros Curriculares Nacionais - PCN para o Ensino Fundamental indicam que no tratamento da noção de área de uma superfície plana podemos trabalhar com estimativas.

(...) A experiência tem mostrado que os alunos que aprendem mecanicamente fórmulas costumam empregá-las de forma também mecânica e acabam obtendo resultados sobre os quais não têm nenhum tipo de crítica ou controle, além de as esquecerem rapidamente. Desse modo, o trabalho com áreas deve apoiar-se em procedimentos que favoreçam a compreensão das noções envolvidas, como obter a área pela composição e decomposição de figuras cuja eles já sabem calcular (recortes e sobreposição de figuras) por procedimentos de contagem (papel quadriculado, ladrilhamento), por estimativas e aproximações.

(BRASIL, 1998, p. 131)

Apesar do destaque que os PCN dão as estimativas, professores e alunos tem pouca prática com ela, pois não se trata de um conteúdo a ser ensinado, mas uma habilidade útil para o cidadão comum. Este trabalho tem como um dos objetivos discutir um pouco mais sobre estimativas no contexto escolar e oferecer uma sugestão de atividade que possa combinar conteúdo (área de superfícies planas) e a estimativa de medida dessa grandeza. 


\section{Capítulo 3}

\section{Procedimentos metodológicos}

Neste capítulo descrevemos a abordagem metodológica do Design Experiments que foi utilizada na pesquisa e as principais etapas do nosso estudo até a elaboração final do experimento de ensino aplicado aos alunos de uma escola pública.

\section{1 - Design Experiments}

Nosso estudo teve como abordagem metodológica o Design Experiments. Segundo Karrer (2006) o modelo, que surgiu por volta de 1970 nos Estados Unidos, vem da necessidade de validar pesquisas por meio de modelos que não fossem de outras áreas como: psicologia, epistemologia e filosofia. Além disso, preencheu uma lacuna entre a prática da pesquisa e a prática de ensino. Cobb et al. (2003) afirmam que as experiências realizadas neste tipo de investigação podem ser entendidas como uma "ecologia da aprendizagem" pois para os autores trata-se de "um sistema complexo e interativo que envolve vários elementos de diferentes tipos e níveis - projetando seus elementos e antecipando como esses elementos funcionam juntos para apoiar a aprendizagem" (p. 9 - tradução nossa). ${ }^{11}$ Trata-se, portanto de um modo de investigação apropriado para abordar a complexidade dos sistemas educacionais. Segundo os autores, elementos de uma ecologia de aprendizagem normalmente incluem tarefas ou problemas propostos, falas ou discursos dos alunos, normas de participação, ferramentas e materiais relacionados e "as ferramentas e meio materiais fornecidos e os processos práticos pelos quais os professores podem orquestrar as relações entre estes elementos em sala de aula" (p. 9 - tradução nossa). ${ }^{12}$

A maioria dos estudos realizados em sala de aula utilizando Design Experiments são conceituados como casos de processo de apoio aos grupos de estudantes que aprendem em um domínio particular. Neste caso a intenção teórica é de acordo com Cobb et al.(2003) “identificar e explicar padrões sucessivos no pensamento do aluno, relacionando esses

\footnotetext{
${ }^{11}$ Learning ecology - a complex, interacting system involving multiple elements of different types an levels - by designing its elements and by anticipating how these elements function together to support learning.

${ }^{12}$ The tools and related material means provided, and the practical means by which classroom teachers can orchestrate relations among these elements.
} 
padrões com os meios pelos quais o desenvolvimento foi apoiado e organizado"(p. 11 tradução nossa) ${ }^{13}$. No entanto, diferentes investigações em sala de aula podem concentrar-se em diferentes constelações de problemas. Por exemplo, podemos ter como enfoque a relação entre normas de sala de aula, padrões para a argumentação matemática e aprendizado dos alunos.

Cobb et al.(2003) advertem que além de esclarecer a intenção teórica do Design Experiments, a equipe de pesquisa também "deve especificar as ideias disciplinares significativas e as formas de raciocínio que constituem os objetivos potenciais ou os pontos finais para a aprendizagem dos estudantes" (p. 11- tradução nossa $)^{14}$. Uma das características distintivas desse tipo de metodologia é que a equipe de pesquisa aprofunda sua compreensão do fenômeno sob investigação enquanto a experiência está em andamento.

Como parte do processo de preparação para este tipo de metodologia, deve-se especificar o ponto de partida intelectual e social dos estudantes. Em domínios relativamente bem pesquisados pode-se aproveitar a literatura para desenvolver conjecturas sobre as interpretações e entendimentos iniciais dos estudantes. Entretanto, em áreas menos pesquisadas, geralmente é preciso conduzir um trabalho "piloto" para documentar esse entendimento. De posse desses dados é especificado o ponto de partida, os meios que apoiarão o aprendizado e os pontos futuros, Karrer (2006) afirma que o objetivo é "formular um projeto inicial que seja capaz de testar conjecturas sobre mudanças expressivas no raciocínio dos estudantes, especificando os significados que darão suporte a estas mudanças" (p.201).

As configurações deste tipo de metodologia podem variar quanto ao tipo e alcance. $\mathrm{O}$ foco dos estudos pode estar na aprendizagem dos alunos, no ensino realizado pelos professores, na produção de novos currículos ou materiais educativos, na formação de professores, ou em mudanças nos sistemas educativos.

De qualquer forma, independente do foco a que se aplica uma das características importantes mencionadas por Karrer (2006) “é a quebra consciente entre a divisão dos papéis professor-pesquisador, já que estudantes, professores e pesquisadores são visto como

\footnotetext{
${ }^{13}$ Identify and account for successive patterns in student thinking by relating these patterns to the means by which their development was supported and organized.

${ }^{14}$ The research team also specifies its assumptions about the intellectual and social starting points for the envisioned forms of learning.
} 
colaboradores do processo" (p. 199). Esse método de investigação tem como objetivo compreender como os estudantes aprendem, buscando meios para apoiar tal aprendizagem, bem como avaliar se os meios utilizados contribuíram no desenvolvimento dessa aprendizagem no decorrer do processo.

A expressão Design Experiments é traduzida por Barbosa e Oliveira (2015) como "pesquisa de desenvolvimento" e referem-se aquelas "investigações que envolvem delineamento, desenvolvimento e avaliação de artefatos para serem utilizados na abordagem de um determinado problema, à medida que se busca compreender/explicar suas características, usos e repercussões" (p. 527). Por delineamento, entende-se a elaboração do artefato em sua primeira versão; o desenvolvimento refere-se ao processo contínuo de seu refinamento por meio da avaliação sistemática.

A expressão "design experiments" aparece em língua inglesa com outras denominações tais como: design-based research, designs studies, development/developmental research ou design research. A metodologia propõe superar a separação entre pesquisa qualitativa ou quantitativa, desenvolvendo investigações com enfoque no desenvolvimento de aplicações e na busca de soluções práticas e inovadoras para os problemas educacionais. Devido a sua natureza intervencionista o desenvolvimento da pesquisa pretende produzir: produtos educacionais diversos, mudanças nos processos pedagógicos, por exemplo, recomendações de atitude docente, novas propostas didáticas, políticas educacionais como protocolos de avaliação docente ou discente, etc. 
A "pesquisa de desenvolvimento" envolve, geralmente, a geração de um produto educacional que pode ser um material didático ou software educativo. De acordo com Barbosa e Oliveira (2015)

\begin{abstract}
Como a pesquisa de desenvolvimento envolve a geração de um produto educacional, o que, no nosso caso, pode ser um material didático, um software educativo, um programa curricular, etc., ela refere-se, portanto, ao que denominamos genericamente como um tipo de pesquisa de intervenção. Ao lado de outras modalidades, como é o caso da pesquisa-ação (TRIPP, 2005) e da engenharia didática - amplamente utilizada na tradição francesa (ARTIGUE, 1994)-, estudos desta natureza visam realizar intervenções como parte do estudo científico. (BARBOSA; OLIVEIRA 2015, p. 527)
\end{abstract}

Assim, trata-se de, uma vez identificado o problema, gerar uma intervenção que deve ser materializada por meio de algum produto educacional. Este passa pelo processo de análise e refinamento, de modo que, ao fim da investigação, possa ser utilizado por outras pessoas em outros contextos.

Segundo Cobb et al., (2003), Design Experiments possui algumas características convergentes. Em primeiro lugar, o objetivo deste tipo de metodologia é a tentativa de proporcionar o desenvolvimento de modelos ou teorias que apoiem a aprendizagem dos alunos. Em segundo lugar, temos a natureza intervencionista desta metodologia. Desse modo podemos investigar possibilidades de novas formas de aprendizagem e trazer para os estudantes uma nova abordagem de estudo diferente da convencional, praticada na maioria das escolas. Em terceiro lugar, qualquer tipo de Design Experiments tem dois aspectos, sendo um aspecto prospectivo, no qual o experimento é implementado a partir de uma hipótese sobre o processo de aprendizagem e os meios que o apoiem, e o aspecto reflexivo que ocorre durante o desenvolvimento da pesquisa com diferentes níveis de análise das hipóteses que poderão ser confirmadas ou refutadas.

Sendo assim o projeto inicial é uma conjectura sobre os significados que darão suporte a uma forma particular de aprendizagem, a qual será testada. Caso as conjecturas iniciais sejam refutadas, outras conjecturas podem surgir a partir das atividades, interações e intervenções realizadas com os alunos. Essa dinâmica nos revela a característica iterativa e cíclica deste tipo de investigação. 
A última característica revelada pelo redesign é o pragmatismo, sua preocupação está em oferecer meios para que os alunos criem modelos de aprendizagem em domínios específicos.

\section{2 - O papel do professor}

Neste tipo de metodologia o pesquisador assume também o papel de professor. Nesse duplo papel cabe-nos enquanto professor: estimular, encorajar e intervir em momentos críticos que poderão surgir durante o experimento, respeitando as formas de resoluções apresentadas pelos alunos. Como pesquisador é preciso: observar, registrar e analisar os elementos contidos durante a coleta de dados sem confundir os papéis. Existe, portanto uma quebra da visão tradicional em que o pesquisador, professores e alunos desempenham papéis fixos no processo. De acordo com Lobo da Costa e Poloni (2011) Design-Based Research é “considerado como método científico de investigação quando o foco do pesquisador está no pensamento matemático dos sujeitos e nas modificações desses pensamentos que podem ocorrer durante o processo" (p. 3). Para que a atitude do pesquisador seja coerente com essa metodologia, é necessário que ele crie situações que possibilitem mudanças significativas no raciocínio dos estudantes. A metodologia do Design Experiments permite analisar processos de aprendizagem de domínios matemáticos específicos e apresenta um caráter cíclico: atividade, aplicação da atividade, análise, design de nova atividade, aplicação, etc. Isso possibilita aos pesquisadores fazerem suas análises sobre suas conjecturas durante todo o processo. Como bem esquematizou Signorelli (2007, apud, Lobo da Costa e Poloni, 2011) na Figura 7, o Design-Based Research apresenta ciclos de redesign.

Figura 7 - Os Ciclos do Design Experiments

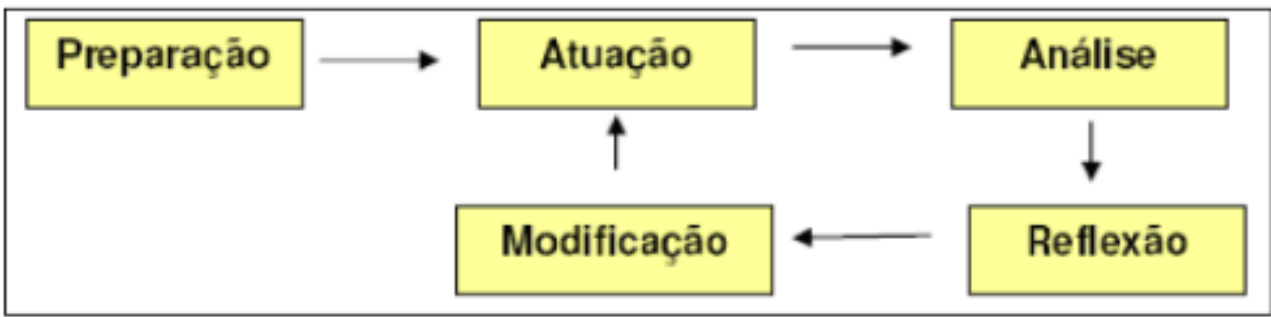

FONTE : Signorelli (2007, apud, Lobo da Costa e Poloni, 2011) 


\section{3 - Relação do nosso estudo com a metodologia}

A metodologia Design Experiments foi adotada na nossa pesquisa pelo fato de nossa proposta ter por objetivo analisar os processos de aprendizagem do conteúdo de áreas de superfícies planas desenvolvido com uma abordagem não tradicional. E também pelo fato de nesta metodologia o professor assumir o papel de pesquisador, conduzindo uma série de sessões de ensino, garantindo um estudo mais profundo e detalhado dos resultados.

Os alunos do $9^{0}$ ano da escola estadual "Daniel Paulo Verano Pontes" já tiveram contato com o conteúdo (áreas de figuras planas), pretendemos observar que tipo de construção os estudantes realizam quando deparados com o conceito matemático de áreas, desenvolvido com ênfase nos processos de medição e na estimativa da medida dessa grandeza. Isso porque não é usual uma abordagem que tenha a preocupação de explorar as estimativas e aproximações quando estudam essa noção.

Portanto, de acordo com as características desta metodologia a pesquisa está organizada em três fases:

\section{Fase 1 - Preparação do experimento}

Começamos nosso estudo fazendo uma revisão bibliográfica das pesquisas existentes no ensino de área, observamos como alguns livros didáticos introduzem e costumam abordar o tema, fizemos também a leitura de orientações curriculares; a pesquisa nos revelou a carência de material de estudo que se referissem as estimativas e de como essa habilidade pode ser trabalhada em sala de aula.

Com os objetivos de obter impressões de professores de Matemática sobre o tema de pesquisa e de aprimorar e refinar nosso experimento de ensino preparamos o material para uma oficina que foi oferecida nos dias 04, 11 e 25 de Abril de 2018 no Centro de Aperfeiçoamento do Ensino de Matemática (CAEM) no Instituto de Matemática e Estatística (IME) da Universidade de São Paulo (USP).

O CAEM é um órgão de extensão do IME, dirigido por professores do Departamento de Matemática do IME-USP. Seu objetivo é prestar serviços de assessoria a professores de Matemática. Dentre outras atividades, o CAEM oferece vários tipos de cursos, seminários para professores dos níveis Infantis, Ensino Fundamental e Médio e desenvolve vários 
projetos. Com exceção de algumas, as atividades são gratuitas para todos os professores, tanto das redes públicas (municipal ou estadual), quanto da rede particular.

Os encontros com os professores foram realizados no período de um mês com três seções semanais de três horas. Durante os encontros, os professores realizaram atividades previamente planejadas. Além disso, solicitamos aos professores do grupo a realização e a análise das atividades que pretendíamos aplicar aos alunos. A oficina contou com seis participantes que deram contribuições importantes para a pesquisa.

\section{Fase 2 - Atuação}

Após a análise dos registros das atividades realizadas pelos professores participantes da oficina e das discussões com o grupo, elaboramos a sequência de intervenções e atividades para serem aplicadas aos alunos do $9^{\circ}$ ano de uma escola da pública.

Para aplicação da pesquisa foi escolhida a escola pública estadual "Daniel Paulo Verano Pontes" localizada no bairro do Rio Pequeno, cerca de $3 \mathrm{~km}$ da Universidade de São Paulo (USP), na zona oeste do estado de São Paulo. Foi determinante para a escolha o fato da equipe de coordenadores e professores da escola acolherem de forma entusiasmada o projeto.

Os encontros com os alunos foram realizados no período de um mês com duas seções semanais de uma hora e quarenta minutos. Durante os encontros, os estudantes realizaram atividades previamente planejadas.

Participaram do nosso estudo aproximadamente 65 alunos, de duas turmas de alunos do $9^{\circ}$ ano da referida escola. Os alunos de tais turmas já tinham tido contato com o conteúdo "área de figuras planas", sendo assim procuramos enfatizar as principais ideias envolvidas nesse tema e introduzimos atividades que envolvessem a estimativa de medida de área e o processo de medição, pois entendemos que essas etapas são fundamentais para a compreensão do objeto de estudo delimitado. 
Fase 3 - Análise e reflexão

A metodologia nos permite uma visão dinâmica dos dados coletados, pois após cada aplicação podemos avaliar a atividade e fazer um redesign da mesma, verificando se os objetivos foram atendidos de forma satisfatória. Sendo assim não é possível prever a próxima etapa, as conjecturas inicias são testadas e podem ser refutadas ou não. Os registros podem ser feitos de várias formas tais como: registros escritos, gravados, fotografados, filmados e, no caso de uma pesquisa que utilize algum programa de computador, também são aceitos os arquivos salvos das atividades de ensino.

Nesta pesquisa a coleta de dados foi realizada através dos registros escritos dos estudantes, observações e anotações no diário de bordo. 


\section{Capitulo 4}

\section{O Experimento com professores}

Neste capítulo descrevemos os resultados e as observações da oficina que realizamos com seis participantes (professores, alunos da graduação e um estudante da pós-graduação) no CAEM (Centro de Aperfeiçoamento do Ensino de Matemática).

$\mathrm{Na}$ fase de experimentação, trabalhamos com alguns professores que participaram de uma oficina oferecida no Centro de Aperfeiçoamento do Ensino de Matemática (CAEM) no Instituto de Matemática e Estatística (IME) da Universidade de São Paulo (USP).

O objetivo da oficina foi discutir o conceito de estimativa apresentando-lhes algumas atividades que podem ser realizadas com os estudantes do ensino fundamental. Apesar dos documentos oficiais destacarem a importância de se desenvolver a habilidade com estimativas, nos livros didáticos encontramos raras atividades que incentivem e mostrem a importância e a utilidade das estimativas nas aplicações práticas e no aprendizado de algum conteúdo de Matemática.

Foram planejados três encontros e em cada um deles foi disponibilizado um texto e as atividades foram realizadas e discutidas pelos participantes.

\subsection{Os participantes}

O público participante da oficina no CAEM era composto por 6 pessoas sendo 2 professores da rede estadual de ensino, 3 alunos do curso de Licenciatura em Matemática da USP e 1 aluno do Mestrado Profissional em Ensino de Matemática oferecido pelo Instituto de Matemática e Estatística da USP.

Foi esclarecido aos participantes que se tratava de um trabalho de pesquisa de nossa dissertação de mestrado e todos concordaram em participar, assinando termo de consentimento.

Os participantes foram muito receptivos e participaram ativamente das atividades. Eles se interessaram pelas atividades e pelas estratégias envolvidas em cada uma delas. Procuramos evidenciar que, dependendo do contexto, basta um valor aproximado para tomarmos uma decisão. Discutimos a importância de trabalhar com estimativas em diversos 
contextos e apresentamos a nossa proposta de atividades e, assim podemos observar a concepção dos professores.

Durante a oficina os participantes nos deram valiosas contribuições e assim realizamos algumas adaptações para a aplicação do experimento de ensino aos estudantes de uma escola da rede estadual de ensino

\subsection{Planejamento}

A sequência de atividades teve como objetivo principal discutir alguns aspectos relacionados com o conceito de área e a importância das estimativas e aproximações na medição dessa grandeza.

As atividades e tarefas foram elaboradas procurando atender os seguintes objetivos:

- abordar o significado de estimativa;

- ampliar a visão da matemática, valorizando os conceitos de estimativa e aproximação;

- enfatizar a importância das referências para realizar estimativas;

- abordar a linguagem da estimativa;

- utilizar estimativa em operações com frações;

- propor atividades que exemplificam o uso da estimativa na resolução de problemas;

- explicitar o processo de decomposição e composição de figuras utilizando malhas;

- utilizar unidades de medidas variadas para determinar a medida de área de uma superfície plana;

- introduzir o cálculo da medida de área por meio de estimativas e aproximações.

Procuramos também discutir com os participantes questões relacionadas ao ensino do tema, bem como obter impressões sobre as atividades propostas. 
Seguimos o seguinte roteiro:

$1^{\mathrm{o}}$ dia - discussão e atividades sobre estimativa em geral e em medida: Atividades 1, 2 da seção 4.3 .

Exibição do vídeo "Matemática na Escola" da série "Matemática em toda parte", neste episódio o professor Antonio José Lopes (Bigode) mostra como as estimativas podem estar presentes nas aulas de Matemática e como ela pode ser usada para avaliar ou tomar uma decisão.

$2^{\circ}$ dia - discussão e atividades sobre o conceito de área, medida de área e estimativa em medida de área: Atividades 3,4 da seção 4.3.

$3^{0}$ dia - discussão sobre ensino e aprendizagem; análise das atividades; contribuições dos participantes: Atividade 5 da seção 4.3.

Proposta de atividades para sala de aula; exibição do vídeo "Estimativas Curiosas" da série "Isto é Matemática" neste episódio o matemático português Rogério Martins fala do número de pessoas em manifestações, quantidade de estrelas do universo, total de grãos de areia presente nas praias, etc.

\subsection{Desenvolvimento e análises}

A seguir apresentamos as atividades que foram propostas e as respectivas observações e análises.

\subsection{1 -Atividade 1}

A Atividade 1 é composta de 6 tarefas com os seguintes objetivos gerais: abordar o significado da estimativa; ampliar a visão da matemática, valorizando os conceitos de estimativa e aproximação; enfatizar a importância das referências para realizar estimativas; abordar a linguagem da estimativa; discutir a relevância de estimular e desenvolver a capacidade de estimar vários tipos de medidas em diversos contextos. 
TAREFA 1.1 Em quais das seguintes situações se utilizam dados exatos e em quais se empregam dados estimados? Explique sua resposta.

a) Preço de um automóvel.

b) Tempo de duração de uma lâmpada.

c) Números de desempregados no Brasil.

d) Preço de 5 barras de chocolate.

Esse exercício objetiva a identificação de dados exatos e estimados e, contribui para a ampliação da visão da matemática.

Se, no ensino da matemática, ignorarmos a estimativa, privilegiando apenas procedimentos que conduzam a respostas exatas e únicas, deixamos de enfatizar uma parte da matemática e impedimos os alunos de ganharem experiência e confiança para desenvolver essa habilidade.

\section{Observações e resultados da Tarefa 1.1}

Os itens a) e d) são exatos e os demais são estimados. No item "a", apenas um dos participantes afirmou que o preço de um automóvel é estimado, justificando que o veículo é vendido em diferentes lugares com preços variados conforme o local de venda, por outro lado, a maioria respondeu tratar- se de um valor fixo e, portanto exato.

No item " $b$ " todos disseram se tratar de um valor estimado argumentando que o tempo de duração da lâmpada varia com o processo de fabricação e que depende também da instalação elétrica e do número de vezes que é acesa. Um dos participantes mencionou que o tempo de duração é calculado seguindo um modelo probabilístico sendo, portanto uma estimativa.

No item "c" todos disseram se tratar de um número estimado justificando que seria inviável ouvir todos os brasileiros para que declarassem se estão ou não desempregados.

No item "d" dois participantes disseram se tratar de um dado estimado justificando que na compra de mais de uma unidade pode haver um desconto. Os outros participantes disseram se tratar de um valor exato, pois o valor da unidade sendo fixo temos que o preço de 5 barras será multiplicado pelo preço de cada unidade. 
TAREFA 1.2 Realize as seguintes tarefas:

1. Dê uma estimativa da altura do seu colega sentado ao lado.

2. Qual deve ser a temperatura no interior da sala? E fora da sala?

3. Dê um valor aproximado para:

a) O comprimento do seu palmo.

b) A altura da porta da sala.

c) A altura de uma cesta de basquete.

d) O número de pessoas que cabem em $1 \mathrm{~m}^{2}$.

Esse exercício objetiva a realização de algumas estimativas usando a percepção e algum valor de referência conhecido.

Uma das habilidades necessárias para realizar estimativas de medida é o conhecimento de referências. Trata-se, neste caso, de conhecer a medida de grandezas que estão muito próximas, como ocorre com o comprimento de algumas partes do nosso corpo (palmo, pé, dedo) ou de objetos frequentes em nosso cotidiano (altura usual de uma porta ou altura do teto de uma casa). A busca de referências é praticamente ilimitada, ainda mais em nossa sociedade que tem a maior parte dos objetos normalizados.

\section{Observações e resultados da Tarefa 1.2}

Nesta atividade a metade do grupo deu estimativas bem distantes do "valor real" para o comprimento do palmo da mão. Alguns participantes estimaram um valor em torno de 12 $\mathrm{cm}$ e verificaram com uma régua que o valor na verdade estava próximo de $20 \mathrm{~cm}$, evidenciando que não estão familiarizados com algumas medidas do corpo que podem ser usadas para realizar estimativas razoáveis.

Em relação às perguntas que envolveram a grandeza altura os participantes deram estimativas razoáveis, pois a própria altura de cada um deles foi usada como referência. A altura da porta da sala era de $2,10 \mathrm{~m}$ e as estimativas estiveram entre $1,90 \mathrm{~m}-2,00 \mathrm{~m}$; a altura oficial de uma cesta de basquete é de $3,05 \mathrm{~m}$ e as estimativas estiveram entre $2,50 \mathrm{~m}-3,00 \mathrm{~m}$. No item 2 verificamos que a temperatura no interior da sala era de aproximadamente $18,5^{\circ} \mathrm{C}$ e no exterior cerca de $26^{\circ} \mathrm{C}$; a resposta para essa questão dependia da sensibilidade e da 
experiência de cada participante e os valores variaram entre $18^{0} \mathrm{C}-23^{\circ} \mathrm{C}$ (interior) e entre $23^{0} \mathrm{C}-28{ }^{0} \mathrm{C}$ (exterior).

Para o item 3 d) dois participantes responderam que em $1 \mathrm{~m}^{2}$ cabem no máximo 2 pessoas. Essa noção do tamanho do metro quadrado e da quantidade de pessoas que cabem nessa região é importante para fazermos, por exemplo, uma estimativa do número de pessoas numa manifestação.

Nesta atividade destacamos 1 metro quadrado no piso da sala e verificamos a quantidade de pessoas que podem caber no espaço.

Discutimos a relevância deste tipo de atividade em sala de aula. E notamos que os participantes perceberam o quanto tal habilidade não é estimulada.

TAREFA 1.3 Que estratégias e recursos foram utilizados para obter os valores da Tarefa 1.2? Quais termos ou palavras foram utilizados?

O objetivo foi discutir algumas estratégias usadas na hora de estimar uma medida e, também discutir a linguagem da estimativa.

Palavras e frases tais como cerca de, perto de, quase, um pouco mais (ou menos) que, e entre isso e aquilo, fazem parte da linguagem de estimativa. Os professores e estudantes devem compreender que estão tentando chegar o mais perto possível usando métodos rápidos e fáceis, mas não existe estimativa correta. A linguagem pode ajudar a elaborar essa ideia.

\section{Observações e resultados da Tarefa 1.3}

As respostas dos participantes mostraram que eles se apropriaram das principais ideias que envolvem uma estimativa de medida: experiência ou conhecimento prévio, comparação, percepção, interiorização de unidades de medida. Com o objetivo de legitimar as estimativas e mostrar a sua utilidade os professores podem, por exemplo, introduzir a estimativa com atividades onde a estimativa é a melhor solução, ou ainda, enfatizar aquelas situações nas quais apenas uma estimativa é necessária; aliado a esses dois itens está a linguagem da estimativa que juntamente com as outras atitudes valida o uso da estimativa. São frases tais como: sobre; aproximadamente; cerca de; mais ou menos; etc. 
TAREFA 1.4 Na sua opinião, o que significa estimar um valor? E qual o significado de obter uma aproximação? São conceitos diferentes?

Com esta tarefa discutimos os conceitos de estimativa e aproximação.

Obter um valor aproximado é encontrar um resultado suficientemente preciso para um determinado propósito. A aproximação enfatiza a proximidade com o valor exato e é totalmente controlável; aproxima-se tanto quanto a situação exige. A estimativa leva o erro em conta, mas com menos precisão. Ás vezes, este não tem controle garantido. A aproximação, por exemplo, não possui as seguintes características da estimativa: a valoração é feita geralmente mentalmente; o valor atribuído não é único dependendo de quem faz a avaliação.

\section{Observações e resultados da Tarefa 1.4}

Nesta tarefa interrogamos os participantes a respeito da definição dos conceitos de estimativa e aproximação. Em relação ao conceito de estimativa algumas das respostas foram: "Estimar é um valor médio de alguma coisa, e aproximação é mais próximo do real", "Estimar é dar um valor a algo que desconhecemos, mas sabemos de algo que se aproxima a este valor desconhecido", "Estimar um valor é supor um valor com algumas estratégias como comparar com algo que já conheço", "Para mim, estimamos quando analisamos uma amostra de certa população e concluímos coisas através da amostra e generalizamos para a população", “Estimar é usar experiência própria, dados, etc.".

Os participantes, em sua maioria, definiram a estimativa como "atribuir um valor" sem mencionar as referências e a percepção; um dos participantes utilizou o termo "estimativo" no contexto particular da Estatística. Podemos inferir que os participantes possuem ideias incompletas do processo de estimativa de medida.

Em relação ao conceito de aproximação algumas das respostas foram: “A aproximação é um valor próximo do real utilizando estratégias (estimativas)”, "A aproximação é o quanto "rigoroso" ou precisão você quer numa medida", "Aproximar é obter um valor próximo ao desejado".

Nenhum dos participantes deixou claro que em uma aproximação temos ferramentas para controlar o erro, já no processo de estimar o erro é mais grosseiro. 
TAREFA 1.5 Das manchetes de jornais que aparecem abaixo, quais dados são exatos e quais são aproximados? Explique suas respostas.

a) A inflação diminuiu 0.2 pontos em novembro.

b) O prazo final para entrega da declaração de renda termina este ano em 28 de Abril.

c) Este ano foram apresentadas a Fazenda 6 milhões de declarações.

d) Mais de $15 \%$ das pessoas compram queijo uma vez por semana.

e) Sydney é 14 vezes mais distante de Londres do que de Veneza.

f) Em 1964, um terremoto em Prince Willian Sound, no Alasca, mediu 8,5 na escala Richter e durou 7 minutos.

Nesta atividade objetiva-se o reconhecimento de estimativas.

Nos meios de comunicação, por exemplo, para maior clareza e compreensão das informações são utilizadas estimativas no lugar de quantidades exatas. O ensino escolar deve abranger o duplo caráter da matemática, exato e aproximado, e deve proporcionar aos estudantes atividades que lhe permitam apreciar em que circunstâncias convêm utilizar uma ou outra. 


\section{Observações e resultados da Tarefa 1.5}

Com exceção dos itens a) e b), todas as sentenças são estimativas.

Houve alguma discordância em relação ao item "a" alguns disseram se tratar de um valor aproximado "como a inflação é um índice médio, este é aproximado". Outras pessoas acharam que a sentença "e" utiliza valor exato justificando "pois a distância de Sidney a Londres é um valor discreto se comparada com a distância de Sydney a Veneza".

Os participantes compreenderam que muitas vezes as informações divulgadas são feitas mediante dados estimados, pois é impossível determinar o valor exato. Esse tipo de atividade é importante para que o aluno ganhe confiança na hora de estimar e procure desenvolver tal habilidade.

TAREFA 1.6 Analise o uso do conceito de estimativa nas notícias a seguir, extraídas da internet. Quais os significados de estimativa que aparecem?

a) Chuva faz IBGE melhorar estimativa para nova safra.

b) Ainda não é possível estimar danos dos crimes de Cabral, diz MPF.

c) Estima-se que o país possua cerca de $12 \%$ da disponibilidade de água doce do planeta.

O objetivo desta atividade é discutir o uso do termo "estimativa" no cotidiano e o seu significado nas aulas de matemática.

A palavra "estimativa" tem um significado coloquial amplo, cuja descrição geral pode ser encontrada em qualquer dicionário. Assim, o Dicionário Aurélio Buarque diz:

"Estimativa: avaliação; cômputo".

"Estimar: apreciar. Avaliar o preço, o valor de. Ter em estima. Prezar-se".

A ideia de valoração está presente em todas estas definições, como juízo emitido por alguém, e esse juízo sempre tem um caráter afirmativo. Este sentido de valoração também está presente com o uso do termo "inestimável" para indicar algo que não se pode estimar ou avaliar, por ter um valor altíssimo. 
Dos múltiplos usos do termo "estimativa", e dos mais diferentes campos onde podem ser aplicados, nos limitamos a considerar aqueles casos nos quais o juízo ou valoração é quantitativo e, portanto, o campo no qual se aplica tem de ser necessariamente uma grandeza.

\section{Observações e resultados da Tarefa 1.6}

A palavra estimativa é usada na vida cotidiana com múltiplos sentidos, em expressões como: estimativa do PIB; os jornais estimaram em mil o número de mortos etc. Alguns desses usos ajudam a dar sentido a estimativa na matemática escolar, outros podem gerar obstáculos ao aprendizado. Nesta atividade observamos que alguns participantes apresentaram certa dificuldade na hora de interpretar a palavra estimativa em um determinado contexto. É importante deixar claro para os estudantes o significado que a palavra vai assumir nas aulas de Matemática.

No item "a" todos os participantes responderam que o significado do termo é de uma expectativa positiva para a safra devido ao aumento do volume de chuva, um dos participantes escreveu "como o período de chuvas foi bom, isso faz com que o IBGE forneça uma boa estimativa (previsão)".

Para o item "b" algumas das respostas foram: "Não é possível "calcular" os danos, saber quão grave foram os danos", "Não conseguem fechar o valor final dos desvios de dinheiro feitos pelo ex-governador Cabral", "Estimativa de falta de informações (negativas) para definir os danos; faltou avaliação". Nessa sentença o sentido é de avaliação embora não possua o caráter quantitativo.

Em relação ao item "c" algumas das respostas foram: "Valor aproximado de água doce"," Estimativa de valor incerto sobre a água doce, valor aproximado", “Aproximação, “cerca de $12 \%$ " revela ser uma estimativa. Nesse caso foi realizado um cálculo e chegou- se a esse percentual, mas o valor apresentado é um valor aproximado. 


\subsection{2-Atividade 2}

Essa atividade é composta de 5 tarefas com os seguintes objetivos gerais: enfatizar que a estimativa de medida da grandeza depende do tipo de estratégia utilizada; propor atividades que exemplificam o uso da estimativa na resolução de problemas; estratégias para estimar algumas frações e soma de frações comparando o numerador e o denominador; discutir estratégias para o cálculo estimado; medição e estimativa de medida de área.

TAREFA 2.1 Analise as afirmações abaixo, extraídos da internet. Os valores apresentados nas afirmações são exatos ou estimados?

a) O território brasileiro está localizado na América do Sul, apresenta extensão territorial de $8.514 .876 \mathrm{Km}^{2}$ e é o quinto maior país do planeta.

b) O território nacional tem cerca de 8,5 milhões de quilômetros quadrados.

c) Para a superfície do Brasil foi obtido o valor de $8.515 .759,090 \mathrm{~km}^{2}$, publicado no DOU no 124 de 30/06/2017, conforme Resolução No 02, de 29 de junho de 2017.

d). ...De acordo com a portaria, o Brasil tem 8.515.767,049 quilômetros quadrados.

Com esta tarefa procurou-se discutir que as estimativas produzem resultados diferentes de acordo com a estratégia utilizada.

Para qualquer estimativa, geralmente, existem vários métodos muito bons e diferentes. Os participantes aprenderam estratégias uns com os outros. A discussão das diferentes estratégias também ajudou na compreensão que não existe estimativa "certa". Estratégias diferentes produzem estimativas diferentes.

\section{Observações e resultados da Tarefa 2.1}

Apenas um entre os seis participantes afirmou que todas as sentenças envolviam dados estimados, evidenciando assim uma dificuldade de reconhecer e aceitar que para uma mesma grandeza existe uma variedade de estimativas que depende da estratégia e do método utilizado. Cinco participantes disseram que o item "b" era estimado enquanto que os itens "c" e "d" são exatos. Observamos ainda que o item "b" exemplifica normalmente como a mídia veicula algumas informações facilitando a compreensão e o entendimento de alguns valores. 
TAREFA 2.2 Justifique as suas respostas das questões a seguir

a) A altura de um menino de dez anos é de 1,5 metros. Que altura você acredita que terá quando sua idade for de vinte anos?

b) Escolha a resposta mais adequada a seguinte questão: Um computador custa $\mathrm{R} \$ 2480,00$. Se diminuirmos seu valor em $5 \%$, quanto custará, aproximadamente?
(i) $\mathrm{R} \$ 960,00$
(ii) $\mathrm{R} \$ 2475,00$
(iii) $\mathrm{R} \$ 2360,00$
(iv) $\mathrm{R} \$ 9600,00$

O propósito desta atividade é apresentar problemas cuja resolução envolve estimativas e assim discutir que na escola é costume propor aos alunos problemas aritméticos, cuja solução é obtida por aplicação de uma ou várias operações aritméticas e com solução única. $\mathrm{O}$ objetivo desta atividade foi utilizar problemas não convencionais para alertar aos participantes sobre o uso indiscriminado de algoritmos padronizados e fazê-los enxergar que há outras estratégias alternativas.

A razoabilidade da solução obtida é uma maneira de controlar se utilizamos uma estratégia adequada, e isso pode ser alcançado por uma estimativa.

\section{Observações e resultados da Tarefa 2.2}

O ensino de estratégias de estimativas reforça e estimula processos corretos de resolução de problemas. Reys (1985, apud Segovia, 1989) afirma que a estimativa e o pensamento matemático estão bastante relacionados, enfatiza que o trabalho com estimativa fornece um contex to natural, não apenas para desenvolver, mas também para praticar algumas técnicas importantes do pensamento matemático como: ler um problema e decidir que tipo de resposta é adequada; selecionar uma estratégia apropriada; reconhecer que existe mais de um caminho a ser seguido; verificar a razoabilidade dos resultados.

Para o item "a" os participantes utilizaram seu conhecimento prévio e assim a estimativa para altura ficou no intervalo $1,70 \mathrm{~m}-1,90 \mathrm{~m}$. Todos notaram que não podemos usar a proporcionalidade, pois as grandezas idade e altura não são proporcionais. Um dos participantes detalhou seu raciocínio "Eu com 10 anos devia medir entre 1,40 m - 1,55m e hoje tenho aproximadamente $1,76 \mathrm{~m}$ e 20 anos. Logo vou estimar que aos 20 anos ele terá por volta de $1,68 \mathrm{~m}-1,75 \mathrm{~m}$ ".

Para o item "b" a maioria descartou as alternativas (i) e (iv) então calcularam 5\% ou $10 \%$ de 2480 e assim chegaram a alternativa mais adequada. 
TAREFA 2.3 Estime a soma das seguintes frações:

$$
\begin{gathered}
\text { (i) } \frac{12}{13}+\frac{4}{9} . \\
\text { (ii) } \frac{7}{8}+\frac{5}{6} . \\
\text { (iii) } \frac{9}{10}+\frac{11}{12}+\frac{1}{50} \text {. }
\end{gathered}
$$

Que estratégias podem ser utilizadas para responder a pergunta? Que habilidades são necessárias para responder a questão?

Propõe-se com esta tarefa estimar a fração e a soma de frações, sem efetivamente fazer os cálculos. Reconhecer frações que são próximas de 1, 1/2 ou 0 é importante para estimar a soma de frações e números mistos. Também incentiva os participantes a pensar sobre a quantidade representada pela fração. A ideia é fácil de aprender e contribui para a compreensão das frações.

\section{Observações e resultados da Tarefa 2.3}

Apenas dois participantes tentaram utilizar o algoritmo tradicional para a soma de frações, os demais participantes fizeram uma estimativa comparando o numerador e o denominador das frações.

Uma das pessoas do grupo descreveu a sua estratégia da seguinte maneira: "Eu observei o numerador e o divisor e vi o quanto distantes são os valores 12 e $13=12+1$ e quando o numerador era bem próximo do divisor eu assumi que o valor da divisão estaria bem próximo de 1.Já no caso de 4/9 eu notei que metade de 9 é 4,5 e como o 4 é bem próximo a 4,5 então eu adotei que 4/9 é próximo de 1/2. E no caso de $1 / 50$ eu adotei o valor de 0 , pois 50 é muito superior a 1 então seu valor não será superior a 0,1 . 
TAREFA 2.4 Uma lanchonete oferecia o seguinte cardápio e preços.

\begin{tabular}{|l|l|}
\hline Menu & Preço em R\$ \\
\hline Cheeseburger & 1,85 \\
\hline Batata frita & 1,00 \\
\hline Batata chips & 0,65 \\
\hline Pizza (fatia) & 2,25 \\
\hline Minipizza & 8,00 \\
\hline Milk-shake & 1,75 \\
\hline Sorvete (uma bola) & 1,25 \\
\hline Refrigerante & 1,20 \\
\hline
\end{tabular}

a) Andreia tinha $\mathrm{R}$ \$,00 para gastar numa refeição rápida. Será que ela pode comprar um milk shake, batatas fritas e um cheeseburger?

b) Pedro tinha $\mathrm{R} \$ 6,00$ e quer uma fatia de pizza, batatas fritas, um sorvete e um refrigerante. Será que ele pode pagar?

Como foram feitos os cálculos?

O objetivo desta atividade é discutir estratégias para o cálculo estimado. Às vezes é útil obter uma resposta grosseira ou aproximada para um problema. Ela pode ser uma primeira tentativa de verificação da resposta que você tentou calcular corretamente.

\section{Observações e resultados da Tarefa 2.4}

Todos fizeram estimativas rápidas arredondando os valores ou somando a parte inteira e depois os centavos. Em algumas ocasiões não necessitamos de um valor exato basta uma estimativa, esta pode ser obtida de forma rápida fazendo cálculos com números mais "fáceis" de operar. Um dos participantes explicou seu procedimento "Andreia pode comprar sua refeição, os cálculos foram feitos analisando os itens escolhidos e somando-os, dois valores menores que R\$2,00 e um valor igual a R\$1,00 assim R\$ 5,00 será suficiente”. 
Podemos perceber que Andreia não precisa calcular corretamente a conta. Os preços inferiores a 50 centavos podem ser arredondados para baixo e os superiores ou iguais, arredondados para cima. Basta somar tudo rapidamente e estimar o custo total. No caso de Pedro pode-se somar a parte inteira e depois os centavos.

\section{TAREFA 2.5 Estimar e medir}

a) Observe o tampo da mesa do professor e dê um valor aproximado da sua área.

b) Escolha um dos materiais disponíveis na mesa do professor para medir a área do tampo. Qual você achou mais conveniente? Qual a unidade de medida mais apropriada?

c) Com o material escolhido obtenha uma medida da área do tampo.

d) Compare os valores obtidos.

Essa atividade tem como objetivo estimar e, posteriormente, medir a área da superfície da mesa, também propõe a comparação da estimativa com a medição realizada.

A ideia é usar a informação visual e a noção do tamanho que os participantes têm das unidades para, inicialmente, fazer uma estimativa da medida da área de uma mesa. Logo, em seguida, medir e comparar os valores.

\section{Observações e resultados da Tarefa 2.5}

Para metade dos participantes a diferença entre os valores estimados e obtidos foi razoavelmente grande. A maioria dos estudantes ou professores não está habituado a este tipo de atividade prática que exige também a percepção e a noção do tamanho das unidades.

A maioria escolheu a régua de um metro para medir as dimensões e calcular área através da multiplicação desses valores medidos.

Alguns participantes registraram suas conclusões "O valor estimado foi muito diferente do medido", "Quase $1 \mathrm{~m}^{2}$ de diferença; quase outra mesa". 


\subsubsection{Atividade 3 (estimativa de populações )}

O objetivo dessa atividade é discutir métodos que permite estimar o tamanho de uma determinada população. Com essa atividade mostramos o significado da expressão "fazer estimativa" no âmbito da Estatística, ou seja, estimar nesse contexto é fazer uma inferência quantitativa com base na coleta de dados e no tratamento com métodos estatísticoprobabilísticos desses dados.

TAREFA 3.1 Quantas pessoas participaram de uma manifestação (Ver figura 8)?

Figura8- Pessoas em manifestação

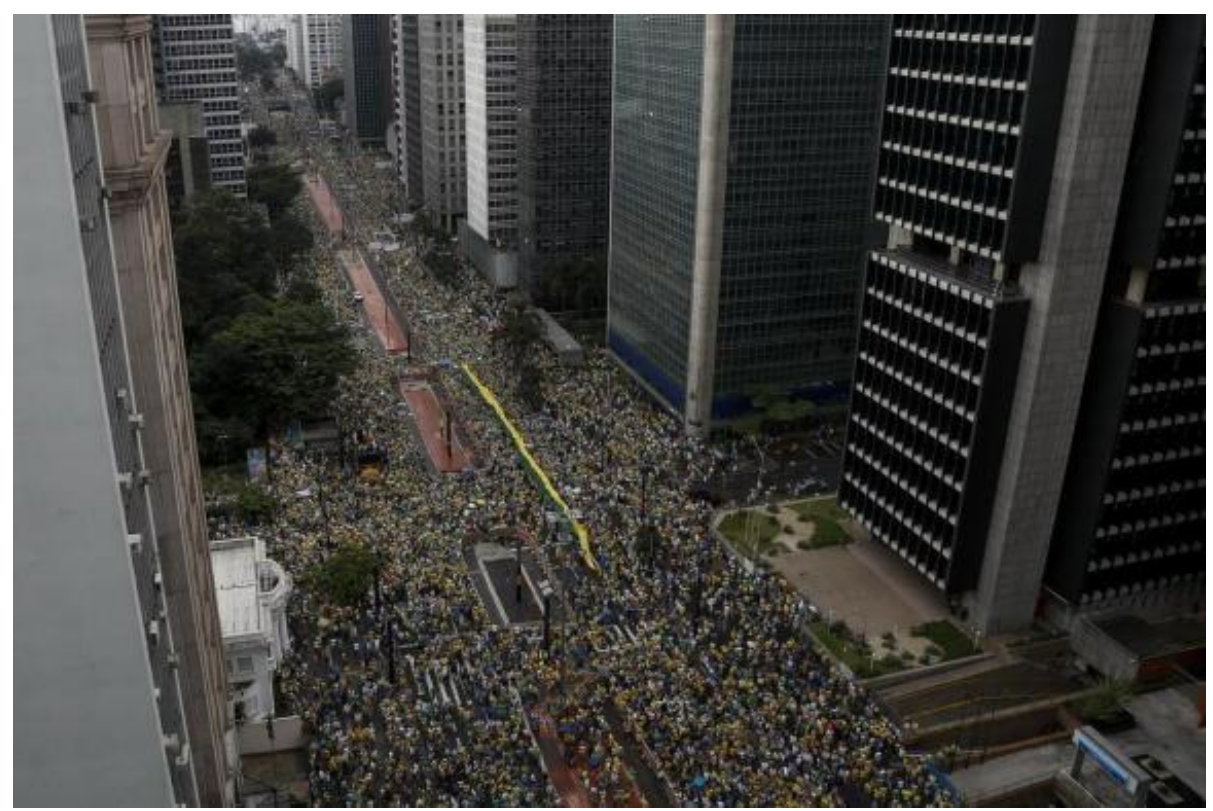

Fonte: Estadão

Atribui-se a Herbert Jacobs, professor de jornalismo da Universidade da Califórnia nos anos 1960, a modernização da estimativa de pessoas em multidões, utilizada até hoje como base para esses cálculos. À época, ele criou uma regra básica de densidade, que vai de uma multidão "pouco densa" a uma multidão "muito densa" - como em um ônibus lotado.

Pesquise sobre formas de avaliar número de pessoas em multidões. 
TAREFA 3.2 Quantos peixes há no lago?

(Adaptado de "Estatística para Todos" CAEM - IME - USP)

Em Estatística há alguns procedimentos que permitem estimar o tamanho de populações. Por exemplo: quantos peixes há na Lagoa Rodrigo de Freitas, no Rio de Janeiro? Já no século XVIII Laplace procurou desenvolver metodologia para estimar o tamanho de populações. A literatura aponta o dinamarquês Carl Petersen como o primeiro pesquisador que no final do século XIX, querendo estimar o número de peixes do Mar Báltico, desenvolveu o método que iremos analisar nesta atividade.

\section{Descrição e resultado da atividade}

Foi apresentada ao grupo uma população de tamanho 60 de "peixes" (em bolinhas de isopor) para que a quantidade seja estimada. Esta população estava confinada num pacote, discutimos que este não é o caso normal - geralmente a população está dispersa. Solicitamos que cada participante escrevesse em um pedaço de papel a sua estimativa para o número de "peixes" apresentados - uma estimativa feita de longe; recolhemos as estimativas para depois verificar quem chegou mais perto do verdadeiro valor.

Em seguida realizamos uma estimativa baseada em coleta de dados, esta atividade permite discutir conceitos como variabilidade, população, amostra, aleatoriedade, tamanho da amostra etc. $\mathrm{O}$ procedimento foi o seguinte: pedimos para que cada participante retirasse duas peças do pacote; então temos uma amostra de 12 elementos da população cujo tamanho $\mathrm{N}$ queremos estimar; pedimos que cada participante fizesse uma marca em cada uma delas, em seguida devolvemos todas as peças marcadas para o pacote e fizemos uma nova coleta de modo aleatório. Novamente pedimos para que cada participante retirasse duas peças do pacote- isto significa que temos uma nova amostra, ou seja, temos 12 elementos retirados, cinco marcados e os outro sete não marcados. Registramos no quadro a razão entre o número de marcados e o número de elementos retirados; esta razão é a frequência relativa amostral de marcados, no caso 5/12. Perguntamos se alguém poderia sugerir qual a frequência relativa populacional de marcados até que um participante se pronunciou dizendo que seria o número de marcados (no caso 5) sobre o tamanho desconhecido da população N, isto é, 12/N. Uma ideia sugerida por um dos participantes foi igualar os dois quocientes $(5 / 12=12 / \mathrm{N})$ obtendo assim uma primeira estimativa baseada no tamanho da amostra. Nesse caso, $\mathrm{N}$ foi de aproximadamente 29 . 
$\mathrm{Na}$ nossa atividade a população $\mathrm{N}$ era de tamanho 60; enfatizamos que seria interessante repetir o procedimento com uma amostra maior diminuindo o erro, o que faz com que a estimativa seja melhor.

\subsubsection{Atividade 4}

O objetivo da atividade é que os participantes adquiram a noção de área de uma superfície plana através do ladrilhamento (contagem de unidades) e que identifiquem a necessidade da utilização de uma unidade de medida para comunicar seus resultados; com a utilização do método de composição e decomposição de figuras buscamos ressaltar os aspectos envolvidos na construção do conceito de área. É composta por 3 tarefas.

TAREFA 4.1 Encontre a medida da área da superfície plana da figura abaixo. Utilize como unidade de medida o quadradinho da malha. Explique o procedimento adotado.

Essa atividade tem como objetivo desenvolver a ideia de que a área é medida por cobertura, ou seja, sobreposição. Embora quadrados sejam as unidades mais comumente usadas, qualquer forma que convenientemente preencha uma superfície plana pode ser usada. 


\section{Observações e resultados da Tarefa 4.1}

Todos os participantes conseguiram encontrar a medida de área da figura dada utilizando estratégias de composição e decomposição. Um dos participantes justificou sua resposta do seguinte modo: "Tem 16 quadradinhos que valem "u" cada. Tem 8 figuras (triângulos) que valem $1 / 2$ cada.Portanto $16 u+8 / 2 u=20 u "$ "

Com este procedimento os alunos percebem que área é um modo conveniente para expressar o tamanho de uma região, e que não se requer necessariamente o uso de fórmulas para achá-la, é suficiente cobrir a figura com a unidade de medida dada e contar o número de vezes que cabe nesta.

TAREFA 4.2 Justifique as respostas das questões abaixo.

a) Qual a medida da área da figura $\mathrm{S}$ usando como unidade de medida $\mathrm{U}$ ?

b) A unidade de medida $U$ representa que parte da figura $S$ ?

U
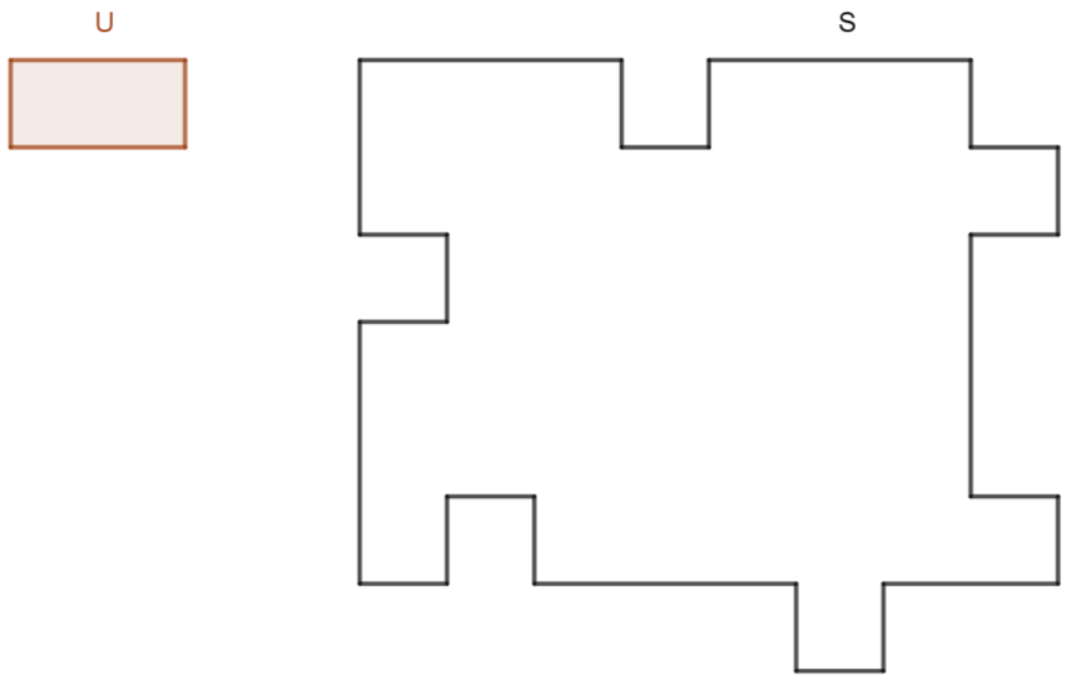

A tarefa pretende mobilizar os conceitos de: área, unidade de medida, medição, estimativa, grandeza e conservação de área, os procedimentos que podem ser utilizados são:

1. Desenhar a unidade de medida dada na figura, repetindo este procedimento até cobrir toda a superfície. 
2. Recortar e sobrepor à unidade de medida na figura.

3. Quadricular a superfície plana e a unidade de medida, resultando uma unidade alternativa para realização da medição.

4. Calcular a medida racional como resultado dos processos de medição.

Esta situação exige que os participantes concebam a área como o tamanho das superfícies, além disso, é um método conveniente que permite determinar o número de unidades exigidas para expressar a medida de uma superfície plana.

\section{Observações e resultados da Tarefa 4.2}

Em geral os participantes utilizaram os seguintes procedimentos: quadricularam tanto a figura quanto a unidade de medida dada, estabelecendo o número de vezes que a unidade cabe na figura; desenharam a unidade de medida, estabelecendo o número de vezes que cabe na figura, com esse método os participantes compreendem que uma figura é composta e pode se decompor em outras, conseguindo comprovar que área é um meio conveniente para expressar o número de unidades requeridas para cobrir uma superfície plana. 
TAREFA 4.3 O TANGRAM

Tangram é um quebra-cabeça chinês de origem milenar. Foi trazido para o ocidente por volta da metade do século XIX. Pouco se sabe da sua origem ou quem inventou.

Com as peças podemos formar várias figuras, utilizando todas elas sem sobrepô-las.

Segundo a Enciclopédia do Tangram é possível montar mais de 5000 figuras.

a) Identifique as seguintes peças do Tangram

$\operatorname{Tg}=$ triângulo grande

Tm = triângulo médio

$\mathrm{Tp}=$ triângulo pequeno

$\mathrm{Q}=$ quadrado

$\mathrm{P}=$ paralelogramo

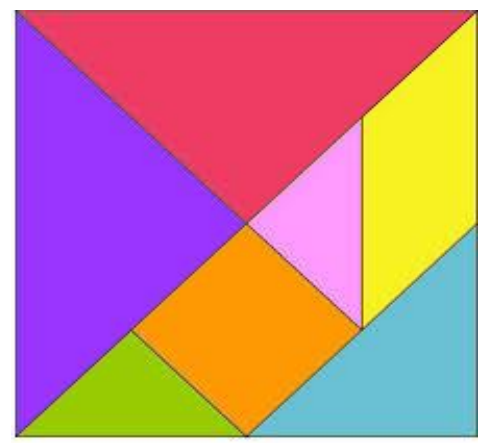


b) Recubra cada peça com o triângulo pequeno (Tp) e complete a tabela. Sendo Tp a unidade de medida da área de cada figura?

$\begin{array}{ll}\text { Peça } & \begin{array}{c}\text { Quantidade } \\ \text { de Tp para cobrir a } \\ \text { peça }\end{array} \\ \text { Q } & \\ \text { P } & \\ \mathrm{Tm} & \\ \mathrm{Tg} & \end{array}$

c) Agora compare as peças do Tangram com o quadrado e complete a tabela. Sendo Q a unidade de medida da área de cada figura?

$\begin{array}{ll}\text { Peça } & \begin{array}{c}\text { Quantidade } \\ \text { de Q para cobrir a } \\ \text { peça }\end{array} \\ \text { P } & \\ \mathrm{Tm} & \\ \mathrm{Tg} & \end{array}$

d) Sendo Tp a unidade de medida, qual a medida da área do quadrado do Tangram?

e) Com as peças do Tangram monte a figura da casa. Qual a medida da área da figura sendo Tp a unidade de medida?

f) Usando todas as peças do Tangram monte:

- Duas figuras de mesma área e perímetros diferentes.

- $\quad$ Duas figuras de mesmo perímetro e áreas diferentes

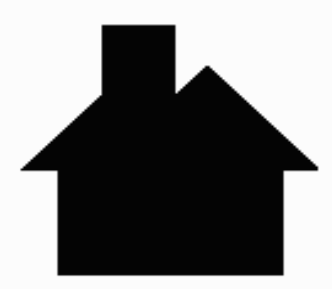


O Tangram é um recurso didático recomendável para trabalharmos alguns conceitos geométricos nas aulas de matemática. Com a utilização do material concreto é possível trabalhar a composição e decomposição de figuras possibilitando aos alunos uma melhor compreensão das fórmulas de cálculo de áreas de alguns polígonos.

\section{Observações e resultados da Tarefa 4.3}

Nos itens b e c os participantes obtiveram medidas de área das figuras utilizando unidades de medidas diferentes, pois um dos objetivos da atividade é dissociar área de número. Quando mudamos a unidade, a medida de área de uma determinada superfície plana é alterada daí a necessidade de indicar o par (número, unidade).

No item c utilizando Tp (triângulo pequeno) como unidade de medida encontraram a medida de área do quadrado do Tangram (16 Tp) e depois observaram que a figura da casa possui a mesma área já que é composta pelas mesmas partes sem sobreposição e sem perdas.

No item $\mathrm{f}$ dois participantes conseguiram montar figuras de mesma área e perímetros diferentes, os outros não utilizaram todas as peças; em relação ao outro item (figuras de mesmo perímetro e áreas diferentes) apenas um participante concluiu a atividade. 


\subsection{5- Atividade 5}

O objetivo da atividade proposta é estimular o uso de estimativas na resolução de problemas, e identificar quando é apropriado o uso da estimativa ou do cálculo. É composta de 3 tarefas. Uma das estratégias de estimativa que foi trabalhada é a técnica de comparação, baseada no uso de unidades de referência, isto é, conhecer e interiorizar a medida de objetos próximos e conhecidos e associá-los com aqueles que se deseja medir.

TAREFA 5.1 Dê um valor aproximado da medida da área da superfície do quadrilátero abaixo utilizando o quadrado da malha como unidade de medida.

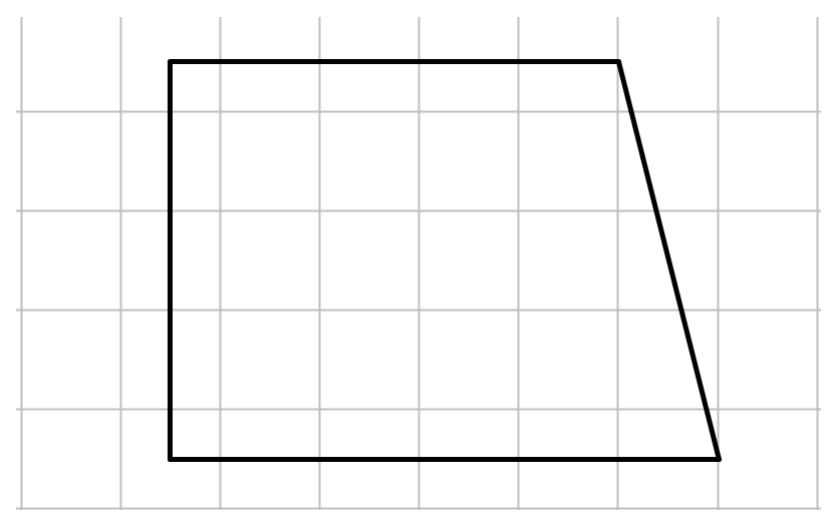

\section{Observações e resultados da Tarefa 5.1}

Alguns participantes conseguiram encontrar a área da figura através de uma translação vertical, outra solução apresentada foi usando a composição e decomposição e um dos participantes deu um valor aproximado sem, no entanto explicitar o seu procedimento.

Para calcular o valor aproximado da área de uma região desenhada numa malha quadriculada podemos adotar o seguinte processo:

1. Conta-se o número de unidades da malha totalmente contidas na região.

2. Conta-se o menor número de unidades de malha que envolve totalmente a região.

3. Calcula-se a média aritmética entre as duas quantidades de unidades de malha contadas nos processos 1 e 2 . 
Esse último método, embora relativamente simples não foi utilizado por nenhum dos participantes.

TAREFA 5.2 Com a "planta" da casa que está na folha em anexo (Ver figura 9), respondas as seguintes perguntas.

1. Sem usar instrumentos de medida, responda as questões a seguir, justificando os procedimentos

a) Levando em conta que uma cama de solteiro tem $2 \mathrm{~m}$ de comprimento e $1 \mathrm{~m}$ de largura. Faça uma estimativa da medida da área do quarto 1.

b) Observe o quarto principal, há uma cama de casal. Quanto você acha que é a medida da área da cama? E do quarto?

c) Levando em conta a medida do quarto 1 . Qual é a medida da área do banheiro?

d) Quais os procedimentos e estratégias envolvidos?

2. Agora usando algum instrumento de medida, responda as mesmas questões.

e) Levando em conta que uma cama de solteiro tem $2 \mathrm{~m}$ de comprimento e $1 \mathrm{~m}$ de largura. Faça uma estimativa da medida da área do quarto 1.

f) Observe o quarto principal, há uma cama de casal. Quanto você acha que é a medida da área da cama? E do quarto?

g) Levando em conta a medida do quarto 1 . Qual é a medida da área do banheiro?

h) Quais os procedimentos e estratégias envolvidos? 


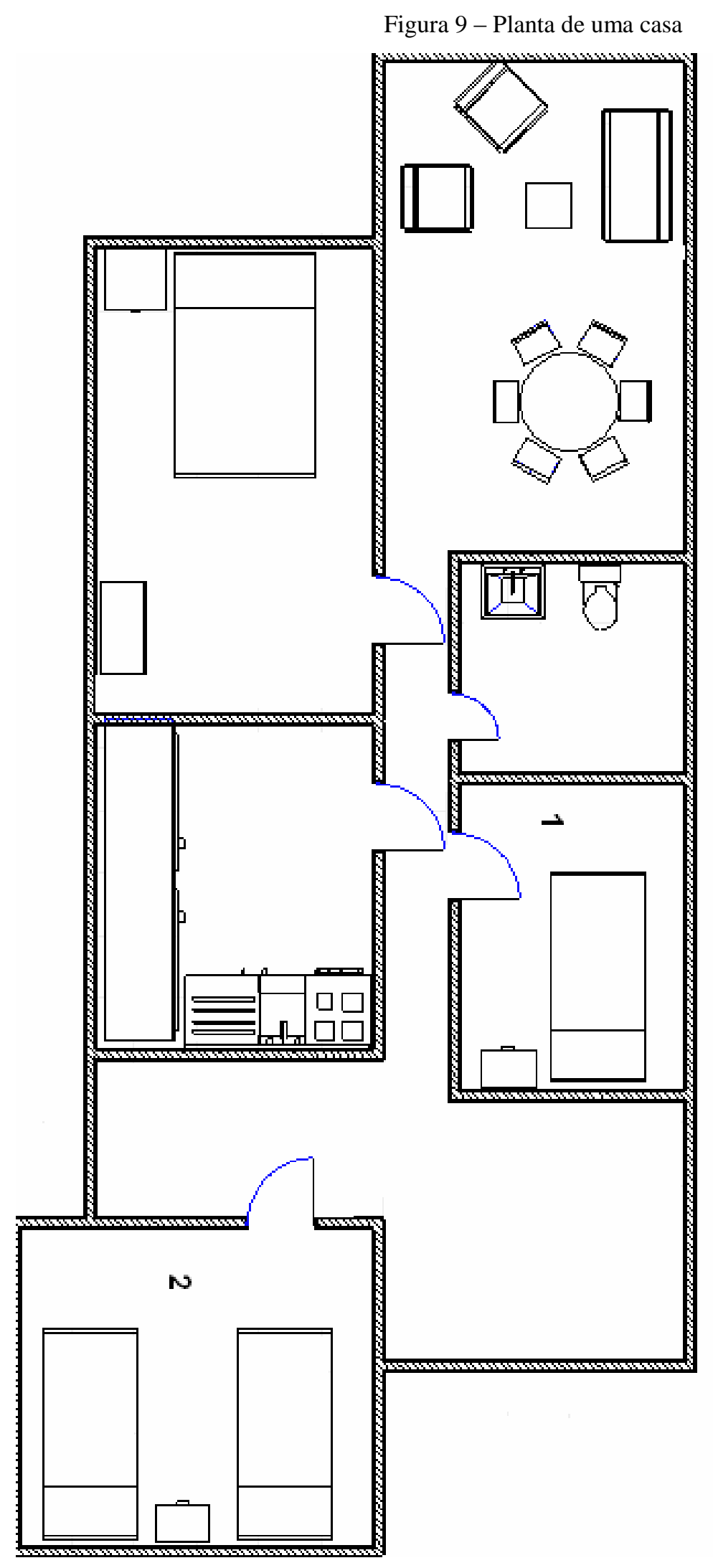

Fonte: ZAPATA, Fabio et.al, 2006 
A tarefa foi organizada em torno dos conceitos de estimativa, unidades padrão, unidades não padronizadas, unidade de medida, comparação.

Espera-se que os participantes escolham como referência a cama e encontrem a medida desta $\left(2 \mathrm{~m}^{2}\right)$ e com essa medida tentem estimar as outras medidas.

\section{Observações e resultados da Tarefa 5.2}

A maioria dos participantes escolheu a cama como unidade de medida e com isso realizaram estimativas da medida de área dos outros objetos. Em geral houve uma tendência em superestimar algumas medidas. Por exemplo, para a medida da área do quarto foi feito uma estimativa de $20 \mathrm{~m}^{2}$ e depois com ajuda de uma régua o valor encontrado foi cerca de $13 \mathrm{~m}^{2}$. Em outro exemplo a primeira estimativa foi de $9 \mathrm{~m}^{2}$ e depois medindo encontrou o valor de aproximadamente $5 \mathrm{~m}^{2}$.

Podemos notar como as pessoas em geral estão pouco familiarizadas com atividades que exigem o uso da estimativa, sobretudo em medida. Porém a tarefa permitiu que os participantes utilizassem uma referência conhecida para a solução do exercício. Suas estimativas em medida em algumas ocasiões são exageradamente grandes. 
TAREFA 5.3 Qual a medida da área da figura utilizando o quadradinho da malha como unidade de medida? Justifique sua resposta.

Como podemos aumentar a precisão desse método? Por quê?

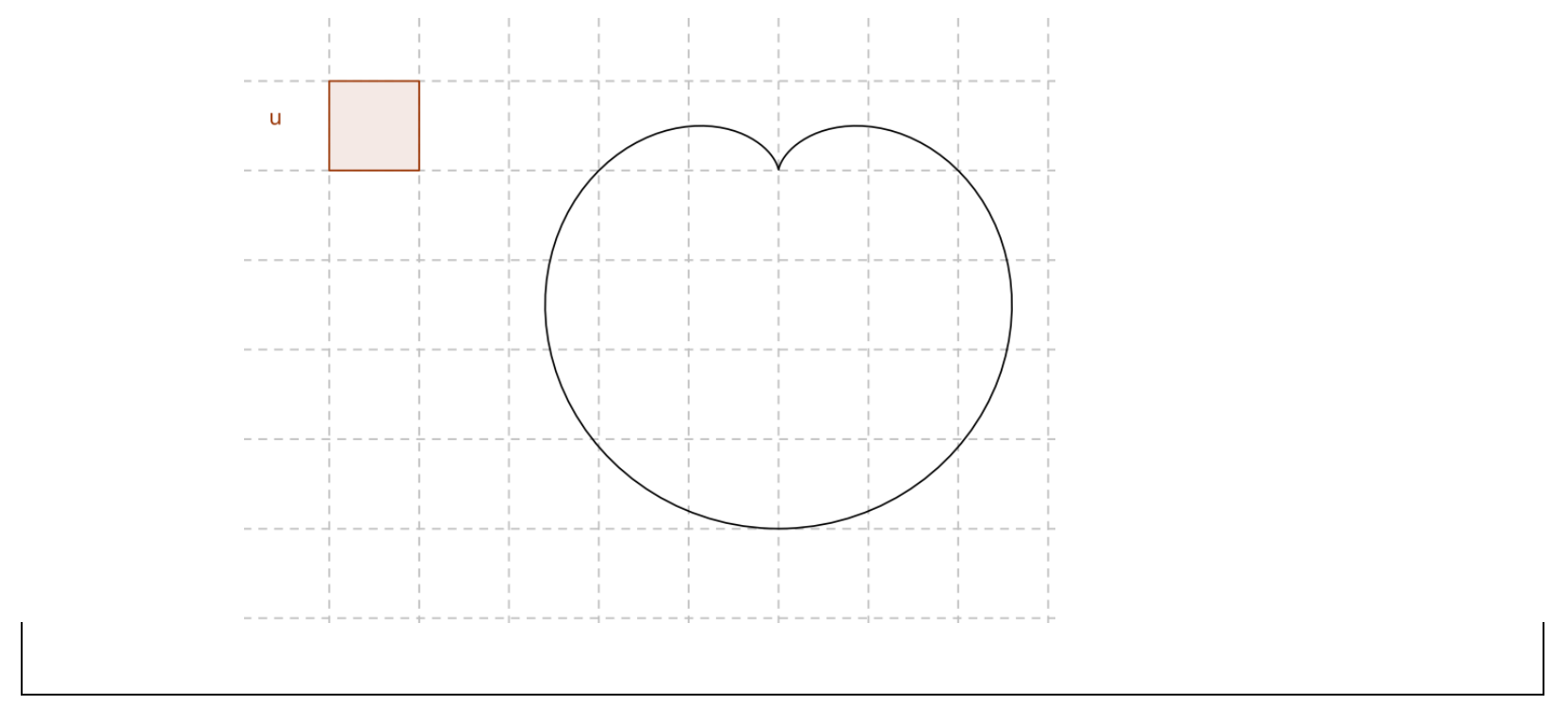

Um dos problemas observado no ensino de área é o uso exclusivo de figuras poligonais. O aluno fica com a impressão de que, exceto o círculo, somente é possível determinar áreas de figuras poligonais e que somente estas figuras teriam fórmulas para a determinação da medida de área. Desse modo, é importante que sejam estudadas áreas de figuras não poligonais.

Nesta situação utiliza-se como unidade de medida o quadradinho, portanto a resposta deve ser expressa nesta unidade. Utilizamos a malha quadriculada, pois sendo a figura irregular esse é um método apropriado para achar a medida de área. Espera-se que os participantes tentem completar os quadradinhos uns com os outros, encontrando dificuldades nas regiões muito curvas.

Como o objetivo principal é a estimativa e não a aproximação, utilizamos apenas uma malha, de um tamanho mais ou menos apropriado, para achar a área da superfície plana na unidade de medida dada. Os participantes devem concluir que quanto menores os quadrados mais precisa fica a medida, isto é, refinar a unidade de medida é importante para melhorar a aproximação. 
Observações e resultados da Tarefa 5.3

Os participantes contaram as unidades inteiras e depois estimaram o restante com as mais diferentes estratégias. Os valores variaram de acordo com o procedimento adotado e as respostas ficaram no intervalo entre 16,25 - 19,0.

Um dos participantes registrou que "Para aumentar a precisão podemos dividir em infinitos retângulos e somá-los".

Ressaltamos que esse tipo de atividade raramente é feito na escola. Em geral trabalhase com polígonos e aplicação de fórmulas para encontrar a medida de área de uma superfície plana. Também são considerados problemas onde é possível achar a área por composição ou decomposição, mas quase nunca consideramos estratégias para o cálculo de área de figuras não poligonais. 


\subsection{Análise geral da oficina}

A nossa investigação foi baseada na metodologia conhecida como Design Experiments. Uma vez escolhido o tema de pesquisa, procuramos identificar e analisar o problema. Fizemos o estudo da literatura sobre o ensino e aprendizagem da noção de área e o conceito de estimativa, essa etapa serviu de subsídios para a confecção de uma primeira versão do nosso experimento.

Depois de definir os conteúdos matemáticos que seriam abordados em nosso estudo decidimos oferecer a oficina para os participantes (professores, alunos de graduação e de pósgraduação) envolvidos com o processo educacional com o intuito de testar nosso design inicial e fazer mudanças ou alterações que forem pertinentes, isto é, refinar e melhorar o nosso entendimento sobre o assunto investigado.

Nosso grupo de participantes mostrou-se pouco familiarizado com as atividades que exigem o uso da estimativa, sobretudo em medida. Em algumas questões isso ficou evidente como, por exemplo, na atividade que pedimos para que fizessem uma estimativa do comprimento do palmo da mão; alguns deles apresentaram estimativas bem distantes do valor medido com uma régua. Na hora de reconhecer dados estimados e exatos também apareceram algumas dúvidas. Essa atitude é compreensível, pois a instrução matemática enfatiza muito a busca por respostas exatas, dessa forma é natural certo estranhamento diante desse tema. Diante dessas observações decidimos incluir no experimento que foi aplicado aos alunos atividades que introduziam o conceito de estimativa para que os mesmos se familiarizassem com o assunto, logo em seguida trabalhamos com as atividades que exigiam a estimativa da medida de área.

$\mathrm{Na}$ oficina percebemos que dois participantes não tinham interiorizado, por exemplo, a noção de tamanho de 1 metro quadrado, fato como esse dificulta a realização de estimativas razoáveis de medida de área que envolva tal unidade. Destacamos ainda que é extremamente importante que os professores disponibilizem para os alunos modelos físicos das principais unidades de medida para que se familiarizem com o tamanho delas. Esse episódio nos motivou a realizar uma atividade com os alunos que envolvessem os modelos físicos das principais unidades de medida de área, desse modo os alunos puderam visualizar a unidade e ter a noção do seu tamanho e com isso iniciar o processo de interiorização das principais unidades de medida dessa grandeza, fundamental para estimar medidas. 
Os participantes da oficina ficaram entusiasmados com a possibilidade do trabalho com as estimativas e perceberam que podem trabalhar essa habilidade em vários contextos sem que o aprendizado de determinado conteúdo seja prejudicado. Em suma, um dos nossos objetivos era justamente propor mudanças pedagógicas e despertar uma reflexão sobre o ensino da estimativa.

Os participantes não apresentaram nenhum método simples que permitisse fazer uma estimativa da medida de área de uma figura não poligonal desenhada em uma malha quadriculada, evidenciando que atividades dessa natureza quase sempre estão ausentes nas aulas de Matemática. Decidimos então fazer com os estudantes uma atividade com o objetivo de desenvolver um método relativamente simples que permite estimar a medida de área de uma figura qualquer desenhada numa malha. 


\section{Capítulo 5}

\section{O Experimento com alunos}

Neste capítulo apresentamos o público participante do nosso estudo e fazemos a análise das atividades aplicadas aos alunos do $9^{\circ}$ do ano de uma escola pública estadual.

\subsection{Os alunos e a escola}

Participaram do nosso estudo aproximadamente 65 alunos, duas turmas de alunos do $9^{\circ}$ ano da escola pública estadual "Daniel Paulo Verano Pontes" localizada no bairro do Rio Pequeno, cerca de $3 \mathrm{~km}$ da Universidade de São Paulo (USP), na zona oeste do estado de São Paulo. Escolhemos as turmas do $9^{\circ}$ ano porque os alunos já tiveram contato com o conteúdo "área de figuras planas", sendo assim procuramos enfatizar as principais ideias envolvidas nesse tema e introduzimos atividades que envolvessem a estimativa de medida de área e o processo de medição, pois entendemos que essas etapas são fundamentais para a compreensão do objeto de estudo delimitado.

A escola está organizada em ciclos e atende apenas alunos do ensino fundamental II (do $6^{\circ}$ ao $9^{\circ}$ ano). De acordo com resultados da Prova Brasil - 2015 foi calculada a proporção de alunos com aprendizado adequado a sua etapa escolar: 6\% é a proporção de alunos que aprenderam o adequado (em Matemática) na competência de resolução de problemas até o $9^{\mathrm{O}}$ ano.

O IDEB - Índice de Desenvolvimento da Educação Básica 2017 da escola nos anos finais foi de 4,8 atingindo a meta (4,7) e cresceu (IDEB 2015: 4,0), mas não alcançou 6,0. O IDEB foi criado em 2007 e reúne, em um só indicador, os resultados de dois conceitos igualmente importantes para a qualidade da educação: o fluxo escolar e as médias de desempenho nas avaliações.

Ele é calculado a partir dos dados sobre aprovação escolar, obtidos no Censo Escolar, e das médias de desempenho nas avaliações do INEP (Instituto Nacional de Estudos e Pesquisas Educacionais Anísio Teixeira), o Sistema de Avaliação da Educação Básica (Saeb) - para as unidades da federação e para o país, e a Prova Brasil - para os municípios.

Podemos observar na Tabela 1 que o IDEB da escola vem crescendo nos últimos anos, apesar da queda no período 2011-2013, igualou a média da rede estadual paulista no ano de 2017 e ficou acima da média do Brasil. 
Tabela 1 - Comparativo dos quatro últimos IDEBs ( $\left(9^{\circ}\right.$ ano do Ensino Fundamental)

\begin{tabular}{|c|c|c|c|c|}
\hline IDEB & 2011 & 2013 & 2015 & 2017 \\
\hline Escola & 3,8 & 3,6 & 4,0 & 4,8 \\
\hline Rede Estadual SP & 4,3 & 4,4 & 4,7 & 4,8 \\
\hline Média Brasil & 4,1 & 4,2 & 4,5 & 4,7 \\
\hline
\end{tabular}

Fonte: Gonçalves (2018)

Um indicador da qualidade do ensino da rede estadual paulista é o IDESP (Índice de Desenvolvimento da Educação de São Paulo), criado em 2007, o índice estabelece metas que as escolas devem alcançar anualmente. Os objetivos de cada escola são definidos a partir do desempenho dos alunos no Saresp (Sistema de Avaliação do Rendimento Escolar do Estado de São Paulo). Veja a tabela 2.

Tabela 2 - Comparativo dos quatro últimos IDESPs $\left(9^{\circ}\right.$ ano do Ensino Fundamental)

\begin{tabular}{|c|c|c|c|c|}
\hline IDESP & 2014 & 2015 & 2016 & 2017 \\
\hline Escola & 1,93 & 2,03 & 2,16 & 2,78 \\
\hline Média Estadual & 2,62 & 3,06 & 2,93 & 3,21 \\
\hline
\end{tabular}

Fonte: Gonçalves (2018)

Podemos notar que nos anos observados a média da escola esteve abaixo da média da rede estadual, mas IDESP da escola vem crescendo nos últimos anos mostrando que a escola está evoluindo.

\subsection{Desenvolvimento e análises}

A partir da experiência com professores no CAEM - Centro de Aprendizagem e Aperfeiçoamento do Ensino de Matemática - realizamos um processo de análise e refinamento das atividades para serem aplicadas aos estudantes do $9^{\circ}$ ano do ensino fundamental II da escola pública estadual "Daniel Paulo Verano Pontes”, portanto foram 
realizadas algumas modificações nas atividades visando atender os nossos objetivos de pesquisa.

Foram realizados três encontros, sendo que cada encontro teve duração de 1 hora e 40 minutos e um em cada semana no mês de Agosto de 2018. Durante os encontros, os estudantes realizaram atividades previamente planejadas. As atividades foram realizadas em duplas e contamos com a participação da professora de Matemática das duas turmas que nos ajudou na organização e aplicação do experimento, além disso, incentivou os alunos na realização das atividades sanando algumas dúvidas pontuais que eventualmente um ou outro aluno apresentava.

As atividades que constituem o experimento de ensino deste trabalho estão organizadas em quatro grupos da seguinte forma:

\section{Atividade 1 - Unidades não padronizadas}

Foi composta por três tarefas e aplicada na primeira aula, visando trabalhar o conceito de área de uma superfície plana. O objetivo da atividade é que os participantes adquiram a noção de área de uma superfície plana através do ladrilhamento (contagem de unidades) e que identifiquem a necessidade da utilização de uma unidade de medida para comunicar seus resultados; com a utilização do método de composição e decomposição de figuras buscamos ressaltar os aspectos envolvidos na construção do conceito de área.

O objetivo inicial é desenvolver a ideia de que a área é medida por cobertura, ou seja, sobreposição. Embora quadrados sejam as unidades mais comumente usadas, qualquer forma que convenientemente preencha uma superfície plana pode ser usada.

O uso de unidades informais (não padronizadas) para iniciar atividades de medidas é, de acordo com Van de Walle (2009), benéfico em todos os níveis de ensino e alguns motivos para usá-las são:

- As unidades informais tornam mais fácil se concentrar diretamente sobre o atributo (comprimento, área, volume) medido. Por exemplo, em uma discussão de como medir a área de uma forma irregular, unidades como triângulos, azulejos quadrados podem ser sugeridas. Cada unidade cobre a área e cada uma dará um resultado diferente. A discussão enfoca então o que significa medir área. 
- As unidades informais fornecem uma boa fundamentação para as unidades padrão. Uma discussão sobre a unidade padrão pode ter mais significado após os estudantes terem medido os mesmos objetos com suas próprias unidades e terem chegado a respostas diferentes.

\section{Atividade 2- Unidades padronizadas}

Visando proporcionar aos estudantes familiaridade com modelos concretos, mais comuns, das unidades de medidas de área, esta atividade foi realizada no segundo encontro e foi composta por três tarefas.

O objetivo da atividade é fazer com que os estudantes desenvolvam familiaridade com os modelos concretos, mais comuns, das unidades de medida de área para que sejam capazes de realizar estimativas razoáveis.

O conhecimento das unidades padrão é um objetivo válido de um programa de medida e deve ser adotado. Os estudantes devem não apenas desenvolver uma familiaridade com as unidades padrão, mas devem também aprender as relações apropriadas entre elas. Familiaridade significa que os alunos devem ter uma ideia básica do tamanho das unidades comumente usadas e o que elas estão medindo. A sensibilidade para medidas demanda que os alunos estejam familiarizados com as unidades de medida comuns e que eles possam fazer estimativas em termos dessas unidades e interpretar significativamente as medidas descritas com unidades padrão.

É importante que o aluno esteja familiarizado com as unidades e, além disso, saiba escolher uma unidade de medida razoável para uma determinada situação. A escolha de uma unidade apropriada também é uma questão de exigência necessária de precisão.

Outra meta a ser alcançada, embora menos importante, é o conhecimento de algumas relações importantes entre as unidades. A ênfase deve ser mantida nas relações mais utilizadas, pois exercícios de conversão tediosos contribuem muito pouco para aumentar a sensibilidade e apreciação métrica dos alunos.

Medir envolve uma comparação de um atributo de um objeto com uma unidade que tenha o mesmo atributo. Comprimentos são comparados às unidades de comprimento, áreas ás unidades de áreas, e assim por diante. Antes que qualquer coisa possa ser medida é necessário compreender o atributo a ser medido. 


\section{Atividade 3- Estimativa em geral}

O objetivo da atividade foi abordar o conceito de estimativa e também enfatizar a importância das referências para realizar estimativas. Foi composta por duas tarefas e realizada no terceiro encontro.

Uma estimativa de medida é de acordo com Albarracín et.al (2016, p. 94) "atribuir perceptivamente um valor ou um intervalo de valores em uma unidade correspondente a uma grandeza discreta ou contínua por meio dos conhecimentos prévios ou por comparação indireta de algum objeto auxiliar”. É, portanto uma conjectura que deveria ser ensinada nas aulas, porém atividades envolvendo estimativas geralmente não são desenvolvidas por motivos diversos: falta de habilidade dos professores, dificuldade para ensiná-las ou por falta de orientações e estratégias para desenvolvê-las.

É necessário que os alunos sejam capazes de realizar estimativas, as quais são úteis em situações nas quais não dispomos de um instrumento, por exemplo, quando precisamos comprar tinta necessária para pintar uma casa, quantidade de azulejos para o piso de uma sala, distância que nos encontremos de um lugar, etc. As estimativas são úteis quando a medição exata é difícil e pode se ter uma margem de erro na medida, então é importante que os alunos adquiram mediante a prática esta habilidade e possam utilizá-la em situações do cotidiano.

A estimativa de medidas é, de acordo com Van de Walle (2009), o processo de usar informação mental e visual para medir ou fazer comparações, sem o uso de instrumentos de medida. É uma habilidade prática.

Além de seu valor fora da sala de aula, as atividades de estimar medidas ajudam os estudantes a se concentrar no atributo medido, acrescenta motivação intrínseca e ajuda a desenvolver familiaridade com unidades padrão. Assim, a estimativa de medidas melhora o ensino de Medidas e desenvolve uma valiosa habilidade para a vida.

\section{Atividade 4- Estimativa de áreas}

O objetivo da atividade é estimular o uso de estimativas na resolução de problemas, e identificar quando é apropriado o uso da estimativa ou do cálculo; desenvolver um método para estimar a medida de área de figuras não poligonais desenhadas numa malha quadriculada.

Uma das estratégias de estimativa que foi trabalhada nas atividades é a técnica de comparação, baseada no uso de referências, isto é, conhecer e interiorizar a medida de objetos 
próximos e conhecidos e associá-los com aqueles que se desejam medir. Foi realizada também no terceiro e último encontro.

A seguir apresentamos as atividades e suas respectivas tarefas com observações e análises. Não percebemos nenhuma diferença significativa entre as turmas, portanto foi feita uma análise em conjunto das duas turmas. 


\subsubsection{Atividade 1 - Unidades não padronizadas.}

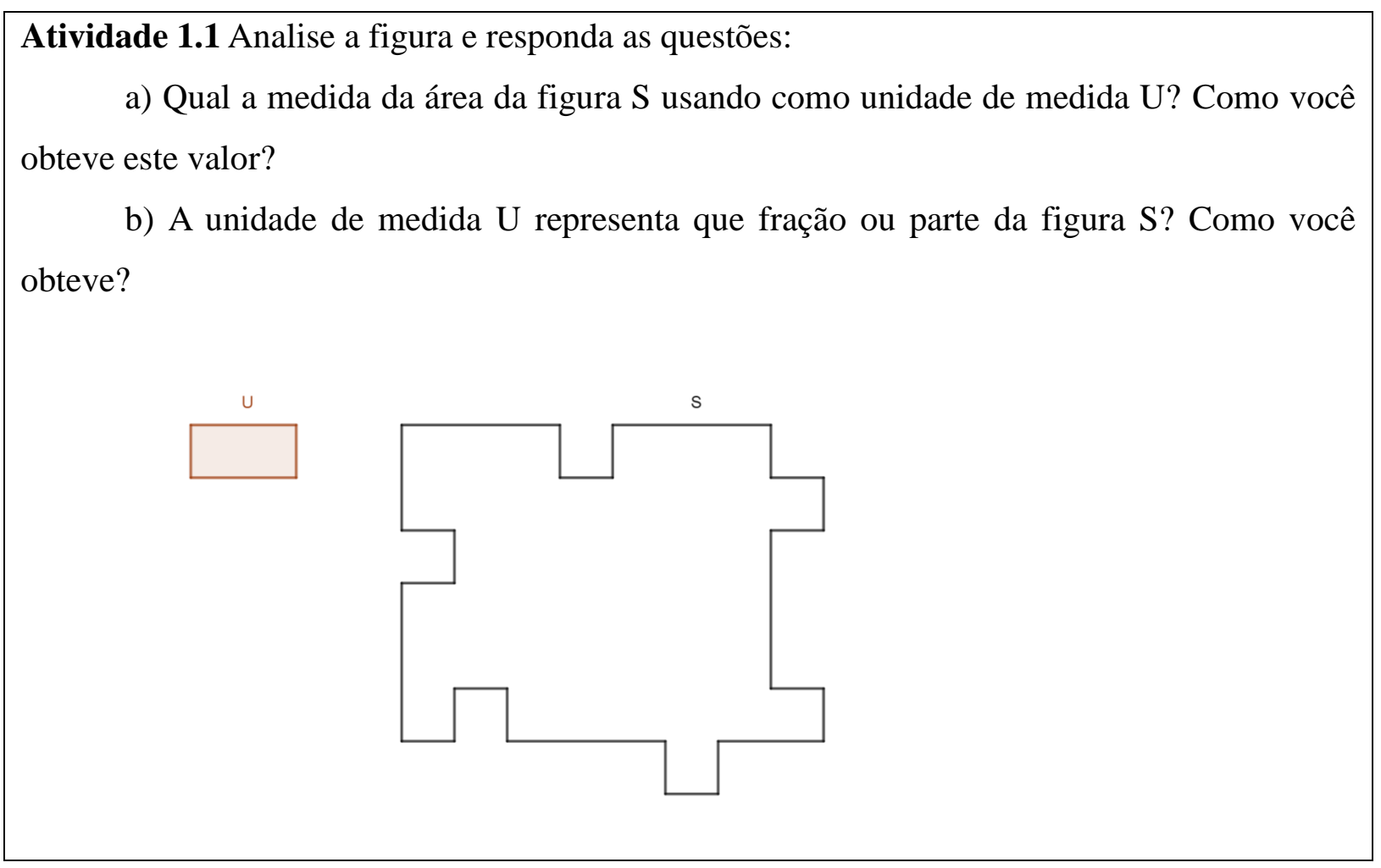

A tarefa visou mobilizar os conceitos de: área, unidade de medida, medição, estimativa, composição e decomposição, os procedimentos esperados são:

1. Desenhar a unidade de medida dada na figura, repetindo este procedimento até cobrir toda a superfície.

2. Recortar e sobrepor à unidade de medida na figura.

3. Quadricular a superfície plana e a unidade de medida, resultando uma unidade alternativa para realização da medição.

4. Calcular a medida racional como resultado dos processos de medição.

Esta situação exige que os participantes concebam a área como o tamanho das superfícies planas, além disso, é um método conveniente que permite determinar o número de unidades exigidas para expressar a medida de uma superfície plana.

Uma superfície plana é composta de sub-regiões e podemos realizar diferentes divisões em partes de mesmo tamanho e organizá-las para recompor a superfície original. As partes componentes tem a mesma área, isto faz com que o estudante adquirira o conceito de unidade, e faça o uso da iteração para atribuir um número a uma superfície plana dada. 


\section{Aplicação da Atividade 1.1: observações e resultados}

Os estudantes, de modo geral, utilizaram os procedimentos esperados. O procedimento de desenhar a unidade de medida estabelecendo assim o número de vezes que a unidade cabe na figura foi realizado por aproximadamente $84 \%$ dos alunos. Cerca de $37 \%$ dos alunos que utilizaram este método responderam corretamente e $47 \%$ responderam incorretamente.

Os procedimentos 2 e 3 ( recortar e sobrepor à unidade de medida na figura; quadricular a superfície plana e a unidade de medida, resultando uma unidade alternativa para realização da medição) não foram realizados por nenhum estudante.Cerca de $16 \%$ dos alunos realizaram algumas medições para depois tentar calcular a área da figura através de fórmulas; nenhum aluno que utilizou essa estratégia conseguiu chegar na resposta correta. Os principais obstáculos foram à dificuldade com o manuseio da régua e o fato da unidade de medida ser um retângulo e não um quadrado como na maioria dos exercícios que eles já resolveram. Muitos se atrapalhavam na hora de fazer as medições ou no momento de fazer os cálculos.

Nenhum estudante realizou o procedimento de quadricular tanto a figura quanto unidade de medida dada, estabelecendo o número de vezes que cabe na figura. Os alunos não reconheceram que a unidade dada, pode ser composta e decomposta em outras unidades, podendo determinar o número de vezes que cabe essa nova unidade na figura. 
Mostramos em seguida o procedimento executado por um dos alunos na Figura 10:

Figura 10 - Resolução da Atividade 1.1 - Aluno A

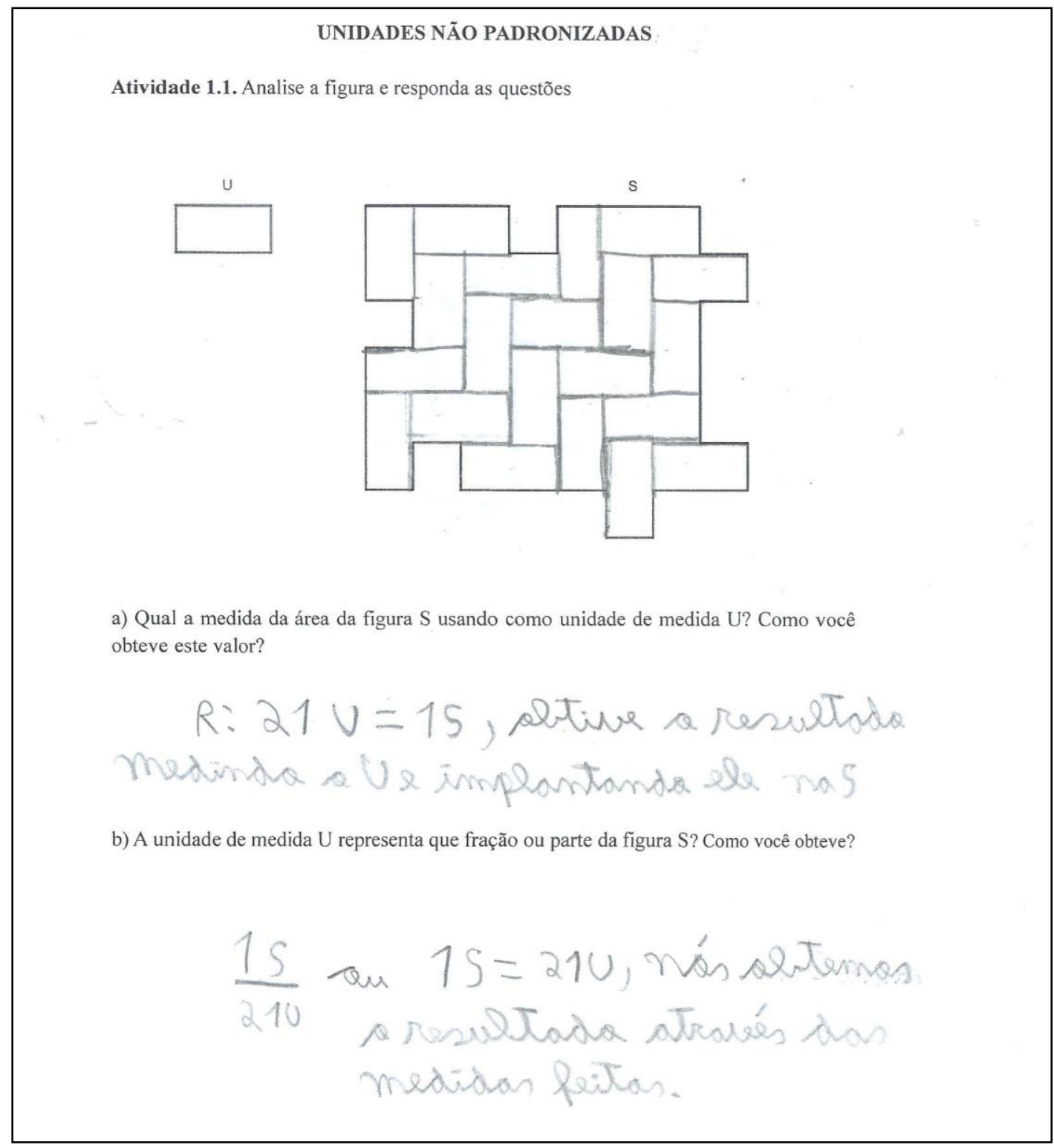

Fonte: Autor

$\mathrm{O}$ aluno A desenhou a unidade de medida na figura e, repetiu esse procedimento até preencher completamente a figura obtendo a medida de área na unidade desejada; conseguiu expressar as suas ações de forma clara e percebeu que 21 unidades " $U$ " formam a figura " $S$ ". Para responder do item " $b$ " todos os estudantes recorreram à resposta da pergunta do item "a" e de acordo com essa resposta reconheciam a respectiva fração. Assim $68 \%$ dos alunos 
responderam corretamente e $32 \%$ incorretamente. Alguns dos alunos justificaram a resposta: " $1 / 21$, sabendo que 21 "U" couberam em $\mathrm{S}$ ".

\section{Atividade 1.2}

Utilizando como unidade de medida " $u$ " indicada na malha, encontre a medida da área da superfície plana da figura abaixo. Explique o procedimento adotado.

Essa atividade tem como objetivo desenvolver a ideia de que a área é medida por cobertura, ou seja, sobreposição. Embora quadrados sejam as unidades mais comumente usadas, qualquer forma que convenientemente preencha uma superfície plana pode ser usada. Esta atividade pretende mobilizar os seguintes conceitos: unidade de medida, medição, conceito de área, estimativa, grandeza, composição e decomposição de figuras.

A atividade permite efetuar a técnica de recobrimento, a qual é uma atividade prévia para a compreensão do significado das fórmulas. 


\section{Aplicação da Atividade 1.2: observações e resultados}

A totalidade dos alunos percebeu que o quadrado da malha pode ser decomposto em duas unidades " $u$ ", sendo assim eles dividiram cada quadrado em dois triângulos e efetuaram a contagem do número de unidades que preenchiam a figura. Aproximadamente $73 \%$ dos alunos acertou a resposta, 25\% dos alunos não responderam (entregaram em branco) e apenas um aluno se equivocou na contagem das unidades de área. Apresentamos, em seguida, a resolução realizada por um dos alunos participantes.

Com as Atividades 1.1 e 1.2 acreditamos que os alunos compreenderam que uma figura é composta por partes e pode ser decomposta de diferentes modos, comprovando que a área é um meio conveniente para expressar o tamanho de uma região, isto é, para expressar o número de unidades necessárias para cobrir uma superfície plana, e que não se requer necessariamente o uso de fórmulas para achá-la, é suficiente preencher a figura com a unidade de medida dada e contar o número de vezes que cabe nesta. Os alunos adquiriram também o conceito de unidade de medida, ao fazer o uso da iteração da mesma para atribuir o par (número, unidade) para a medida de área da superfície plana. 
A seguir reproduzimos na Figura 11 a resolução de um aluno.

Figura 11 - Resolução da Atividade 1.2 - Aluno B

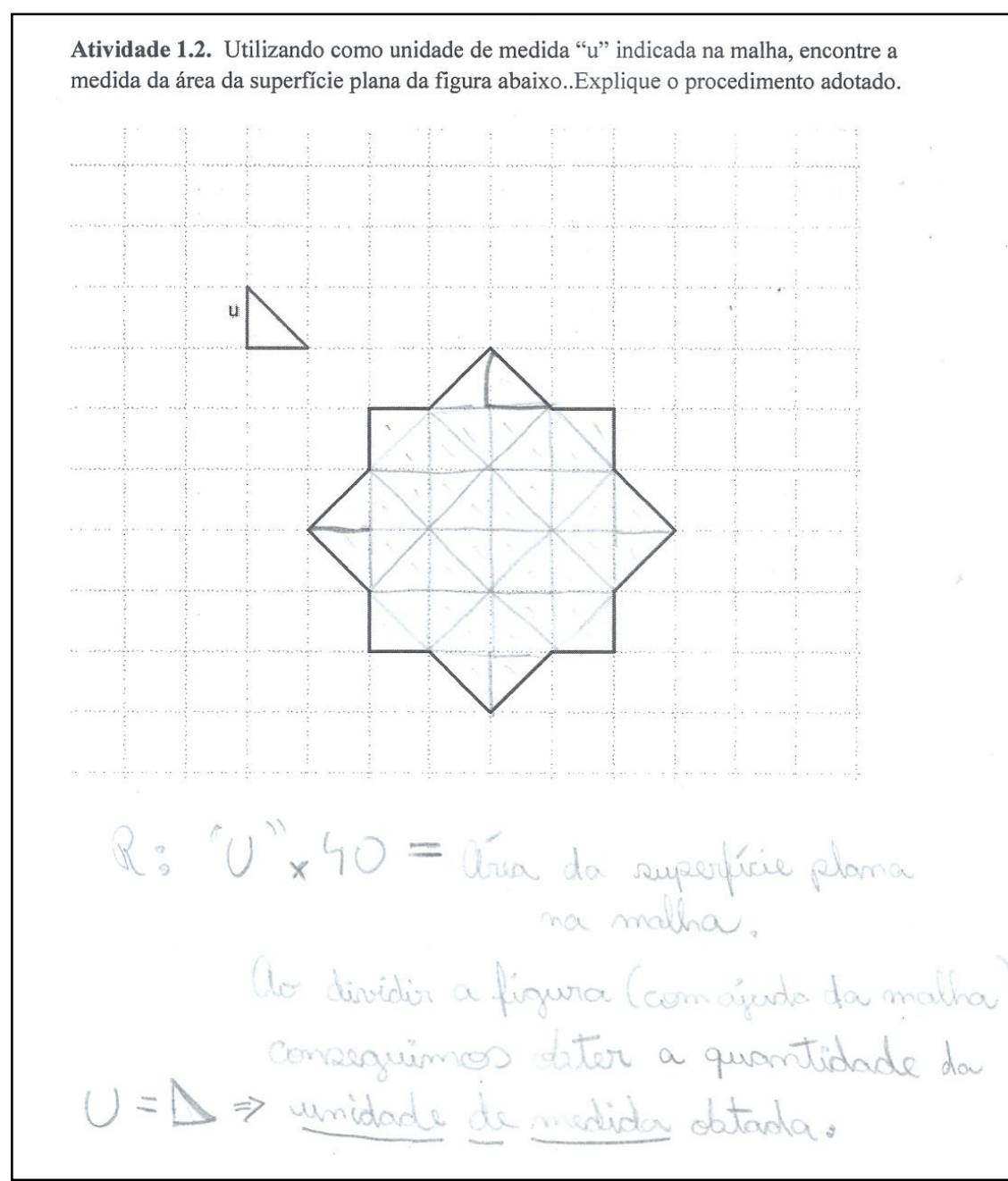

Fonte: Autor

O aluno B percebeu que cada quadradinho da malha pode ser decomposto em duas unidades " $u$ ". Desse modo ele dividiu cada quadradinho da malha em duas unidades de medida " $u$ " e efetuou a contagem. 
Atividade 1.3 Dê um valor aproximado da medida da área da superfície do quadrilátero abaixo utilizando o quadrado da malha como unidade de medida. Descreva, com suas palavras, qual foi sua estratégia para obter o valor.

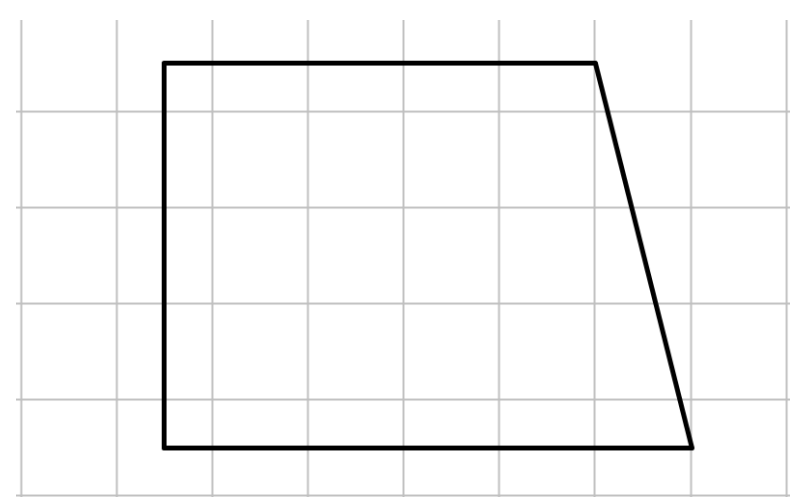

Esta atividade objetiva desenvolver a habilidade de estimar a medida de área de uma figura desenhada numa malha quadriculada. Para calcular o valor aproximado da área de uma região desenhada numa malha quadriculada podemos adotar o seguinte processo:

1. Conta-se o número de unidades da malha totalmente contidas na região.

2. Conta-se o menor número de unidades de malha que envolve totalmente a região.

3. Calcula-se a média aritmética entre as duas quantidades de unidades de malha contadas nos processos 1 e 2 .

\section{Aplicação da Atividade 1.3: observações e resultados}

O método para estimar a medida de área, descrito acima, não foi utilizado por nenhum dos participantes, a maioria dos estudantes utilizou a estratégia muito útil de decomposição e composição de figuras para atribuir a medida de área.

Nesta atividade cerca de $30 \%$ dos estudantes chegaram à resposta exata de 20 unidades de área, $11 \%$ obtiveram o resultado de 20,5 unidades de área, 30\% deram como resposta 19 unidades de área, $15 \%$ deram como resposta 21 unidades de área e os demais alunos não concluíram o exercício. 
A maioria dos alunos chegou à medida da área através do processo de composição e decomposição, alguns alunos ficaram receosos na hora de tentar juntar as partes para formar uma unidade inteira, provavelmente não estão habituados a este tipo de atividade que exige a busca por um valor aproximado.

Nenhum dos estudantes teve a ideia de transladar a figura verticalmente para encontrar a medida da área. Vejamos a resolução apresentada por um estudante na Figura 12.

Figura 12- Resolução da Atividade 1.3 - Aluno C

Dê um valor aproximado da medida da área da superfície do quadrilátero abaixo utilizando o quadrado da malha como unidade de medida
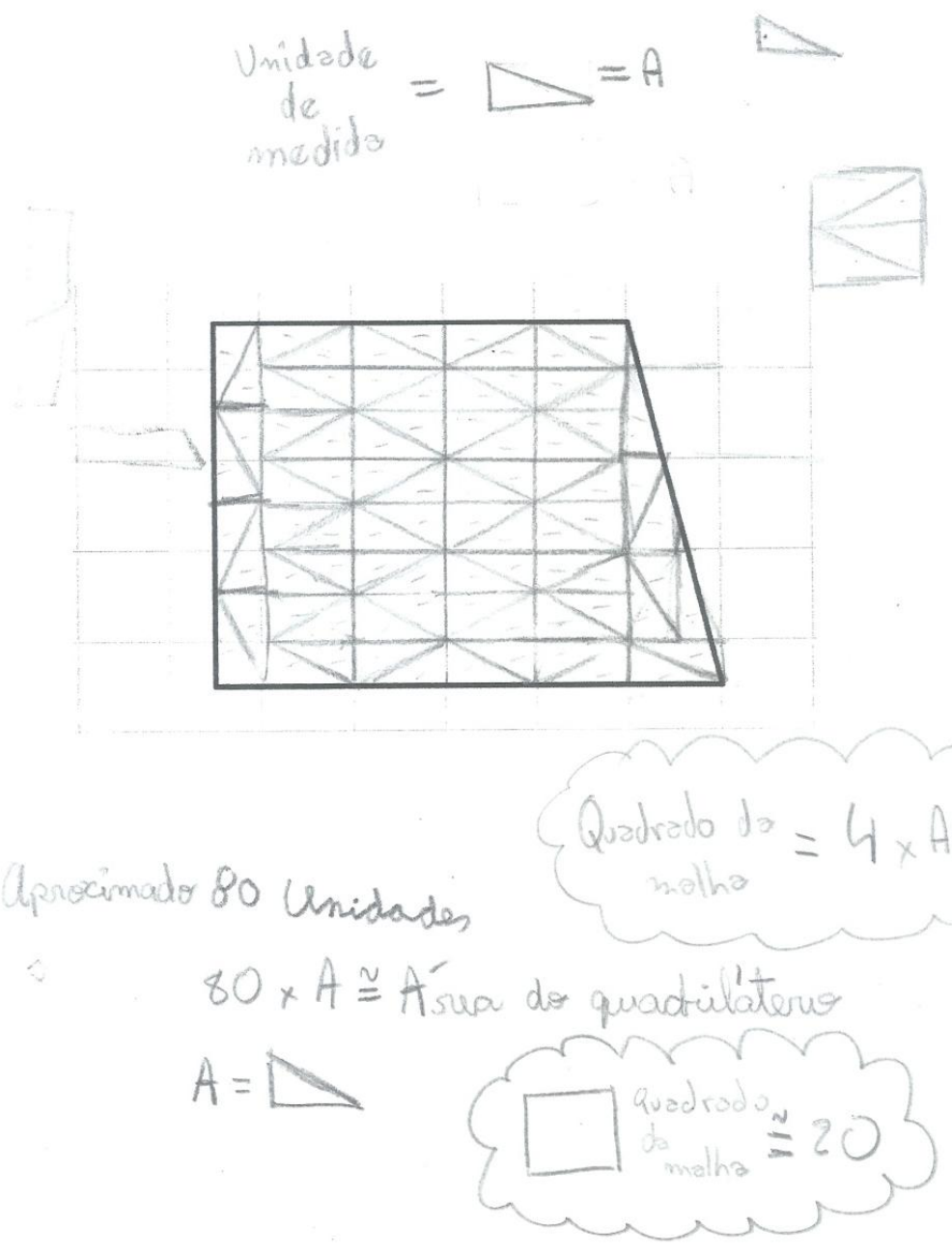

Fonte: Autor 
O aluno C utilizou a estratégia de decomposição e composição para encontrar a medida de área. Essa técnica foi utilizada por praticamente todos os estudantes com relativo sucesso e a maioria conseguiu chegar bem próximo do valor exato.

A unidade de medida foi decomposta em outra unidade alternativa e desse modo o aluno conseguiu encontrar a medida de área nessa nova unidade e relacionou com a unidade da malha.

\subsubsection{Atividade 2 - Unidades padronizadas.}

Atividade 2.1 Responda as seguintes perguntas:

a) Quantos centímetros quadrados cabem em $1 \mathrm{dm}^{2}$ ?

b) Quantos decímetros quadrados cabem em $1 \mathrm{~m}^{2}$ ?

c) Quantos centímetros quadrados cabem em $1 \mathrm{~m}^{2}$ ?

Esta atividade tem como objetivo a familiarização com os modelos concretos, mais comuns, de unidades de medida de área, pois a noção do tamanho das unidades e a interiorização de referências são essenciais para a realização de boas estimativas.

Disponibilizamos modelos físicos das unidades para que os alunos tivessem a noção do tamanho e com essa medida interiorizada realizar estimativas razoáveis.

O material utilizado na Atividade 2 é mostrado abaixo na Figura 13:

Figura 13 - Material utilizado na Atividade 2 (unidades de área: $1 \mathrm{dm}^{2}, 1 \mathrm{~cm}^{2}$ )

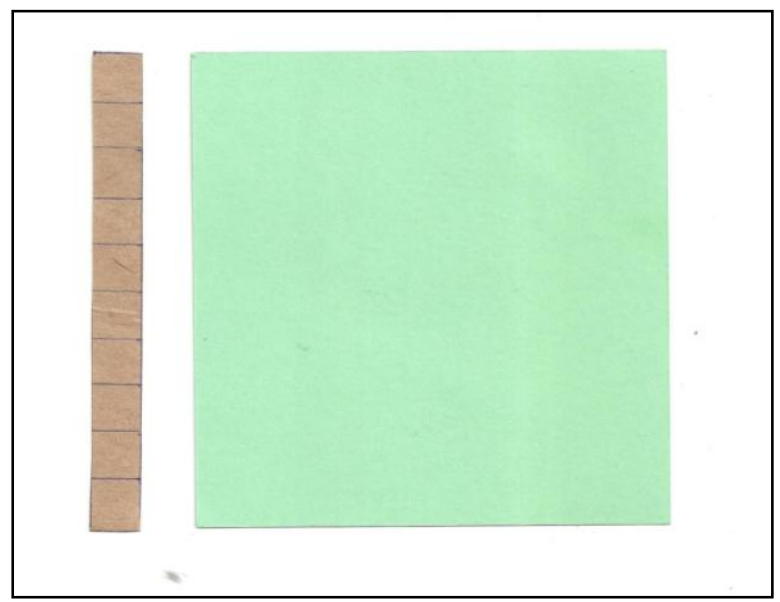

Fonte: Autor 
Embora o objetivo desta atividade não seja realizar conversões de unidades de área, espera-se que a conversão seja uma consequência da medição e que o aluno faça comparação das unidades.

Nessa atividade estão em jogo os seguintes saberes: as relações de equivalência das unidades de medida de área, medição, conceito de área; observamos também que as unidades são comparadas umas com as outras mediante o processo de medição.

A situação envolve os seguintes procedimentos:

1-Os estudantes com as unidades de medidas da grandeza área presentes devem compará-las entre si medindo umas com as outras ou sobrepondo e observar a relação entre elas.

2- O aluno depois de identificar uma relação de equivalência entre as unidades padronizadas da grandeza área deve utilizar o cálculo para achar a resposta para o item c.

\section{Aplicação da Atividade 2.1: observações e resultados}

Cerca de $25 \%$ dos alunos não responderam (entregaram em branco), aproximadamente $7 \%$ responderam corretamente todos os itens, aproximadamente $42 \%$ responderam corretamente os itens a e b, mas não conseguiram responder corretamente o item c que era uma dedução dos itens anteriores; aproximadamente $6 \%$ responderam o item c de forma incorreta e além disso fizeram confusão entre unidades de comprimento e área, dando respostas, por exemplo para o item a " 100 centímetros cabem em $1 \mathrm{dm}^{2}$ ” e cerca de $17 \%$ expressaram de forma incorreta ambos: número e unidade.

Mesmo trabalhando com o material concreto (modelo físico das unidades) a maioria dos alunos apresentaram dificuldades na hora de registrar corretamente o par: número/unidade e poucos estudantes compreenderam a equivalência entre as unidades de área.

Os alunos têm em relação à grandeza área, normalmente, apenas uma abordagem através dos processos de cálculo, assim os estudantes não sentem a necessidade de fazer medições de área por meio de unidades padronizadas ou não. Portanto decidimos aplicar a atividade com o objetivo de que os alunos reconheçam a importância de realizar processos de medição também para medir áreas.

Podemos observar abaixo a resolução da atividade feita por um aluno (Ver Figura 14): 
Figura 14 - Resolução da Atividade 2.1 - Aluno D

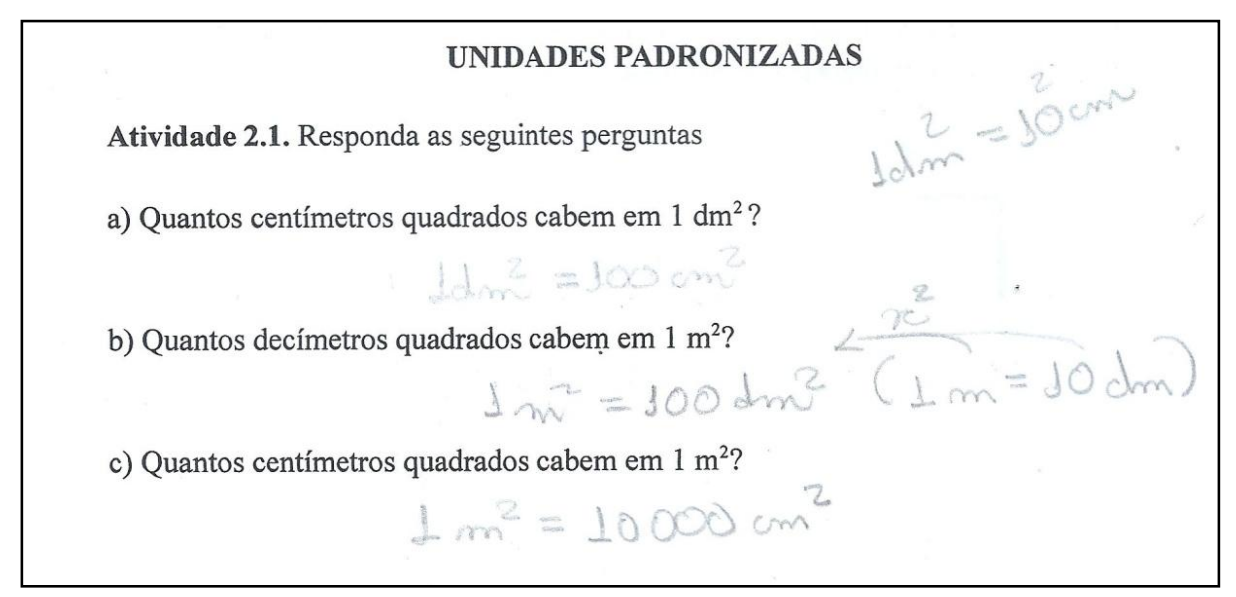

Fonte: Autor

O aluno D respondeu corretamente, no item "b" observou que $1 \mathrm{~m}=10 \mathrm{dm}$ e que elavando os dois membros da igualdade ao quadrado obtinha que $1 \mathrm{~m}^{2}=100 \mathrm{dm}^{2}$.

\section{Atividade 2.2}

a) Observe o tampo de sua carteira e estime qual é a sua área. Responda na unidade de medida que achar mais adequada.

b) Agora utilizando as figuras disponíveis, meça a área da sua carteira. Que valor obteve? Qual o procedimento que utilizou?

c) Compare os resultados encontrados nos itens anteriores. Sua estimativa foi boa? E de seus colegas?

Esta atividade objetiva estimar e, posteriormente, medir a área da superfície da carteira com uma das unidades de medida.

Estimar medidas e desenvolver referências pessoais para as unidades de medida comumente usadas ajuda os alunos a aumentar sua familiaridade com as unidades, previne erros em medidas e ajuda no uso significativo da medida. É muito importante que os alunos estimem uma medida antes de a medirem. Isso é verdade com unidades informais (não padronizadas) e com unidades padrão. Além disso, os estudantes precisam de prática no uso de bom senso na seleção de unidades padrão adequadas. 


\section{Aplicação da Atividade 2.2: observações e resultados}

Para metade dos participantes a diferença entre os valores estimados e obtidos foi razoavelmente grande. A maioria dos estudantes não está habituada a este tipo de atividade prática que exige também a percepção e a noção do tamanho das unidades.

A maioria fez uma estimativa utilizando o modelo da unidade $\left(\mathrm{dm}^{2}\right)$ e logo em seguida realizaram medições com essa unidade para confrontar os valores medidos e estimados. Outros alunos também fizeram medições com uma régua e calcularam a medida da área fazendo base $\mathrm{x}$ altura. No processo de medição nenhum dos alunos utilizou mais de uma unidade com o objetivo de obter uma maior precisão na medida.

Os estudantes em sua maioria tiveram a habilidade de escolher uma unidade de medida apropriada para medir a área do tampo da carteira, o que mostra que estão construindo o processo de estimativa que exige além da escolha da unidade outras habilidades e conceitos. Na Figura 15 exibimos o procedimento realizado por um estudante.

Figura 15 - Resolução da Atividade 2.2 - Aluno E

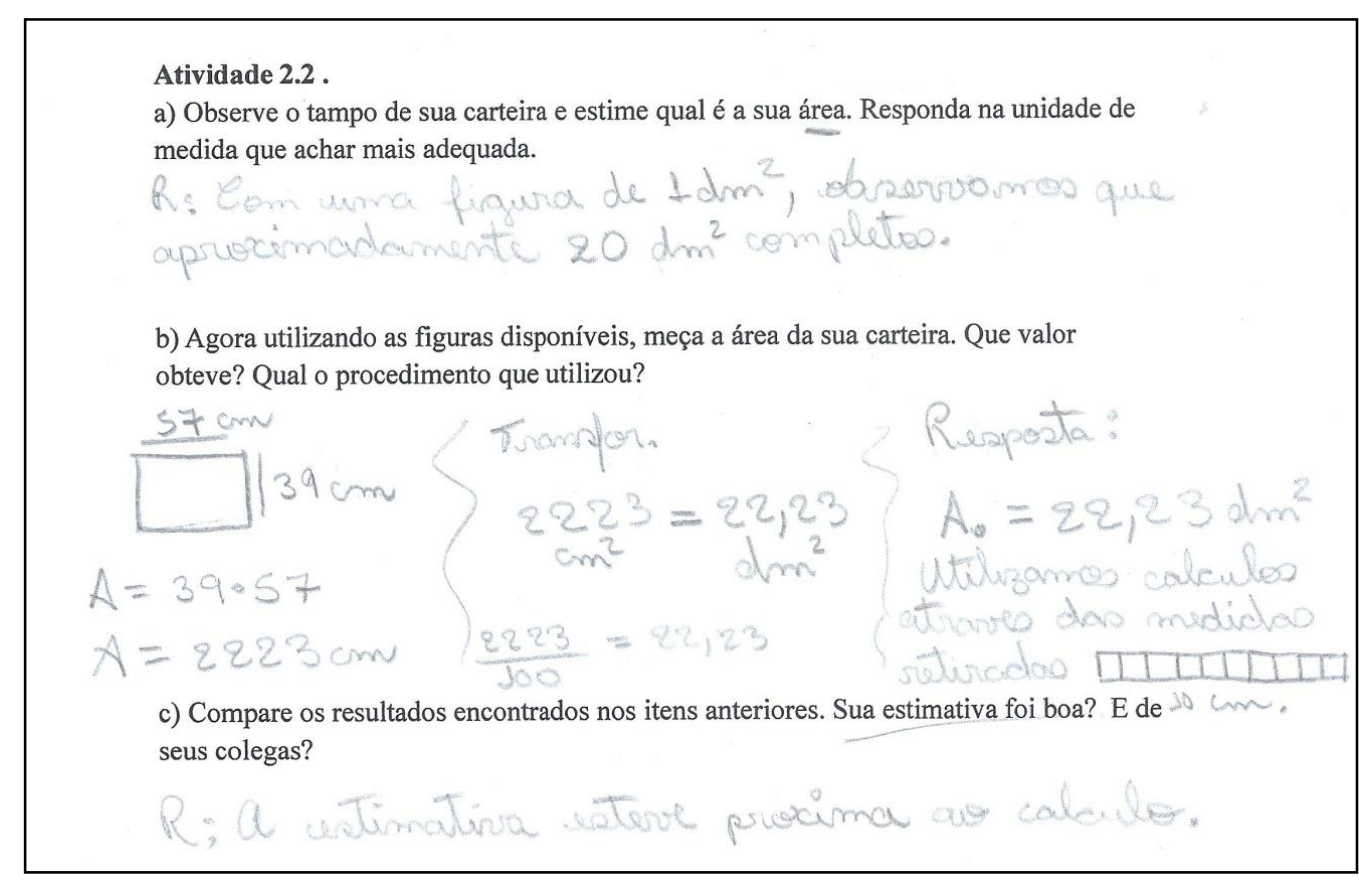

Fonte: Autor

O aluno E fez uma estimativa da medida de área utilizando a unidade $\mathrm{dm}^{2}$, em seguida mediu as dimensões da mesa com uma régua e através da fórmula calculou a medida de área na unidade $\mathrm{cm}^{2}$, por último realizou uma conversão de unidades para comparar os valores estimado e medido. 


\section{Atividade 2.3}

a) Com uma tesoura, corte a figura de $1 \mathrm{dm}^{2}$ que você recebeu em vários pedaços. Crie uma figura com todos esses pedaços, sem sobrepor nenhum deles, e cole-a num papel. Qual a área da figura criada por você? Justifique sua resposta.

b) Paulo comprou um papel medindo $1 \mathrm{~m}^{2}$ e deseja recortá-lo para obter 7 pedaços de modo que cada pedaço mede $20 \mathrm{~cm}^{2}$. Ele vai conseguir? Justifique sua resposta.

Essa atividade (Veja Figura 16) tem como objetivo abordar a invariância de área. Dizemos que dois polígonos são equidecomponíveis se é possível decompor um deles em um número finito de partes e, por meio de um rearranjo dessas partes, compor outro polígono. Por exemplo, um paralelogramo é equidecomponível com um retângulo.

Polígonos equidecomponíveis tem a mesma área e a recíproca também é verdadeira, ou seja, polígonos de mesma área são equidecomponíveis.

\section{Aplicação da Atividade 2.3: observações e resultados}

Cerca de $30 \%$ respondeu corretamente dizendo que as duas figuras possuíam a mesma área, aproximadamente $45 \%$ não respondeu esse item e $25 \%$ disse que área tinha aumentado.

Evidenciando que a conservação da área parece ser uma ideia difícil de ser assimilada por alguns alunos; para esses alunos se a forma da figura muda a medida da área também é alterada.

Em relação ao item "b" cerca de $12.5 \%$ respondeu que era possível recortar o papel conforme o enunciado, cerca de $35 \%$ disse que não era possível, mas não argumentou de forma satisfatória; e cerca de 52,5\% respondeu que era possível recortar o papel e que ainda iria sobrar e alguns desses alunos argumentaram utilizando o exercício anterior

"Sim, e ainda vai sobrar porque $1 \mathrm{~m}^{2}=10.000 \mathrm{~cm}^{2}$ e $20 \mathrm{~cm}^{2}=140 \mathrm{~cm}^{2}$ ".

"Sim, ele vai conseguir, pois $1 \mathrm{~m}^{2}=10.000 \mathrm{~cm}^{2}$ e vai ter de sobra ainda por cima". 
Figura 16 - Produção dos alunos na Atividade 2.3

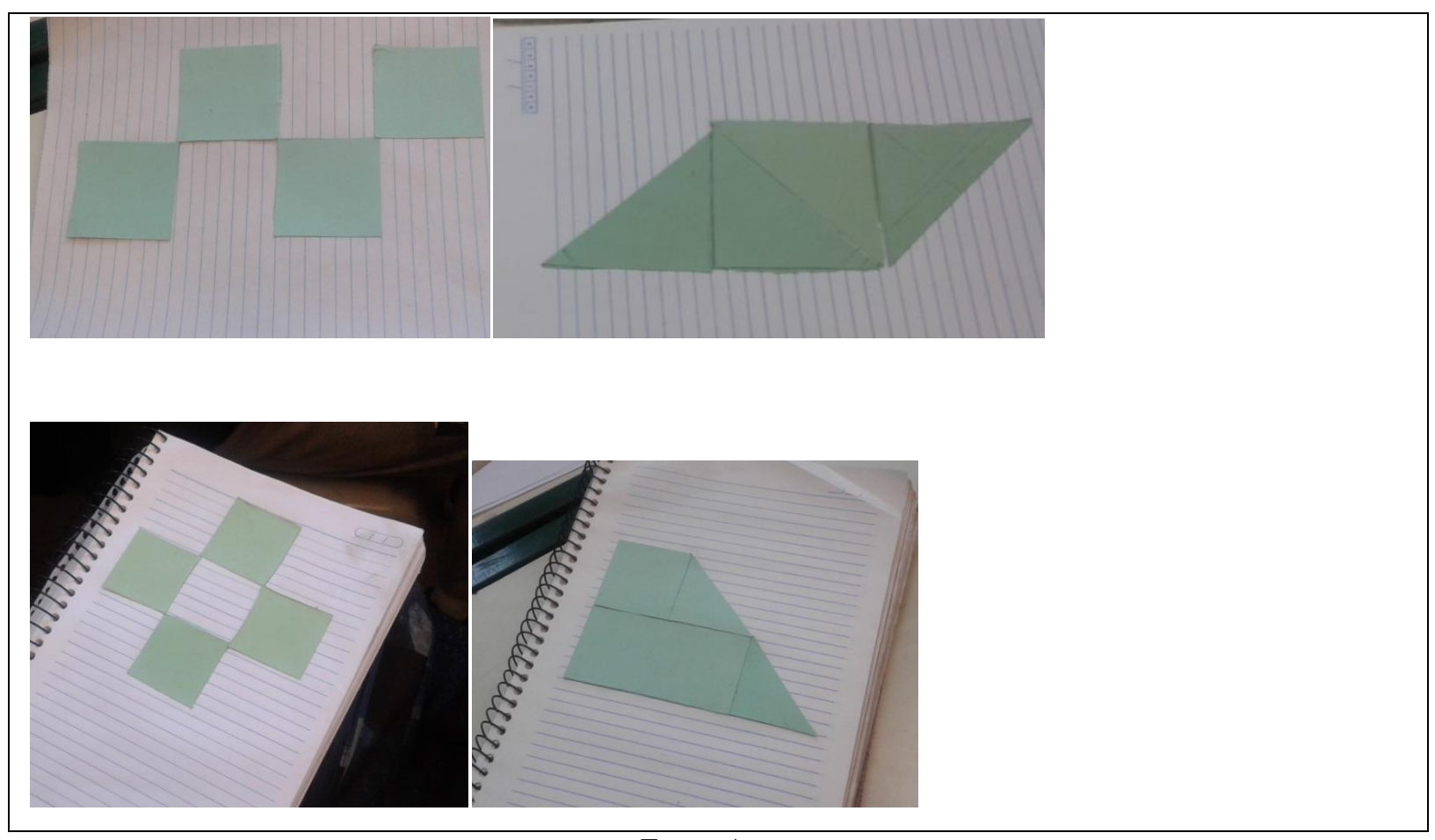

Fonte: Autor

\subsection{Atividade 3 - Estimativa em geral}

\section{Atividade 3.1}

Em quais das seguintes situações se utilizam dados exatos e em quais se empregam dados estimados (aproximados)? Explique sua resposta.

a) Preço de um automóvel.

b) Tempo de duração de uma lâmpada.

c) Números de desempregados no Brasil.

d) Cinco barras de chocolate a 50 centavos cada custam $R \$ 2,50$.

Essa atividade objetiva a identificação de dados exatos e estimados e, contribui para a ampliação da visão da matemática. Se, no ensino da matemática, ignorar a estimativa, enfatizando apenas procedimentos que conduzam a respostas exatas e únicas, ignora-se uma parte da matemática e impedimos os alunos de ganharem experiência e confiança para desenvolver essa habilidade. 
Nos meios de comunicação, por exemplo, para maior clareza e compreensão das informações são utilizadas estimativas no lugar de quantidades exatas.

O ensino escolar deve abranger o duplo caráter da matemática, exato e aproximado, e deve proporcionar aos estudantes atividades que lhe permitam apreciar em que circunstâncias convêm utilizar uma ou outra.

\section{Aplicação da Atividade 3.1: observações e resultados}

Praticamente a totalidade dos alunos respondeu corretamente os itens b, c e d. Em relação ao item "a" houve muito dúvida e as opiniões ficaram divididas. Cerca de $47 \%$ respondeu que o preço de um automóvel se tratava de um valor exato e aproximadamente 53\% afirmaram que na verdade o valor era estimado.

As justificativas foram as mais diversas:

"Dado estimado, pois se for pagar em parcelas, as últimas não serão exatas porque terão juros"; "Estimado, já que cada loja tem o seu preço"; "Exato, calculam o que gastaram e qual o lucro querem ter"; "Preço exato, para alguém comprar o preço deve ser exato e não aproximado". 
Observamos na Figura 17, as respostas produzidas por um dos alunos.

Figura 17- Resolução da Atividade 3.1 - Aluno F

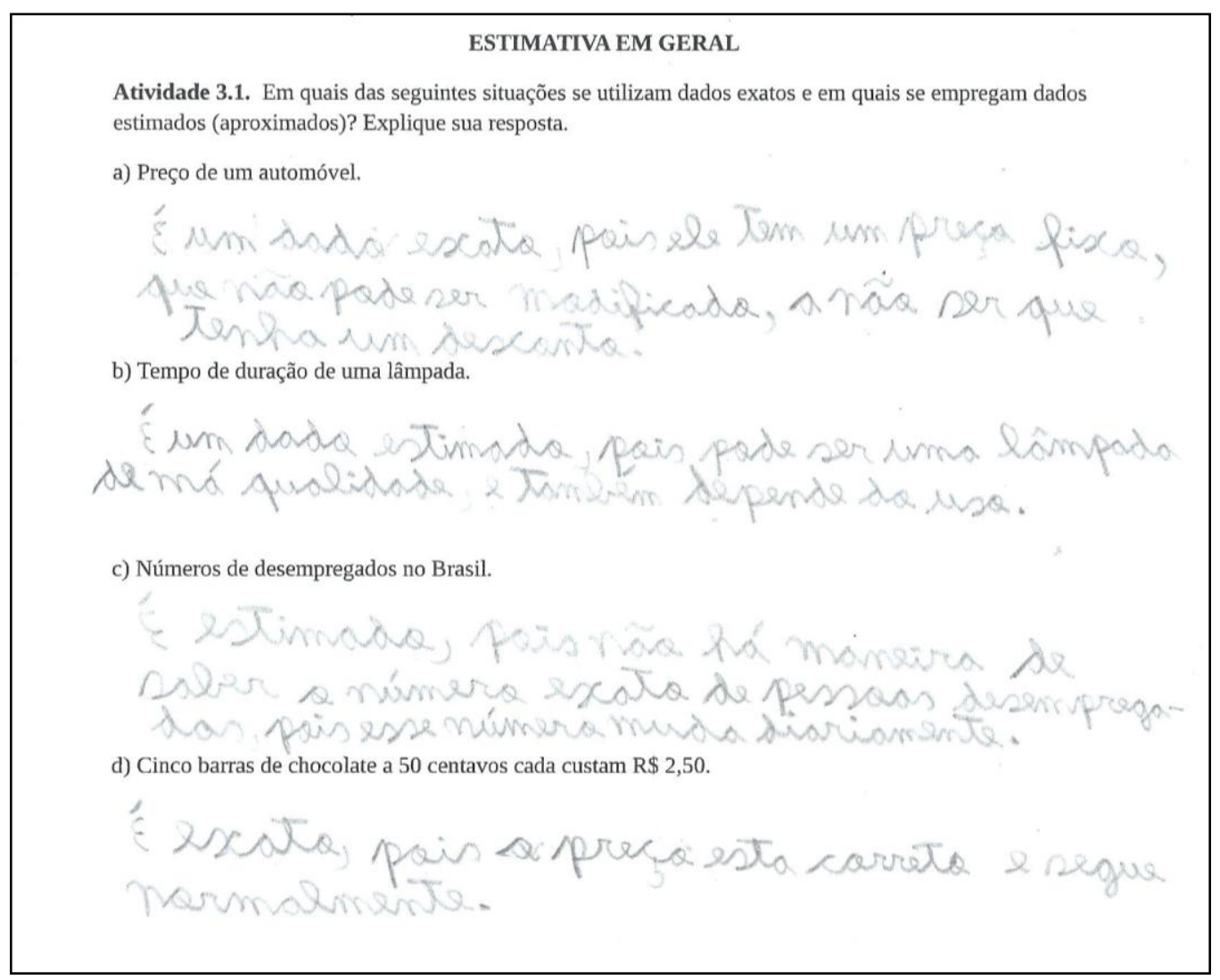

Fonte: autor

$\mathrm{O}$ aluno $\mathrm{F}$ conseguiu distinguir os dados exatos dos dados estimados e justificou com propriedade o porquê utilizamos estimativas em algumas ocasiões. Atividades como essa contribuem para legitimar o uso das estimativas e para ampliar a visão da Matemática.

\section{Atividade 3.2}

Dê um valor aproximado para:

a) O comprimento do palmo da sua mão direita.

b) Agora meça com uma régua. Qual o comprimento do palmo da sua mão direita?

c) Compare os resultados encontrados nos itens anteriores.

d) O número máximo de pessoas que cabem em $1 \mathrm{~m}^{2}$.

Uma das habilidades necessárias para realizar estimativas de medida é o conhecimento de referências. Trata-se, neste caso, de conhecer a medida de grandezas que estão muito 
próximas, como ocorre com o comprimento de algumas partes do nosso corpo (palmo, pé, dedo) ou de objetos frequentes em nosso cotidiano (altura usual de uma porta ou altura do teto de uma casa). A busca de referências é praticamente ilimitada, ainda mais em nossa sociedade que tem a maior parte dos objetos normalizados.

\section{Aplicação da Atividade 3.2: observações e resultados}

Nesta atividade cerca de 6 alunos deram estimativas bem distantes do "valor real" para o comprimento do palmo da mão. Alguns participantes estimaram um valor em torno de 12 $\mathrm{cm}$ e verificaram com uma régua que o valor na verdade estava próximo de $24,5 \mathrm{~cm}$. Evidenciando que não estão familiarizados com algumas medidas do corpo que podem ser usadas para realizar estimativas razoáveis. Em geral as estimativas diferiram cerca de $2 \mathrm{~cm}$ do valor medido.

Em relação ao item "d" aproximadamente $60 \%$ respondeu que em $1 \mathrm{~m}^{2}$ cabem de 9 a 10 pessoas, $30 \%$ disseram que cabem de 4 a 5 pessoas e $10 \%$ responderam que cabe de 2 a 3 pessoas. Essa noção do tamanho do metro quadrado e da quantidade de pessoas que cabem nessa região é importante para fazermos, por exemplo, uma estimativa do número de pessoas numa manifestação. 
Destacamos abaixo na Figura 18, a resolução da atividade apresentada por um dos participantes.

Figura 18 - Resolução da Atividade 3.2 - Aluno G

Atividade 3.2 Dê um valor aproximado para:

a) $\mathrm{O}$ comprimento do palmo da sua mão direita.

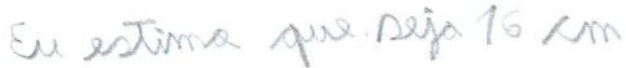

b) Agora meça com uma régua. Qual o comprimento do palmo da sua mão direita?

$\checkmark$ comprimenta sośá do m

c) Compare os resultados encontrados nos itens anteriores.

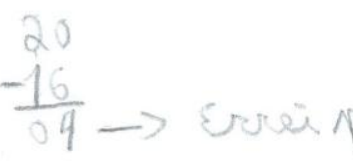

d) O número máximo de pessoas que cabem em $1 \mathrm{~m}^{2}$.

Fonte: Autor

O aluno G cometeu um “erro" de 4 cm em relação ao comprimento do palmo da mão; desenvolver referências é fundamental para a realização de boas estimativas devemos, portanto temos que estimular os estudantes para que tenham a noção do comprimento de algumas unidades básicas de medida. Em relação ao item d foi dada uma estimativa muito baixa para o número máximo de pessoas que cabem em $1 \mathrm{~m}^{2}$ evidenciando que o aluno não tem essa unidade de medida de área interiorizada. No final da atividade foi mostrado aos estudantes um modelo físico de $1 \mathrm{~m}^{2}$ e alguns alunos se surpreenderam, pois couberam de 8 a 
9 alunos bem juntinhos. A atividade também é útil para discutir um conceito presente nas aulas de Geografia, a ideia de densidade demográfica, ou seja, a razão entre população e área.

\subsection{4 - Atividade 4 - Estimativa de áreas}

Atividade 4.1 Com a "planta" da casa que você acabou de receber (Ver Figura 19), responda as seguintes perguntas, explicando as respostas.

a) Levando em conta que uma cama de solteiro tem $2 \mathrm{~m}$ de comprimento e $1 \mathrm{~m}$ de largura. Faça uma estimativa da medida da área do quarto 1.

b) Observe o quarto principal, há uma cama de casal. Quanto você acha que é a medida da área da cama? E do quarto?

c) Levando em conta a medida do quarto 1. Qual é a medida da área do banheiro?

Nesta atividade apresentamos a planta de uma casa, com a qual o estudante utilizando unidades de referência como a cama poderá encontrar a medida de área dos outros cômodos.

A medida da área do quarto 1 é de aproximadamente $7 \mathrm{~m}^{2}$, cama de casal $\left(3,1 \mathrm{~m}^{2}\right)$, quarto $\left(13,0 \mathrm{~m}^{2}\right)$ e do banheiro $\left(5 \mathrm{~m}^{2}\right)$. 
Figura 19 - Planta de uma casa

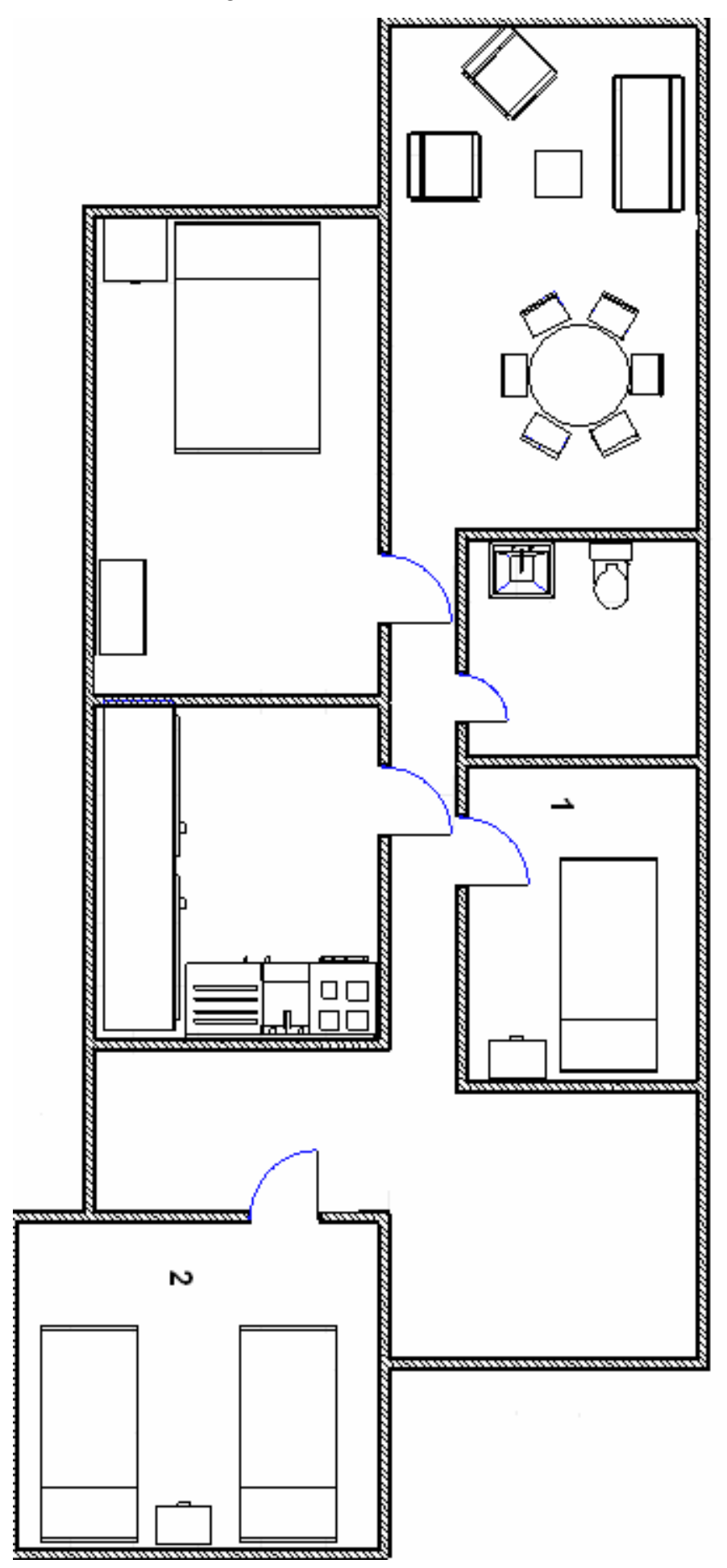

Fonte: ZAPATA, Fabio et.al, 2006 


\section{Aplicação da Atividade 4.1: observações e resultados}

As respostas dos alunos foram classificadas em três tipos:

Tipo 1 : Respostas perto da medida real.

Tipo 2: Respostas razoavelmente perto da medida real.

Tipo 3: Respostas longe da medida real.

No item "a", a maioria dos alunos não utilizou a medida da área da cama do quarto 1 como unidade de medida para dar um valor aproximado das outras medidas.Muitos dos alunos usou uma régua para realizar medições e através da formula base $\mathrm{x}$ altura determinar a medida das áreas pedidas mas a grande maioria não conseguiu dar boas estimativas pois apresentaram dificuldades na hora de converter as medidas.

Para este item consideramos resposta como Tipo 1, para a área do quarto 1, quando estiverem no intervalo de $6 \mathrm{~m}^{2}-7 \mathrm{~m}^{2}$. Serão consideradas respostas do Tipo 2 aquelas que estão entre $5 \mathrm{~m}^{2}-5.9 \mathrm{~m}^{2}$ e $7.1 \mathrm{~m}^{2}-8.0 \mathrm{~m}^{2}$ e respostas do Tipo 3 as menores que $5 \mathrm{~m}^{2}$ e maiores que $8 \mathrm{~m}^{2}$.

Cerca de $45 \%$ dos estudantes deu resposta do Tipo 1, aproximadamente $11 \%$ deram respostas do Tipo 2 e $44 \%$ deram resposta do Tipo 3.

Alguns alunos justificaram sua resposta:

"cabe 3 camas e meia, então $7 \mathrm{~m}^{2}$ ".

“Aproximadamente $6 \mathrm{~m}^{2}$, já que cabem 3 camas e1/4".

Quando uma unidade não cabe um número inteiro de vezes em uma região, os alunos, em geral, não se preocupam em estimar essa fração da unidade.

Para a pergunta do item "b" consideramos para a área da cama resposta como Tipo 1, quando estiverem no intervalo de $3 \mathrm{~m}^{2}$ a $4 \mathrm{~m}^{2}$. Serão consideradas respostas do Tipo 2 aquelas que estão entre $2 \mathrm{~m}^{2}-2.9 \mathrm{~m}^{2}$ e $4.1 \mathrm{~m}^{2}-5.0 \mathrm{~m}^{2}$ e respostas do Tipo 3 as menores que $2 \mathrm{~m}^{2}$ e maiores que $5.0 \mathrm{~m}^{2}$.

Por volta de $28 \%$ dos estudantes deram respostas do Tipo 1, 20\% deram respostas do Tipo 2 e aproximadamente $52 \%$ deram respostas do Tipo 3 para a área da cama.

Em relação à área do quarto consideramos como resposta do Tipo 1, quando estiverem no intervalo de $13 \mathrm{~m}^{2}-14 \mathrm{~m}^{2}$. Serão consideradas respostas do Tipo 2 aquelas que estão entre $12 \mathrm{~m}^{2}-12.9 \mathrm{~m}^{2}$ e $14.1 \mathrm{~m}^{2}-15 \mathrm{~m}^{2}$ e respostas do Tipo 3 as menores que $12 \mathrm{~m}^{2}$ e maiores que $15 \mathrm{~m}^{2}$. 
Nenhum dos estudantes deu resposta do Tipo 1, aproximadamente 13\% deram respostas do Tipo 2 e cerca de $87 \%$ deu resposta do Tipo 3.

Para o tem "c" consideramos respostas como Tipo 1, para a área do banheiro,quando estiverem no intervalo de $4 \mathrm{~m}^{2}-5 \mathrm{~m}^{2}$. Serão consideradas respostas do Tipo 2 aquelas que estiverem entre $3 \mathrm{~m}^{2}-3.9 \mathrm{~m}^{2}$ e $5 \mathrm{~m}^{2}-6.0 \mathrm{~m}^{2}$ e respostas do Tipo 3 as menores que $3 \mathrm{~m}^{2}$ e maiores que $6 \mathrm{~m}^{2}$.

Cerca de $40 \%$ dos estudantes deu resposta do Tipo 1, aproximadamente $13 \%$ deram respostas do Tipo 2 e $47 \%$ deram resposta do Tipo 3.

Podemos perceber na Tabela 3 abaixo que com exceção do item "a" as estimativas realizadas pelos estudantes ficaram distantes do "verdadeiro" valor.

Tabela 3 - Desempenho dos alunos na Atividade 4.1

\begin{tabular}{|l|l|l|l|}
\hline & Tipo 1 & Tipo 2 & Tipo 3 \\
\hline Item a & 24 & 6 & 23 \\
\hline Item b (cama) & 14 & 10 & 26 \\
\hline Item b (quarto) & 0 & 6 & 41 \\
\hline Item c & 21 & 7 & 25 \\
\hline Total & 59 & 29 & 115 \\
\hline
\end{tabular}

Fonte: Autor

A dificuldade maior foi em relação à estimativa da medida de área do quarto, pois a região era maior e, além disso, podemos inferir que atividades desse tipo não costumam estar presente nas aulas de Matemática. 
Atividade 4.2 - Em algumas ocasiões precisamos estimar a área de uma figura qualquer desenhada em uma malha quadriculada. Com base nisso, faça o que se pede:

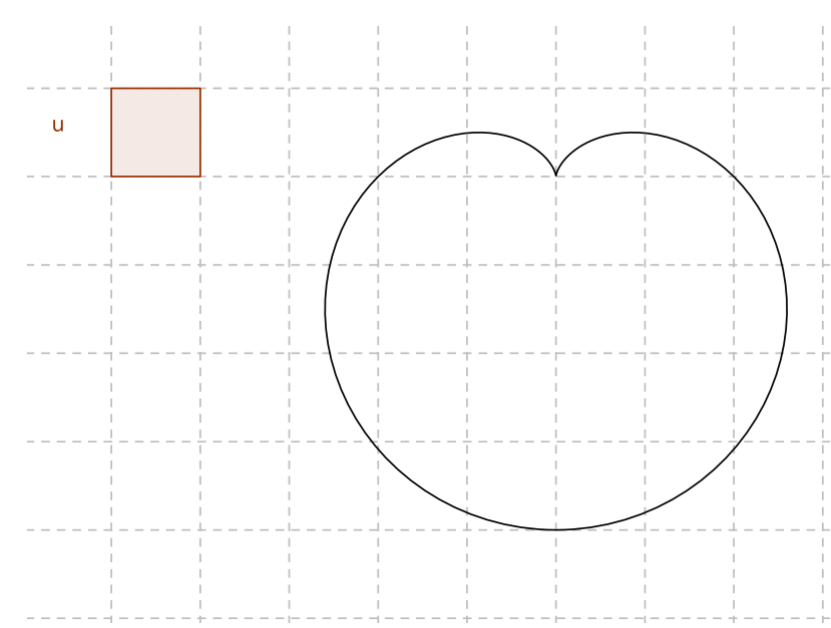

a) A figura cobre totalmente quantos quadrados?

b) Quantos quadrados a figura cobre total ou parcialmente?

c) Com base nos itens anteriores, podemos dizer que área da figura está entre que valores?

d) Que critério você poderia utilizar para calcular a área dos quadrados que estão parcialmente preenchidos? Utilize isso para dar um valor aproximado para a área da figura acima.

Objetivo: desenvolver um método para estimar a medida de área de figuras irregulares desenhadas numa malha quadriculada.

Nesta situação é utilizado o quadriculado, já que por se tratar de superfícies irregulares é um método apropriado para achar sua área, a ideia é realizar um método relativamente simples que nos permite estimar a medida de área de uma determinada superfície plana. 


\section{Aplicação da Atividade 4.2: observações e resultados}

Um método relativamente simples para estimar a área de uma figura qualquer, mas que não foi mencionado é o seguinte. Em primeiro lugar, teremos de desenhar a figura sobre uma malha quadriculada e contar os quadrados que estão totalmente dentro da figura, o desafio em seguida é estimar os "pedaços de quadrados" que estão no interior da figura e que ainda não foram contados. Admitindo que, em média, cada "pedaço" contribui para a área total da figura com metade do quadrado da malha, podemos estimar a área total da figura como sendo a soma dos quadrados das malhas que estejam totalmente no interior da figura com "metade" do total de quadrados do contorno da malha que ainda não foram contados como quadrados inteiros dentro da figura. Seguindo este método um valor aproximado para a medida da área da figura é de 19 unidades de área.

Os participantes contaram as unidades inteiras e depois estimaram o restante com as mais diferentes estratégias. Os valores variaram de acordo com o procedimento adotado, aproximadamente 8,5\% estimaram 19 unidades de área enquanto 32\% responderam 20 unidades de área, cerca de $13 \%$ deram como estimativas 17 e 18 unidades de área.Os demais deram valores distantes do valor esperado ou não responderam.

"Contei os quadrados que estavam cortados e cheguei a uma resposta". "Eu somei, duas metades é igual a um inteiro. A área é aproximadamente $19 \mathrm{~m}^{2}$ ", 
Mostramos a resolução da atividade feita por um dos estudantes, na Figura 20.

Figura 20 - Resolução da Atividade 4.2 - Aluno H

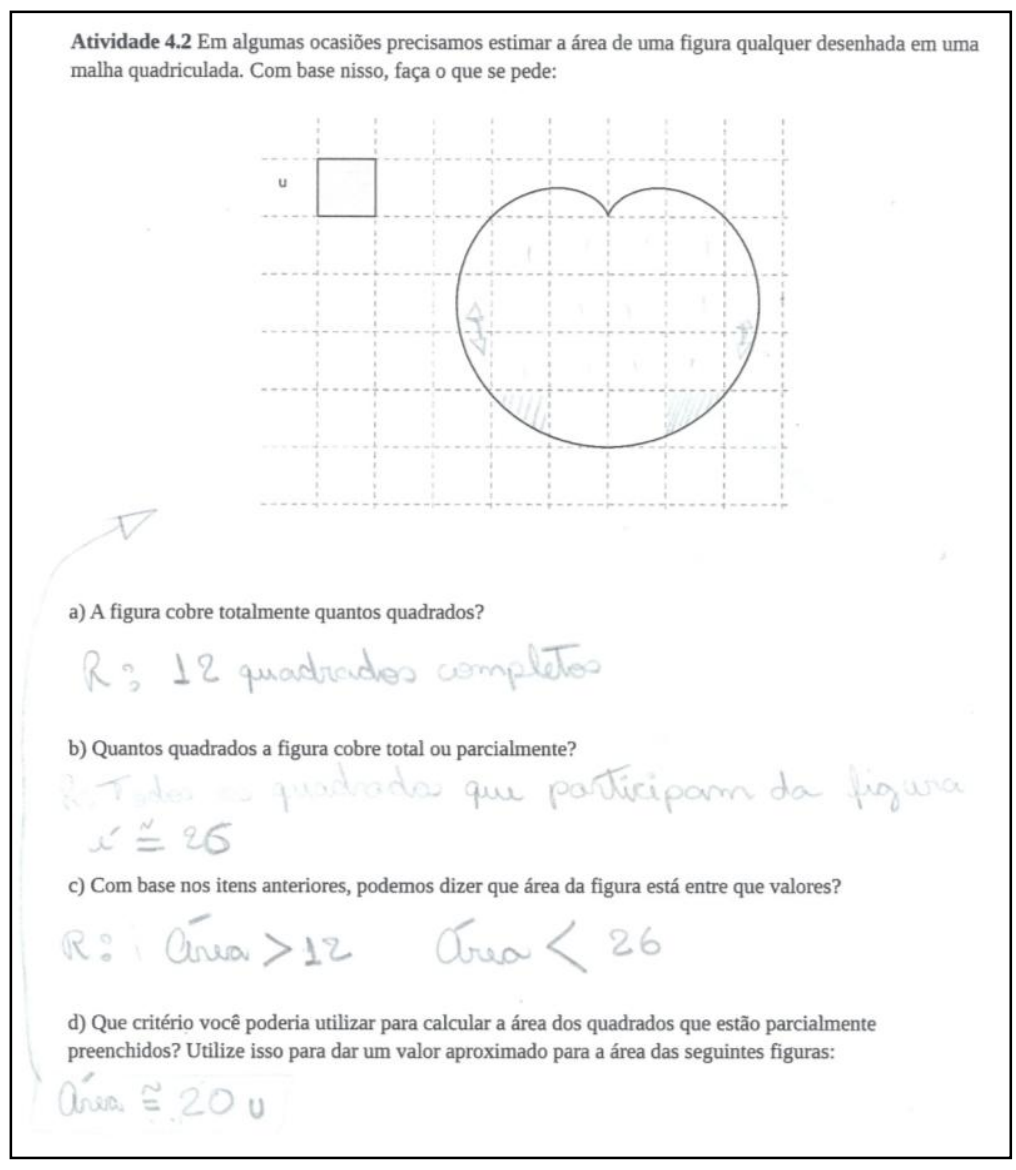

Fonte: Autor

O aluno H resolveu a questão utilizando o processo de composição e decomposição, essa foi à estratégia adotada por todos os participantes. Um procedimento esperado era que após a realização de duas estimativas: uma por excesso (item b) e a o outra por falta (item a) os alunos pudessem pensar em uma estimativa da medida de área, simplesmente fazendo uma média aritmética entre esses dois valores, esse último procedimento não foi sugerido por nenhum dos estudantes. 
Atividade 4.3 Utilize o procedimento anterior para calcular a área aproximada do Estado de Minas Gerais, destacado no mapa a seguir (Ver Figura 21 ):

O mapa está em escala e conhecemos a área da unidade da malha, basta multiplicarmos a unidade da malha pela quantidade estimada de "quadradinhos" para termos a medida de área aproximada do Estado de Minas Gerais.

Figura 21 - Mapa do Brasil

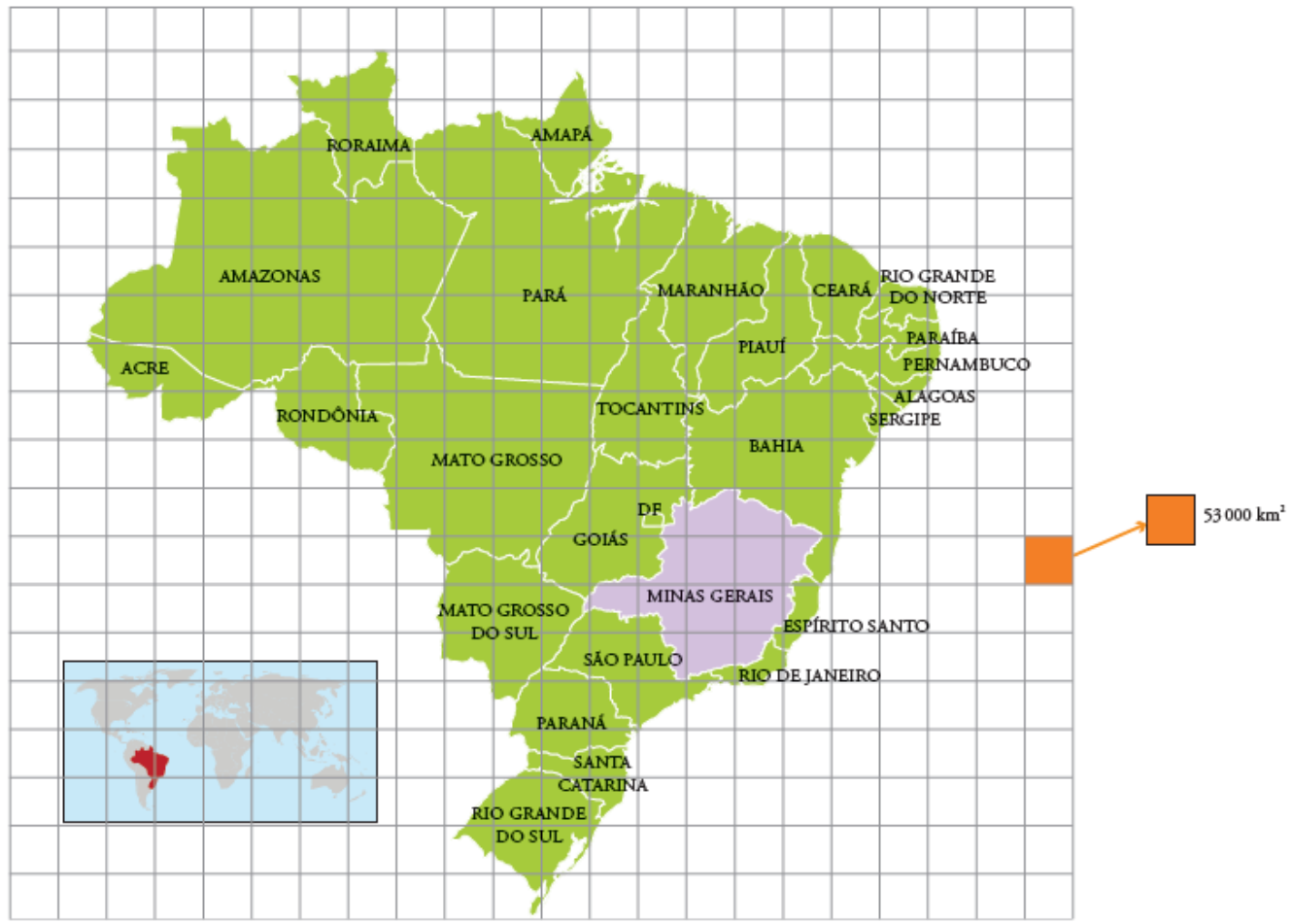

Fonte: Caderno do aluno (Matemática), 2014 - 2017

Nesta atividade foi solicitado aos participantes que realizassem uma estimativa da medida de área do Estado de Minas Gerais utilizando a comparação com a unidade de medida em destaque. Esperávamos que fossem utilizadas as ideias envolvidas na atividade anterior. 


\section{Aplicação da Atividade 4.3: observações e resultados}

Nessa atividade cerca de $37 \%$ dos estudantes não responderam a questão ou não utilizaram o procedimento descrito no exercício anterior. Aproximadamente 37,5\% utilizaram o procedimento anterior para obter a área do estado de Minas Gerais, destes 16\% responderam $530.000 \mathrm{~km}^{2}$ (10 unidades de área) e $21.5 \%$ responderam $583.000 \mathrm{~km}^{2}$ (11 unidades de área) este é o valor aproximado da medida de área segundo o método anterior. Tivemos ainda que $11 \%$ deram como respostas $586.000 \mathrm{~km}^{2}$ sem, no entanto, apresentar justificativa. Cerca de $14,5 \%$ estimaram 9 unidades de área ou valores maiores ou iguais 12 unidades de área. Mostramos na Figura 22, a resolução apresentada por um dos estudantes.

Figura 22 - Resolução da Atividade 4.3 - Aluno I

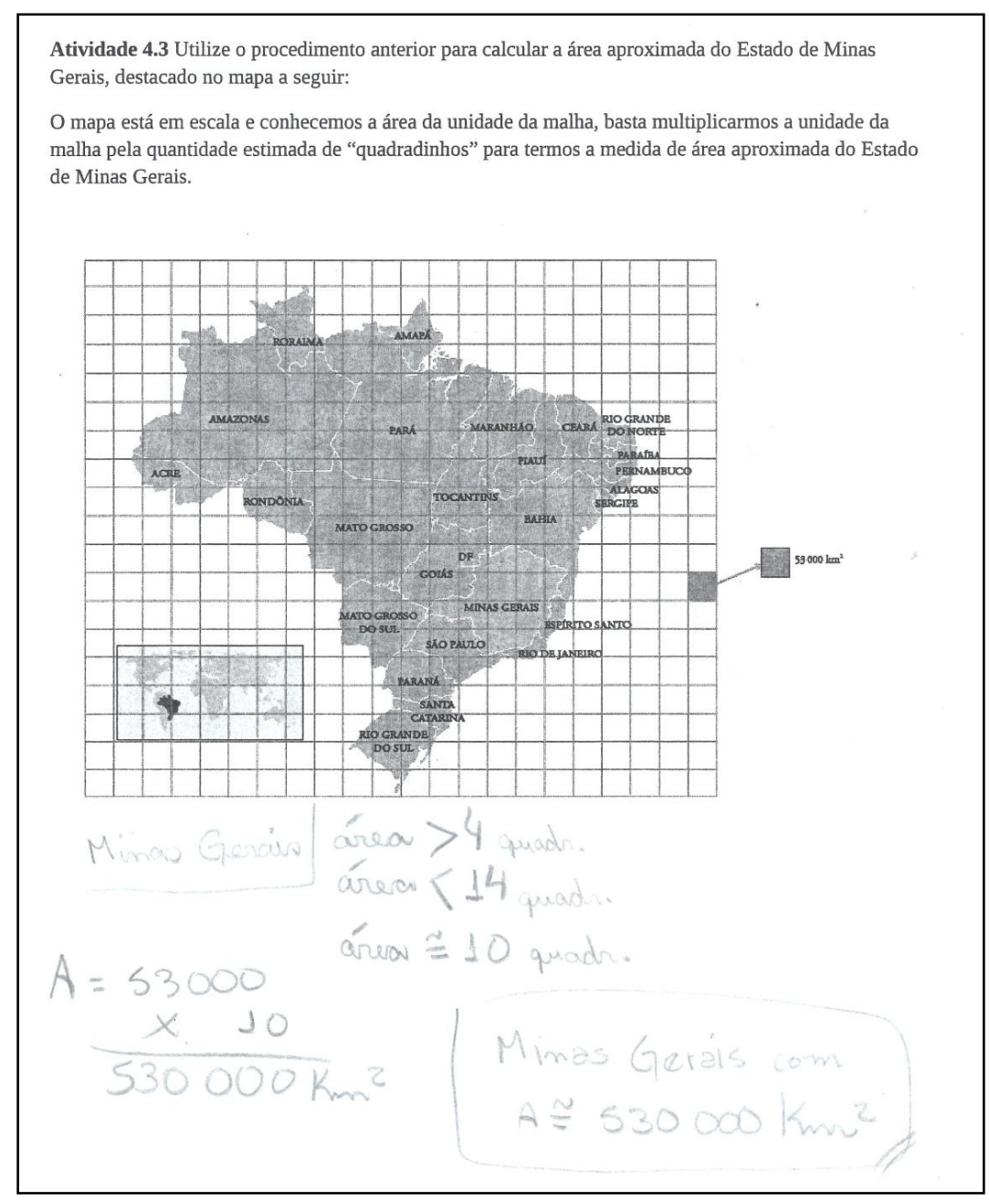

Fonte: Autor 
O aluno I conseguiu verificar que a medida de área estava entre 4 e 14 unidades de área, com essa informação deu um valor aproximado para a medida de área do estado de Minas Gerais. 


\section{Capitulo 6}

\section{Considerações finais}

Neste capítulo apresentamos algumas conclusões acerca do trabalho apresentado.

Nosso trabalho teve como objetivo analisar a influência das estimativas e aproximações para a compreensão do conceito de área. Procuramos avaliar se uma abordagem que utilize essas ideias pode contribuir para o aprendizado do processo de medida dessa grandeza.

De acordo com os estudos preliminares decidimos fazer uma abordagem que possibilitasse ao estudante desenvolver a prática de estimativas, a capacidade de escolher unidades de medidas adequadas e refletir sobre o caráter aproximado e incerto dos resultados das medições. Antes de aplicarmos a sequência de ensino aos estudantes da escola pública realizamos uma oficina com professores de Matemática e estudantes de graduação, após os resultados elaboramos a versão final do experimento de ensino.

No início da aplicação das atividades nas turmas de alunos do $9^{\circ}$ ano percebemos certa empolgação dos alunos diante do perfil das atividades. Os estudantes trabalharam em duplas, assim discutiam e trocavam ideias para resolver as questões. Todavia, apresentaram dificuldades no registro das justificativas e conclusões. Desse modo algumas atividades ficaram incompletas ou em branco.

Gostaríamos de destacar a participação ativa da professora das duas turmas, que esteve presente durante todo o experimento, encorajando os alunos a encontrar por si mesmo as respostas para cada atividade, sempre questionando- os e fazendo com que justificasse seus procedimentos.

As atividades aplicadas foram elaboradas de modo que tivessem mais de uma forma de chegar a resposta. Percebemos que isso deu oportunidade para os alunos serem mais criativos na construção de uma solução. Consideremos que isso foi um ponto positivo e que atividades desse tipo podem vir a desenvolver criatividade, autonomia e segurança para resolução de um problema.

Alguns estudantes apresentaram dificuldade com o uso da régua, outros quiseram aplicar fórmulas indiscriminadamente para achar a medida de área em situações na qual essa não era a melhor opção. Muitos dos estudantes não tinham ideia da noção de tamanho das 
principais unidades de medidas de áreas e ficaram surpresos quando trabalharam com os modelos físicos das unidades. Acreditamos que atividades dessa natureza podem auxiliar no desenvolvimento de habilidades com o uso de instrumentos de medida e também na conscientização das principais unidades de medida.

Durante a resolução das tarefas vários alunos procuraram desenvolver sozinhos as atividades propostas, apenas alguns esperavam alguma orientação da professora sobre o procedimento adotado ou apontava alguma dúvida. Observando os registros dos estudantes percebemos que eles procuraram resolver as questões com empenho e entusiasmo, apresentando maior dificuldade nas atividades que envolviam estimativas. Isto era esperado, pois as atividades que exijam essa habilidade costumam ser raras em sala de aula.

Notamos que alguns alunos foram capazes de estabelecer relações entre os dados da questão, selecionar estratégia e julgar a razoabilidade da resposta, enquanto outros estudantes simplesmente aplicaram uma fórmula sem fazer nenhuma previsão ou argumentar por que fizeram determinada escolha.

O trabalho com as estimativas parece favorecer uma relação mais pessoal com o conhecimento. Observamos que estudantes buscaram estratégias particulares, discutiram suas escolhas e analisaram a validade da sua resposta. Alguns estudantes ficaram orgulhosos do seu desempenho nas tarefas, pois se sentiram capazes de fazer Matemática. Podemos inferir, de acordo com nossa investigação, que o trabalho com as estimativas e aproximações influencia na capacidade de resolver problemas.

Baseado nas observações e nos resultados das aplicações das atividades nos parece que um bom caminho para iniciar os processos de medição da grandeza área é a partir de unidades não padronizadas, pois permite que o aluno perceba a natureza contínua e aproximada da medida. Em seguida, podemos utilizar as unidades padronizadas, exibindo modelos físicos das unidades de medida, pois os alunos já perceberam a necessidade de sua utilização. Por último podemos utilizar situações que envolvam a estimativa de medida de áreas para construir níveis de medição mais complexos.

Em relação ao experimento de ensino, algumas mudanças podem ser realizadas visando à articulação entre a habilidade de estimar e o conceito de área. Poderiam ser incluídas mais atividades de estimativas de área, por falta e por excesso. Apresentar para os alunos algumas figuras e pedir que façam, utilizando a malha quadriculada, uma estimativa de área (por falta e por excesso) de cada uma. Os alunos precisam perceber que quando a figura 
não se encaixa perfeitamente no quadriculado sua área será considerada por excesso se contar os quadradinhos que ultrapassam a figura; será considerada por falta se contar apenas os quadradinhos internos a figura. Outra atividade que não fizemos e que poderia ser realizada, envolvendo a estimativa da medida de área de uma superfície plana, faz uso do geoplano e do papel quadriculado.

Nossa pesquisa apontou a necessidade e importância no desenvolvimento da habilidade de se fazer estimativas, nos mais diversos contextos. A experiência com professores e alunos de graduação na oficina do CAEM nos alertou para este fato, pois alguns participantes demonstraram pouca familiaridade com estimativa de medidas. Quando foram expostos a situações variadas perceberam a necessidade de desenvolver tal habilidade na educação básica. $\mathrm{O}$ experimento com os alunos nos fez perceber ser possível abordar o conceito de área utilizando estimativas e aproximações. Os resultados foram animadores e promissores. Com o desenvolvimento das atividades podemos observar que alguns alunos adquiriram a percepção da diferença entre área e sua medida e também descobriram que é possível estimar a medida de área de uma figura plana qualquer.

Sendo assim, concluímos que é possível e desejável introduzir atividades envolvendo estimativas em sala de aula. Apesar da importância da estimativa parece que a sua presença ainda é incipiente no ensino de Matemática. O professor tem um papel importante no desenvolvimento das habilidades de estimativa dos alunos e pode trabalhar com este tema em diversos contextos tais como: estimar medida de área de figuras não poligonais com o uso da malha quadriculada, cálculo estimado (quatro operações), estimar frações e soma de frações, estimar medida de ângulo e de comprimento. Inicialmente, alguns estudantes podem mostrar resistência em estimar, outros estudantes vão apreciar as ideias e procedimentos que são inerentes aos processos de estimativa. Não estamos propondo trocar ou descartar o cálculo escrito e exato no qual são utilizados algoritmos e fórmulas, mas sim desenvolver a habilidade de estimar para ser utilizada em situações cotidianas e ter assim outros recursos para resolver problemas. 


\section{Referências}

ALBARRACÍN, L.; GORGORIÓ, N.; PIZARRO, N. Caracterización de las tareas de estimación y medición de magnitudes. In: Números: Revista de Didactica de las Matematicas, v. 91, mar. 2016, p. $91-103$.

AVILA, G. Grandezas incomensuráveis e números irracionais -RPM 05

BARBOSA, J.C.; OLIVEIRA, A.M.P. Por que a pesquisa de desenvolvimento na educação matemática? Revista do programa de pós- graduação em educação matemática da Universidade Federal De Mato Grosso do Sul, v.8, número temático - 2015.

BELlEMAIN, P. M. B.; LIMA, P. F. Coleção explorando o ensino - Matemática. Brasília: 2010. v. 17. Capítulo7

BOAVENTURA, E.M.; MATTA, A.E.R.; SILVA, F.P.S. Design- based research ou pesquisa de desenvolvimento: metodologia para pesquisa aplicada de inovação em educação do século XXI. Revista da FAEEBA - Educação e Contemporaneidade, Salvador, v.23, n. 42, p - 23-36, jul/dez 2014.

BONGIOVANNI, V. As duas maiores contribuições de Eudoxo de Cnido: "a teoria das proporções e o método de exaustão". Revista iberoamericana de educación matemática (UNIÓN), junho de 2005, número 2, p. 91-110.

BRASIL, Secretaria de Educação Fundamental. Parâmetros Curriculares Nacionais: introdução aos parâmetros curriculares nacionais/ Secretaria de Educação Fundamental. Brasília: MEC/SEF, 1997.

BRASIL, Secretaria de Educação Fundamental. Parâmetros Curriculares Nacionais: Matemática: Ensino de quinta a oitava séries/ Secretaria de Educação Fundamental. Brasília: MEC/SEF, 1998. 
BRASIL, Base Nacional Comum Curricular (BNCC). Educação é a base. Brasília, MEC/CONSED/UNDIME, 2018.

COBB, P.; CONFREY, J.; DISESSA, A.; LEHRER, R.; SCHAUBLE, L. Design Experiments in Education Research. Educational Researcher, v.32, n.1, p. 9-13, 2003.

CORBELLINI, A.; GIONGO, I. M.; QUARTIERI, M. T.; REHFELDT, M.J.H. Anais: II Seminario Institucional do PIBID Univates, Porto Alegre, 2012.

COURANT, R.; ROBBINS, H. O que é Matemática? Tradução Adalberto da Silva Brito. Rio de Janeiro: Ciência Moderna Ltda., 2000. 600p.

DOUADY, R.; PERRIN-GLORIAN, M. J. Un processus d apprentissage du concept d`aire de surface plane. Educational Studies in Mathematics. v. 20, n. 4, p. 387 - 424, 1989.

EVES, H. Introdução á História da Matemática. Campinas: Editora da Unicamp, 2011.

FERREIRA, L. de F.D A construção do conceito de área e da relação entre área e perímetro no $3^{0}$ ciclo do ensino fundamental: estudos sob a ótica da teoria dos campos conceituais. 2010. 193f. Dissertação (Mestrado em Educação Matemática) - Universidade Federal de Pernambuco, Recife, 2010.

GUIDORIZZI, H.L. Um curso de cálculo. Rio de Janeiro: Livros Técnicos e Científicos (LTC), 1997, v. 1, 3.ed, 585p.

KARRER, M. Articulação entre álgebra linear e geometria - um estudo sobre as transformações lineares na perspectiva dos registros de representação semiótica. 2006. 435f. Tese (Doutorado em Educação Matemática) - PUC/SP.

LIMA, E. L. Medida e Forma em Geometria. Rio de Janeiro: Lamgraf Artesanato Gráfico LTDA, 1991, p. 1 - 55. 
LIMA, P. F.; SILVA, M. F. F. Frações e Grandezas Geométricas: Um estudo exploratório da abordagem dada pelos livros didáticos. Anais: VIII Encontro Nacional de Educação Matemática. 2004

LOBO DA COSTA, N.M; POLONI, M.Y. Design based research: uma metodologia para pesquisa em formação de professores que ensinam matemática. XIII - Conferência Interamericana de educação matemática - CIAEM, Recife, Brasil, 2011

MACHADO,N.J. O que é contar e medir? É argumentar - Revista Cálculo editora segmento, n. 25, p. 50- 57, fev. 2013

PARRA,C.; SAIZ, I. Didática da matemática: reflexões psicopedagógicas. Tradução Juan Acuña Llorens. Porto Alegre: Artes Médicas, 1996.

SÃO PAULO, Secretaria de Estado da Educação. Proposta Curricular para o Ensino de Matemática $1^{0}$ Grau. Coordenadoria e Estudos de Normas Pedagógicas - 22 ed. 2008 .

SEGOVIA, I. , CASTRO, E. , CASTRO, E. , \& RICO, L. Estimación em cálculo y medida. Madrid: Sintesis, 1989

SMOOTHEY, M. Atividades e Jogos com Estimativas. São Paulo: Scipione, 1998

VAN DE WALLE, John A. A Matemática no ensino fundamental: formação de professores e aplicação em sala de aula. 6. ed. Porto Alegre; Artmed, 2009 


\section{Apêndice}

\section{Anexo I - Atividades com professores}

\section{ATIVIDADE 1}

TAREFA 1.1 Em quais das seguintes situações se utilizam dados exatos e em quais se empregam dados estimados? Explique sua resposta.
a) Preço de um automóvel.
b) Tempo de duração de uma lâmpada.
c) Números de desempregados no Brasil.
d) Preço de 5 barras de chocolate.

TAREFA 1.2. Realize as seguintes tarefas:

1. Dê uma estimativa da altura do seu colega sentado ao lado.

2. Qual deve ser a temperatura no interior da sala? E fora da sala?

3. Dê um valor aproximado para:

a) O comprimento do seu palmo.

b) A altura da porta da sala.

c) A altura de uma cesta de basquete.

d) O número de pessoas que cabem em $1 \mathrm{~m}^{2}$

TAREFA 1.3 Que estratégias e recursos foram utilizados para obter os valores da Tarefa 1.2? Quais termos ou palavras foram utilizados?

TAREFA 1.4. Na sua opinião, o que significa estimar um valor? E qual o significado de obter uma aproximação? São conceitos diferentes?

TAREFA 1.5. Das manchetes de jornais que aparecem abaixo, quais dados são exatos e quais são aproximados? Explique suas respostas.

a) A inflação diminuiu 0.2 pontos em novembro. 
b) O prazo final para entrega da declaração de renda termina este ano em 28 de Abril.

c) Este ano foram apresentadas a Fazenda 6 milhões de declarações.

d) Mais de $15 \%$ das pessoas compram queijo uma vez por semana.

e) Sydney é 14 vezes mais distante de Londres do que de Veneza.

f) Em 1964, um terremoto em Prince Willian Sound, no Alasca, mediu 8,5 na escala Richter e durou 7 minutos.

TAREFA 1.6 Analise o uso do conceito de estimativa nas notícias a seguir, extraídas da internet. Quais os significados de estimativa que aparecem?

a) Chuva faz IBGE melhorar estimativa para nova safra

b) Ainda não é possível estimar danos dos crimes de Cabral, diz MPF

Estima-se que o país possua cerca de $12 \%$ da disponibilidade de água doce do planeta

\section{ATIVIDADE 2}

TAREFA 2.1 Analise as afirmações abaixo, extraídos da internet. Os valores apresentados nas afirmações são exatos ou estimados?

a) O território brasileiro está localizado na América do Sul, apresenta extensão territorial de 8.514.876 $\mathrm{Km}^{2}$ e é o quinto maior país do planeta...

b) $\mathrm{O}$ território nacional tem cerca de 8,5 milhões de quilômetros quadrados.

c) Para a superfície do Brasil foi obtido o valor de $8.515 .759,090 \mathrm{~km}^{2}$, publicado no DOU $\mathrm{n}^{\circ}$ 124 de 30/06/2017, conforme Resolução No 02, de 29 de junho de 2017.

d). ...De acordo com a portaria, o Brasil tem 8.515.767,049 quilômetros quadrados

TAREFA 2.2 Justifique as suas respostas das questões a seguir 
a) A altura de um menino de dez anos é de 1,5 metros. Que altura você acredita que terá quando sua idade for de vinte anos?

b) Escolha a resposta mais adequada a seguinte questão: Um computador custa $R \$ 2480,00$. Se diminuirmos seu valor em 5\%, quanto custará, aproximadamente?
(i) $\mathrm{R} \$ 960,00$
(ii) $\mathrm{R} \$ 2475,00$
(iii) $\mathrm{R} \$ 2360,00$
(iv) $\mathrm{R} \$ 9600,00$

TAREFA 2.3 Estime a soma das seguintes frações:

$$
\begin{gathered}
\text { (i) } \frac{12}{13}+\frac{4}{9} \\
\text { (ii) } \frac{7}{8}+\frac{5}{6} \\
\text { (iii) } \frac{9}{10}+\frac{11}{12}+\frac{1}{50}
\end{gathered}
$$

Que estratégias podem ser utilizadas para responder a pergunta? Que habilidades são necessárias para responder a questão?

TAREFA 2.4 Uma lanchonete oferecia o seguinte cardápio e preços.

\begin{tabular}{|ll|}
\hline Menu & Preço em R\$ \\
\hline Cheeseburger & 1,85 \\
\hline Batata frita & 1,00 \\
\hline Batata chips & 0,65 \\
\hline Pizza (fatia) & 2,25 \\
\hline Minipizza & 8,00 \\
\hline Milk-shake & 1,75 \\
\hline Sorvete (uma bola) & 1,25 \\
\hline Refrigerante & 1,20 \\
\hline
\end{tabular}

a) Andreia tinha $\mathrm{R} \$ 5,00$ para gastar numa refeição rápida. Será que ela pode comprar um milk shake, batatas fritas e um cheeseburger?

b) Pedro tinha $\mathrm{R} \$ 6,00$ e quer uma fatia de pizza, batatas fritas, um sorvete e um refrigerante. Será que ele pode pagar? 
Como foram feitos os cálculos?

TAREFA 2.5. Estimar e medir

a) Observe o tampo da mesa do professor e dê um valor aproximado da sua área.

b) Escolha um dos materiais disponíveis na mesa do professor para medir a área do tampo.

Qual você achou mais conveniente? Qual a unidade de medida mais apropriada?

c) Com o material escolhido obtenha uma medida da área do tampo.

d) Compare os valores obtidos.

\section{ATIVIDADE 3}

TAREFA 3.1 Quantas pessoas participaram de uma manifestação

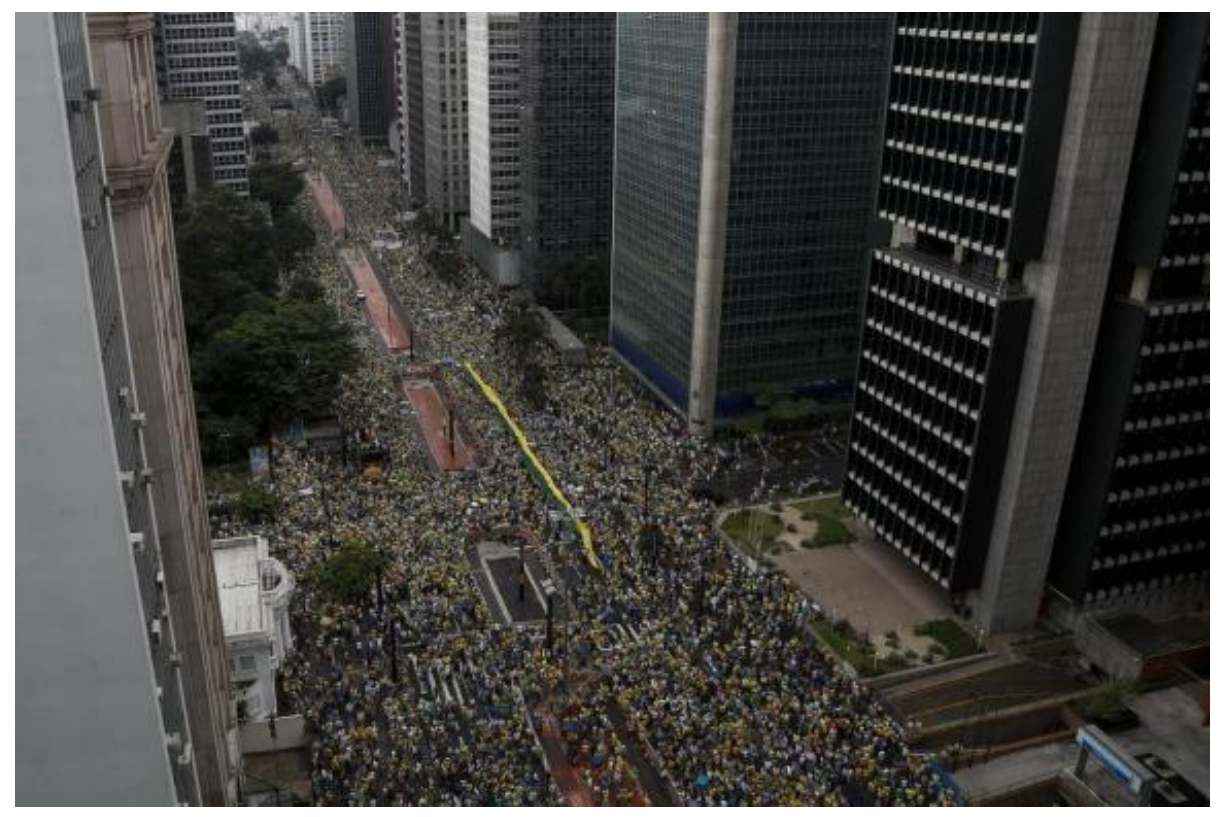

Atribui-se a Herbert Jacobs, professor de jornalismo da Universidade da Califórnia nos anos 1960, a modernização da estimativa de pessoas em multidões, utilizada até hoje como base para esses cálculos. À época, ele criou uma regra básica de densidade, que vai de uma multidão "pouco densa" a uma multidão "muito densa" - como em um ônibus lotado.

Pesquise sobre formas de avaliar número de pessoas em multidões. 
TAREFA 3.2 Quantos peixes há no lago?

(Adaptado de "Estatística para Todos" CAEM - IME - USP)

Em Estatística há alguns procedimentos que permitem estimar o tamanho de populações. Por exemplo: quantos peixes há na Lagoa Rodrigo de Freitas, no Rio de Janeiro? Já no século XVIII Laplace procurou desenvolver metodologia para estimar o tamanho de populações. A literatura aponta o dinamarquês Carl Petersen como o primeiro pesquisador que no final do século XIX, querendo estimar o número de peixes do Mar Báltico, desenvolveu o método que iremos analisar nesta atividade.

\section{ATIVIDADE 4}

TAREFA 4.1 Encontre a medida da área da superfície plana da figura abaixo. Utilize como unidade de medida o quadradinho da malha. Explique o procedimento adotado. 
TAREFA 4.2 Justifique as respostas das questões abaixo.

a) Qual a medida da área da figura $\mathrm{S}$ usando como unidade de medida $\mathrm{U}$ ?

b) A unidade de medida $U$ representa que parte da figura $S$ ?

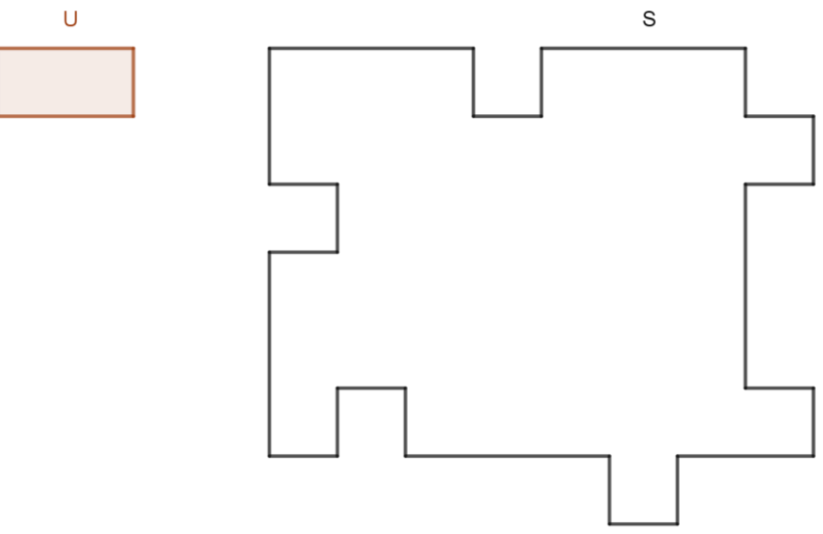

\section{TAREFA 4.3 O TANGRAM}

Tangram é um quebra-cabeça chinês de origem milenar. Foi trazido para o ocidente por volta da metade do século XIX. Pouco se sabe da sua origem ou quem inventou.

Com as peças podemos formar várias figuras, utilizando todas elas sem sobrepô-las.

Segundo a Enciclopédia do Tangram é possível montar mais de 5000 figuras.

a) Identifique as seguintes peças do Tangram

$\mathrm{Tg}=$ triângulo grande

Tm $=$ triângulo médio

$\mathrm{Tp}=$ triângulo pequeno

$\mathrm{Q}=$ quadrado

$\mathrm{P}=$ paralelogramo
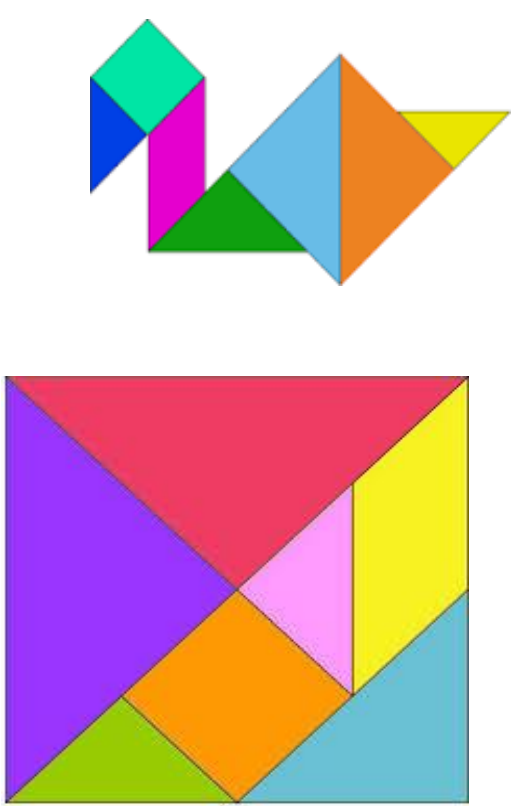
b) Recubra cada peça com o triângulo pequeno (Tp) e complete a tabela. Sendo Tp a unidade de medida da área de cada figura?

$\begin{array}{ll}\text { Peça } & \begin{array}{c}\text { Quantidade } \\ \text { de Tp para cobrir a } \\ \text { peça }\end{array} \\ \text { Q } & \\ \text { P } & \\ \mathrm{Tm} & \mathrm{Tg}\end{array}$

c) Agora compare as peças do Tangram com o quadrado e complete a tabela. Sendo Q a unidade de medida da área de cada figura?

Peça $\begin{gathered}\text { Quantidade } \\ \text { de Q para cobrir a } \\ \text { peça }\end{gathered}$
P
Tm

$\operatorname{Tg}$

d) Sendo Tp a unidade de medida, qual a medida da área do quadrado do Tangram?

e) Com as peças do Tangram monte a figura da casa. Qual a medida da área da figura sendo Tp a unidade de medida?

f) Usando todas as peças do Tangram monte:

- Duas figuras de mesma área e perímetros diferentes.

- Duas figuras de mesmo perímetro e áreas diferentes

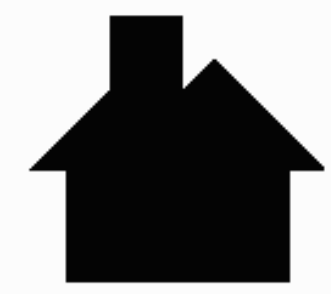




\section{ATIVIDADE 5}

TAREFA 5.1 Dê um valor aproximado da medida da área da superfície do quadrilátero abaixo utilizando o quadrado da malha como unidade de medida.

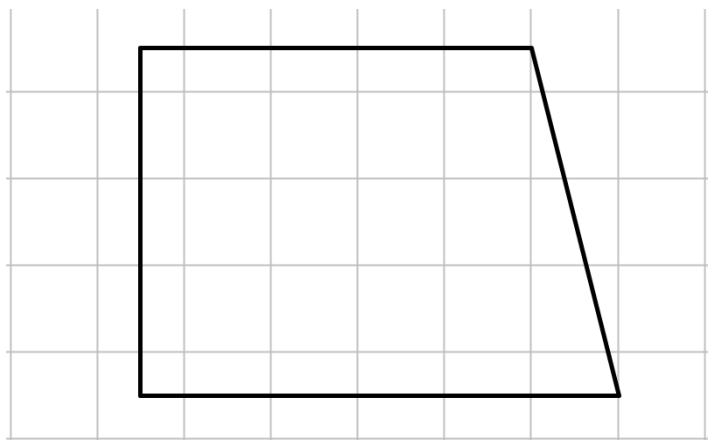

TAREFA 5.2 - Com a "planta" da casa que está na folha em anexo, respondas as seguintes perguntas.

1.Sem usar instrumentos de medida, responda as questões a seguir, justificando os procedimentos

a) Levando em conta que uma cama de solteiro tem $2 \mathrm{~m}$ de comprimento e $1 \mathrm{~m}$ de largura. Faça ma estimativa da medida da área do quarto 1.

b) Observe o quarto principal, há uma cama de casal. Quanto você acha que é a medida da área da cama? E do quarto?

c) Levando em conta a medida do quarto 1. Qual é a medida da área do banheiro?

d)Quais os procedimentos e estratégias envolvidos?

2. Agora usando algum instrumento de medida, responda as mesmas questões.

e) Levando em conta que uma cama de solteiro tem $2 \mathrm{~m}$ de comprimento e $1 \mathrm{~m}$ de largura. Faça ma estimativa da medida da área do quarto 1.

f) Observe o quarto principal, há uma cama de casal. Quanto você acha que é a medida da área da cama? E do quarto?

g) Levando em conta a medida do quarto 1. Qual é a medida da área do banheiro? 
h) Quais os procedimentos e estratégias envolvidos?

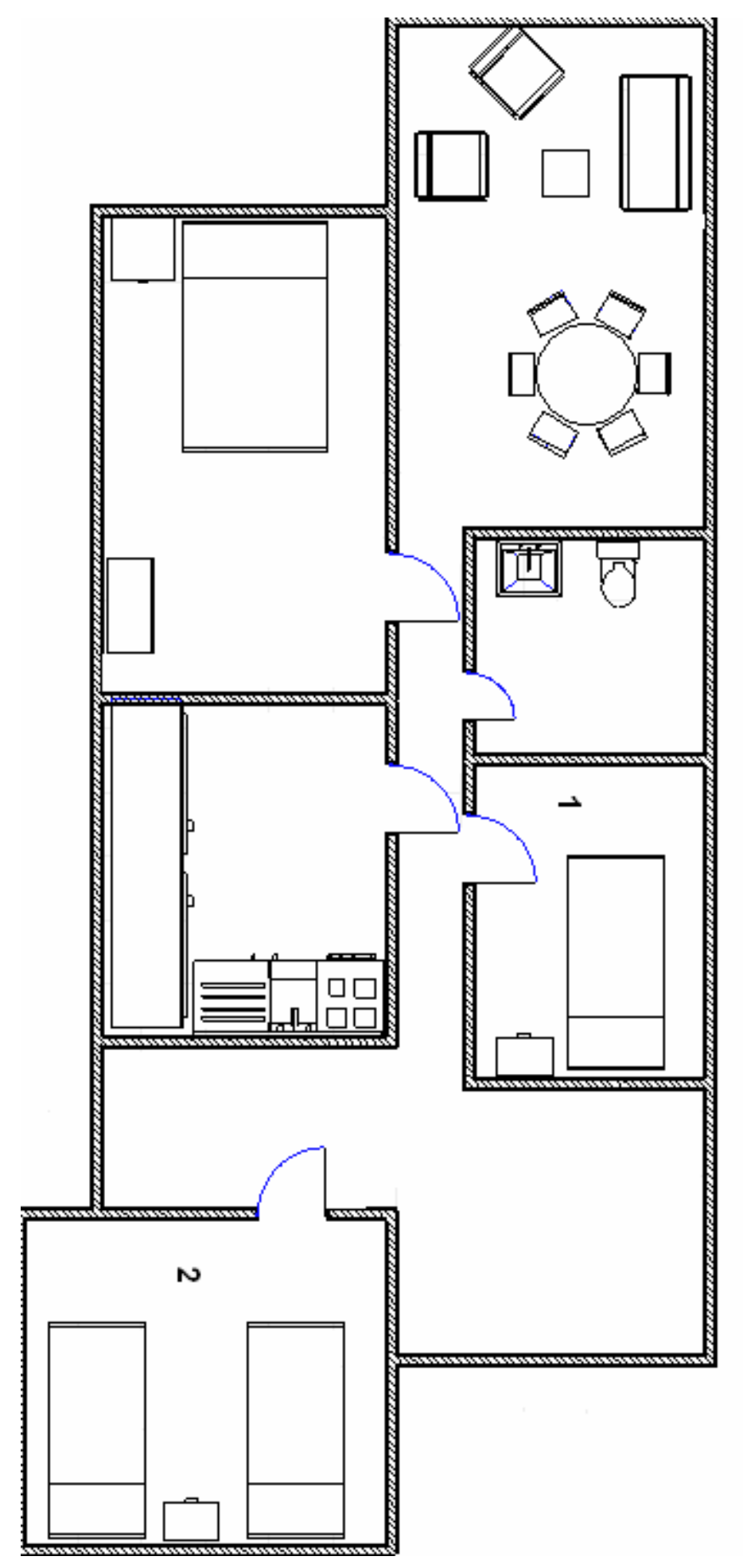


TAREFA 5.3 Qual a medida da área da figura utilizando o quadradinho da malha como unidade de medida? Justifique sua resposta.

Como podemos aumentar a precisão desse método? Por quê?

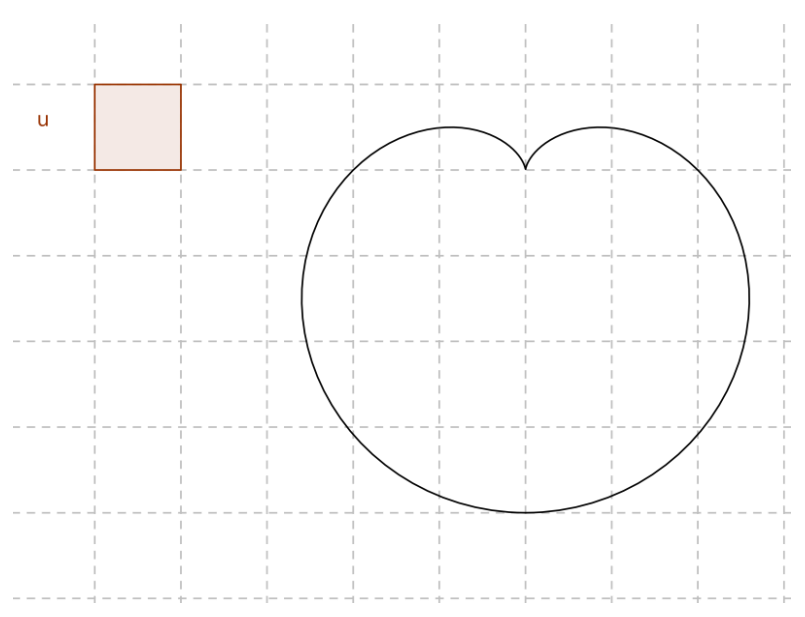




\section{Anexo II - experimento com os alunos}

Atividade 1.1 Analise a figura e responda as questões

a) Qual a medida da área da figura $\mathrm{S}$ usando como unidade de medida U? Como você obteve este valor?

b) A unidade de medida $U$ representa que fração ou parte da figura S? Como você obteve?

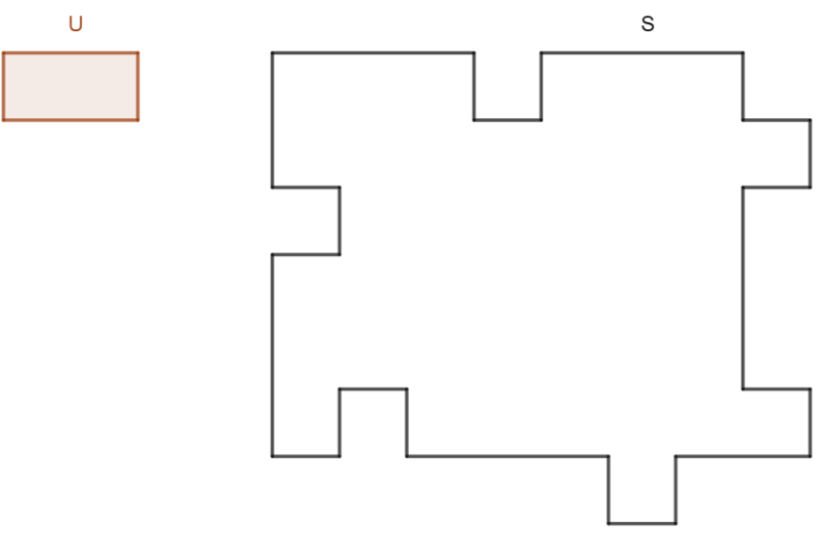


Atividade 1.2. Utilizando como unidade de medida "u" indicada na malha, encontre a medida da área da superfície plana da figura abaixo. Explique o procedimento adotado.

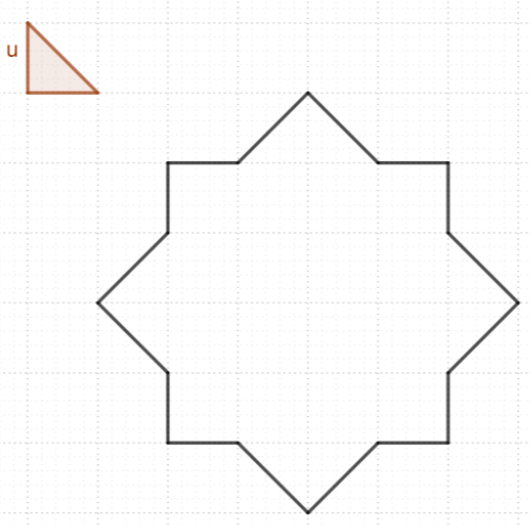

Atividade 1.3. Dê um valor aproximado da medida da área da superfície do quadrilátero abaixo utilizando o quadrado da malha como unidade de medida. Descreva, com suas palavras, qual foi sua estratégia para obter o valor.

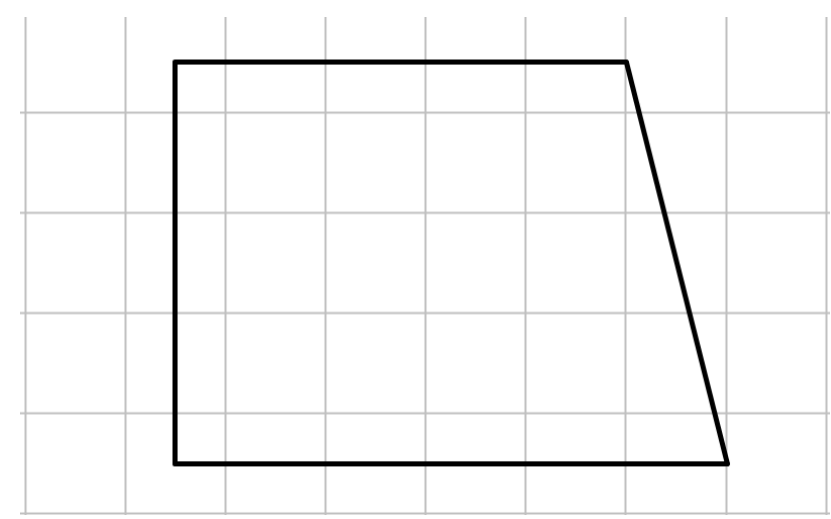


Atividade 2.1 Responda as seguintes perguntas:

a) Quantos centímetros quadrados cabem em $1 \mathrm{dm}^{2}$ ?

b) Quantos decímetros quadrados cabem em $1 \mathrm{~m}^{2}$ ?

c) Quantos centímetros quadrados cabem em $1 \mathrm{~m}^{2}$ ?

\section{Atividade 2.2}

a) Observe o tampo de sua carteira e estime qual é a sua área. Responda na unidade de medida que achar mais adequada.

b) Agora utilizando as figuras disponíveis, meça a área da sua carteira. Que valor obteve? Qual o procedimento que utilizou?

c) Compare os resultados encontrados nos itens anteriores. Sua estimativa foi boa? E de seus colegas?

\section{Atividade 2.3}

a) Com uma tesoura, corte a figura de $1 \mathrm{dm}^{2}$ que você recebeu em vários pedaços.Crie uma figura com todos esses pedaços, sem sobrepor nenhum deles, e cole-a num papel. Qual a área da figura criada por você? Justifique sua resposta.

b) Paulo comprou um papel medindo $1 \mathrm{~m}^{2}$ e deseja recortá-lo para obter 7 pedaços de modo que cada pedaço mede $20 \mathrm{~cm}^{2}$. Ele vai conseguir? Justifique sua resposta. 


\section{Atividade 3.1}

Em quais das seguintes situações se utilizam dados exatos e em quais se empregam dados estimados (aproximados)? Explique sua resposta.

a) Preço de um automóvel.

b) Tempo de duração de uma lâmpada.

c) Números de desempregados no Brasil.

d) Cinco barras de chocolate a 50 centavos cada custam $R \$ 2,50$.

\section{Atividade 3.2}

Dê um valor aproximado para:
a) O comprimento do palmo da sua mão direita.
b) Agora meça com uma régua. Qual o comprimento do palmo da sua mão direita?
c) Compare os resultados encontrados nos itens anteriores.
d) O número máximo de pessoas que cabem em $1 \mathrm{~m}^{2}$. 
Atividade 4.1 Com a "planta" da casa que você acabou de receber, responda as seguintes perguntas, explicando as respostas.

a)Levando em conta que uma cama de solteiro tem $2 \mathrm{~m}$ de comprimento e $1 \mathrm{~m}$ de largura. Faça uma estimativa da medida da área do quarto 1.

b) Observe o quarto principal, há uma cama de casal. Quanto você acha que é a medida da área da cama? E do quarto?

c) Levando em conta a medida do quarto 1. Qual é a medida da área do banheiro? 


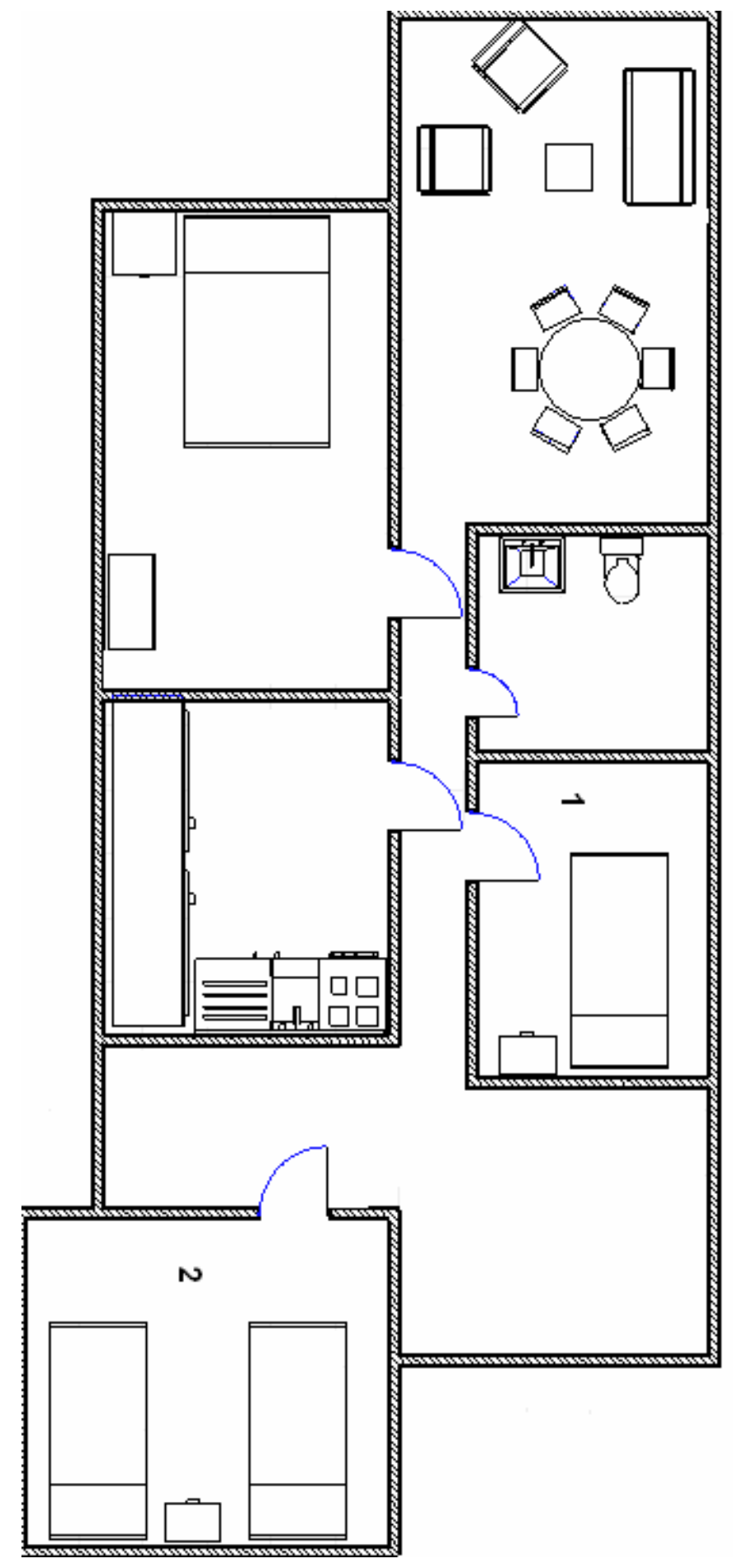


Atividade 4.2 - Em algumas ocasiões precisamos estimar a área de uma figura qualquer desenhada em uma malha quadriculada. Com base nisso, faça o que se pede:

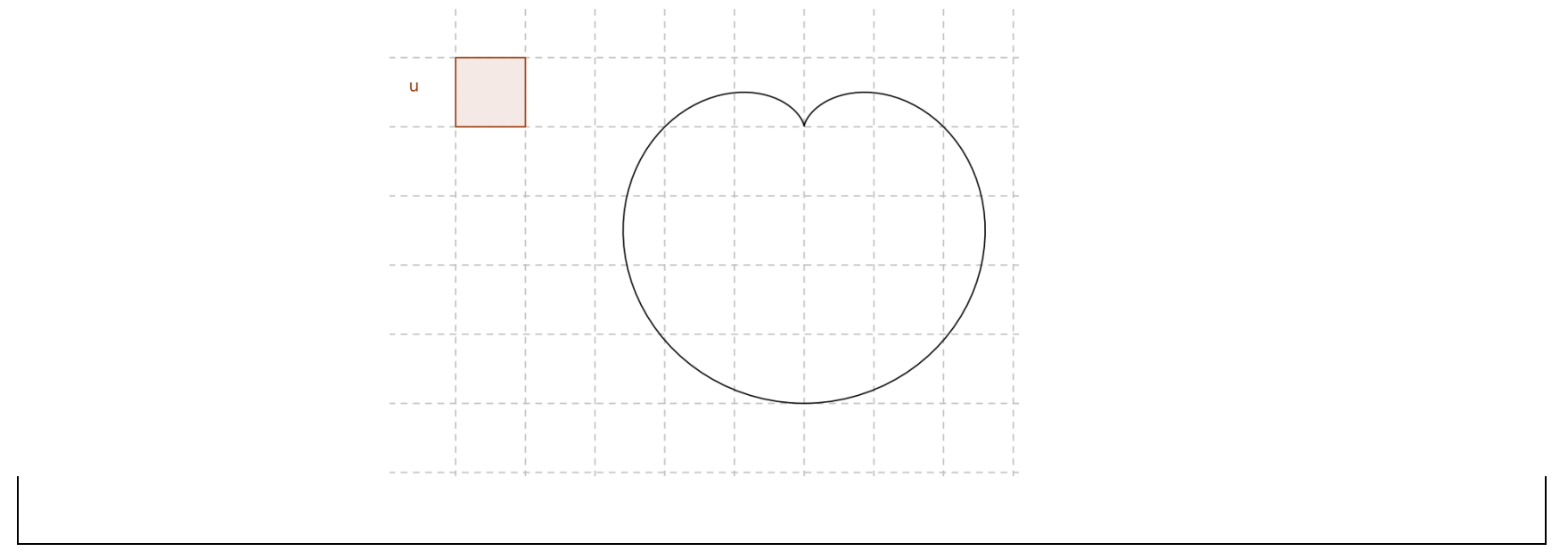

a) A figura cobre totalmente quantos quadrados?

b) Quantos quadrados a figura cobre total ou parcialmente?

c) Com base nos itens anteriores, podemos dizer que área da figura está entre que valores?

d) Que critério você poderia utilizar para calcular a área dos quadrados que estão parcialmente preenchidos? Utilize isso para dar um valor aproximado para a área da figura acima: 
Atividade 4.3 Utilize o procedimento anterior para calcular a área aproximada do Estado de Minas Gerais, destacado no mapa a seguir:

O mapa está em escala e conhecemos a área da unidade da malha, basta multiplicarmos a unidade da malha pela quantidade estimada de "quadradinhos" para termos a medida de área aproximada do Estado de Minas Gerais.

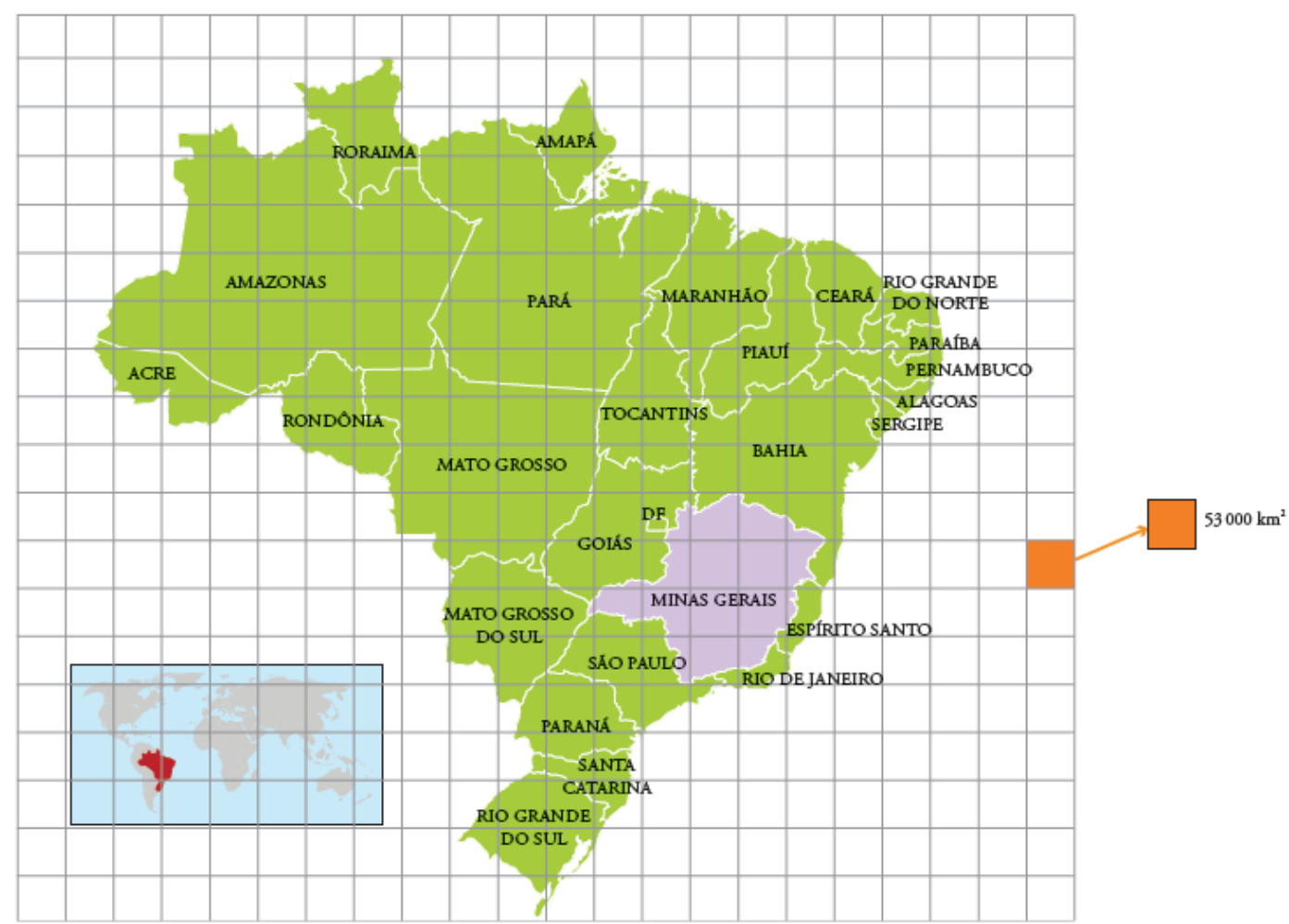

